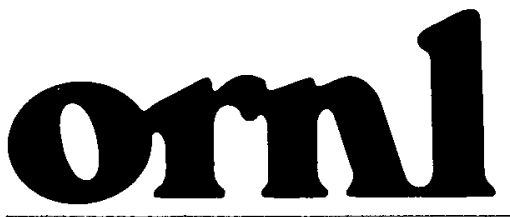

OAK RIDGE NATIONAL LABORATORY

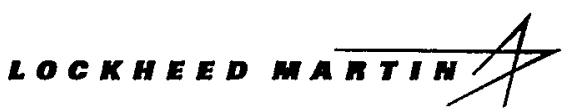

F⿸尸由IMET

FFA 112890

$9 \mathrm{ST}$

\title{
REPORT ON THE FEASIBILITY STUDY FOR IMPROVING ELECTRIC MOTOR SERVICE CENTERS IN GHANA
}

J. S. Hsu

P. A. Jallouk

R. H. Staunton

December 10, 1999

Prepared by

Oak Ridge National Laboratory

Oak Ridge, Tennessee 37831

managed by

LOCKHEED MARTIN ENERGY RESEARCH CORP.

for the

U.S. DEPARTMENT OF ENERGY

Under contract DE-AC-05-96OR22464

MANAGED AND OPERATED BY

LOCKHEED MARTIN ENERGY RESEARCH CORPORATION FOR THE UNTED STATES

DEPARTMENT OF ENERGY

ORNL-27 (3-96) 
The submitted manuscript has been authored by a contractor of the U.S. Government. Accordingly, the U.S. Government retains a nonexclusive, royalty-free license to publish or reproduce the published form of this contribution, or allow others to do so, for U.S. Government purposes. 


\section{DISCLAIMER}

This report was prepared as an account of work sponsored by an agency of the United States Government. Neither the United States Government nor any agency thereof, nor any of their employees, make any warranty, express or implied, or assumes any legal liability or responsibility for the accuracy, completeness, or usefulness of any information, apparatus, product, or process disclosed, or represents that its use would not infringe privately owned rights. Reference herein to any specific commercial product, process, or service by trade name, trademark, manufacturer, or otherwise does not necessarily constitute or imply its endorsement, recommendation, or favoring by the United States Government or any agency thereof. The views and opinions of authors expressed herein do not necessarily state or reflect those of the United States Government or any agency thereof. 


\section{DISCLAIMER}

Portions of this document may be illegible in electronic image products. Images are produced from the best available original document. 


\section{TABLE OF CONTENTS}

Page

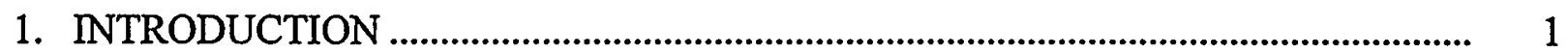

2. ACCOMPLISHMENTS ON PROGRAM TASKS ......................................................

Task 1 Selection of Motor Centers...................................................................................... 1

Task 2 Upgrading Repair Capability of the Selected Centers.......................................... 2

Task 3 New Motor Sales at Motor Centers.......................................................................... 3

Task 4 Value-Added Services Provided by the Motors Centers...................................... 3

Subtask 4.1 Motor Efficiency Labeling ................................................................ 3

Subtask 4.2 Efficiency Standards for New Motors ............................................. 3

Subtask 4.3 Testing Standards for Repaired Motors........................................... 3

Subtask 4.4 System Performance Optimization..................................................... 4

Task 5 Seminar and Final Report........................................................................................ 4

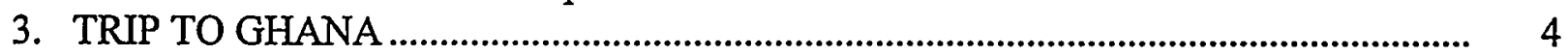

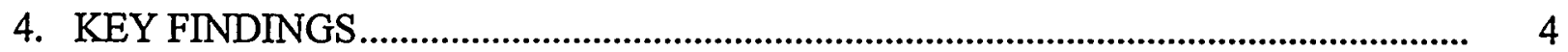

Task 1 Selection of Motor Centers...................................................................................... 5

Task 2 Upgrading Repair Capability of the Selected Centers.......................................... 5

Task 3 New Motor Sales at Motor Centers ........................................................................... 7

Task 4 Value-Added Services Provided by the Motor Centers ...................................... 8

Task 5 Seminar ........................................................................................................ 11

APPENDIX A - TRIP ITINERARY ..................................................................... A

APPENDIX B - A REWIND MOTOR FACILITY …….................................................... B-1

APPENDIX C - EASA STANDARDS................................................................. C-1

APPENDIX D - LIST OF EQUIPMENT NEEDED FOR A REWIND/REPAIR

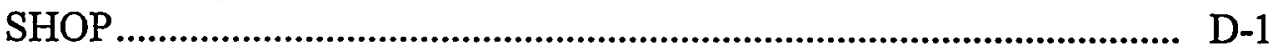

APPENDIX E - MOTOR WINDING REMOVAL METHODS........................................ E-1

APPENDIX F - LIST OF MANUFACTURERS AND SUPPLIERS............................... F-1

APPENDIX G - MANUFACTURING ELECTRIC FANS IN GHANA ......................... G-1

APPENDIX H - EASA PACKAGE AND BROCHURES AND ADDITIONAL CONTACTS WITH EASA .............................................................. H-1

APPENDIX I - INFORMATION ON NVLAP AND IEEE STANDARD 112.............. I-1

APPENDIX J - ELECTRIC MACHINERY SYSTEMS TEST CENTER AND ROTOR BALANCING FACILITY AT THE OAK RIDGE NATIONAL LABORATORY 


\section{INTRODUCTIÓN}

On March 3 and 4, 1998, a visit was made to Oak Ridge National Laboratory (ORNL) by two officials from Ghana: Mr. I. K. Mintah, Acting Executive Director, Technical Wing, Ministry of Mines and Energy (MOME) and Dr. A. K. Ofosu-Ahenkorah, Coordinator, Energy Efficiency and Conservation Program, MOME. As a result of this visit, Dr. John S. Hsu of ORNL was invited by MOME to visit the Republic of Ghana in order to study the feasibility of improving electric motor service centers in Ghana.

The MOME in the Republic of Ghana wishes to develop one-stop shopping, repair, and advisory centers that will provide service to industrial and commercial users of electric motors. Currently, a lack of technical expertise at motor repair shops results in large efficiency losses up to 30 percent when a motor is rewound. In addition, there are no energy efficiency standards on labeling requirements for new motors. Hence, users do not have the information needed for economically comparing motor selection options on a life-cycle basis. Improving motor repair performance and providing users information to allow them to make better decisions regarding motor purchase will significantly improve the efficiency of motors used by industry. This will result in decreased electrical consumption and, in effect, provide a very cost-effective increase in available electrical capacity. ·

In Ghana today, motor purchases are expensive and take longer than is acceptable. Thus, motor rewinding is the preferred option for industrial customers since it is cheaper and requires less down time in the plant. Therefore, the feasibility study needs to assess the centers in each industrial zone in Ghana prior to making recommendations for improving their motor repair capabilities. The addition of a motor sales component to the shops is the next step in the process of making them a one-stop shop and plans need to be developed for adding this capacity. Since these shops will be the primary information source for industrial customers, it would also be advantageous if they could provide value-added services such as efficiency testing and performing optimization studies for the users of motor-driven systems. The shops need to adopt new practices including labeling motors with data that includes efficiency specification(s) and other standards for improving quality. A planning task needs to be included to address this longer-term addition to the centers' list of services.

\section{ACCOMPLISHMENTS ON PROGRAM TASKS}

Prior to Dr. Hsu's visit to Ghana, a plan for the feasibility study consisting of five tasks was prepared. The activities comprising each task and the progress made to date are described below:

\section{Task 1: Selection of Motor Centers}

A preliminary list of eight centers was compiled for consideration. In addition to a sample listing of the sites, MOME provided information on each site. This included total annual volume of repair, number of employees, total annual sales, facility capabilities, location, existing and forecasted industrial base that would be served by the center, and any other information that could be used in the preliminary selection process. ORNL reviewed the 
information before the initial visit to Ghana and assessed the sites for each industrial zone based on the information supplied to MOME.

The initial meetings during the Ghana on-site trip was with representatives of MOME to gather information concerning current motor usage in Ghana as well as future projected industrial development.

Visits were made to select sites on the MOME preliminary selection list to ascertain the current status of equipment and personnel capabilities. Information was gathered regarding the financial status of the facility as well as current rewind specifications, practices and standards, current facility condition, workman skill level, motor repair turn around time, testing and quality assurance procedures, material stocking and purchasing procedures, market share, costs and profitability, and foreign business connections. Based on the preliminary assessment, information gained from the site visits, and motor usage information from MOME, it was decided that a final selection of the center sites, which was scheduled to be made at this time, should be deferred pending further discussions with MOME personnel. ORNL recommends an alternate free enterprise approach facilitated by the government in Section 4.

\section{Task 2: Upgrading Repair Capability of the Selected Centers}

Information gained during the site visits was used to determine equipment, training, and financing requirements needed to improve motor repair performance. Repair standards developed by the Electrical Apparatus Service Association and best practices from smaller repair shops in the United States were used as the basis for defining how to accomplish a quality motor repair. These standards were tailored to the Ghanaian situation to facilitate the development of a set of procedures. The procedures focus on the repair of smaller motors (1-15 hp), which constitute the bulk of motors used in Ghana. In addition, the repair procedures are to address relatively large motors (over $200 \mathrm{hp}$ ) since they are common in Ghanaian industry and consume significant energy.

Once the repair procedures have been established, equipment needs for each of the centers will be identified. The type of equipment, its cost, possible sources, necessary material inventories, minimum floor space, and configuration of the space will be specified. Training needs for personnel at the centers to upgrade their skills and knowledge will be established and specific training programs will be recommended.

After equipment and training needs have been established for each center, ORNL will examine financing options and develop a plan for financing the required upgrade program. The financing plan will take cognizance of the fact that the intent is to develop these centers as private enterprises or joint ventures with overseas partners. 


\section{Task 3: New Motor Sales at Motor Centers}

In addition to upgraded repair capabilities, it is desired to have the centers sell new motors. Information gained from MOME in Task 1 will define the anticipated market for new motors. Because of continued rural electrification activities, it is anticipated that single-phase motors in the 5-15 hp size ranges will be an important market. A review of international motor manufacturers has been initiated to identify potential partners for a joint motor supply venture. Responses to inquiries were assessed and recommendations prepared regarding the prospects for establishing a partnership.

\section{Task 4: Value-Added Services Provided by the Motor Centers}

The goal is to establish the motor centers as a one-stop shop for electric motor purchase and repair. However, the centers could provide a broader range of services by also providing information services that assist users in selecting the proper equipment for their application. This value-added service would include energy efficiency information, development of efficiency standards for new motors, establishing a motor testing standard for repaired motors that allows a new nameplate to be added when a motor is repaired, and training in performance optimization techniques for motor-driven systems.

Subtask 4.1: Motor Efficiency Labeling - Since efficiency labeling is not standard practice in Ghana, motor users cannot adequately compare new motors when making a purchase. Choosing a motor based on purchase price often is a poor economic choice since the operating cost (electricity cost) for the motor over its lifetime can be an order of magnitude higher. Thus, a life cycle cost analysis is required and this in turn requires knowledge of the operating efficiency of the motor. Adding to the confusion is the fact that efficiency-testing standards in the United States, Europe, and Japan have differences that result in the measured efficiencies not being directly comparable. A plan would be developed for the motor centers that would allow them to present energy efficiency information to customers so that the true economics of the new motor decision can be calculated.

Subtask 4.2: Efficiency Standards for New Motors - A plan would be developed for defining and implementing energy efficiency standards for new motors. The plan would take cognizance of recent international efforts (in the United States, for example, the Energy Policy Act mandates minimum efficiencies for a wide range of motors) so that the Ghanaian standards, if adopted at a national level, would be consistent with other international standards. The standards would also have to be consistent with country-specific parameters (climate, motors in use, applications, etc.).

Subtask 4.3: Testing Standards for Repaired Motors - After a motor has been repaired and returned to service there is often no information available that tells the user what the operating efficiency is. Several techniques exist or are under development that would permit a shop to perform a few simple tests and develop enough information such that a new nameplate could be prepared and attached to the motor. One piece of information contained on the nameplate would be the new full-load efficiency. The end-user thus has better 
information for making future repair/replace decisions and has a good indication of the quality of the repair. A plan will be developed for defining what steps must be taken to implement this value-added function at the motor centers.

Subtask 4.4: System Performance Optimization - This value-added service is designed to capture the greatest amount of energy savings and provide the motor user with the greatest economic benefit. Previous studies in the United States and Canada have indicated that the energy savings potential associated with system optimization is approximately an order of magnitude higher than that attainable through component improvements alone. By correctly matching the system to the application need, downsizing is frequently possible and loading on the system can be changed (e.g., variable speed drives) to match the system need. A plan will be developed to define the steps needed to train motor center personnel in performance optimization techniques and demonstrate the energy and cost savings possible.

\section{Task 5: Seminar and Final Report}

A one-day workshop will be conducted in Ghana now that the feasibility study is complete. The purpose of the workshop is to present the findings contained in the draft final report. Workshop participants will include representatives from the government and the motor centers. The agenda will include the following topics:

1) Description of assessment technique;

2) Summary of resources needed to establish centers with improved repair capabilities;

3) Summary of the potential for creating partnerships for sales of new motors;

4) Overview of value-added services, which may be provided by the motor centers, and summary of impact on energy usage;

5) Suggested approaches for establishing efficiency standards for new motors, testing standards for repaired motors, and motor efficiency labeling; and

6) Summary of expected impacts of single-phase motors in rural areas and role of standards and labeling.

\section{TRIP TO GHANA}

From March 26, 1998 to April 9, 1998, a trip to Ghana was made by Dr. John Hsu of ORNL. A detailed itinerary is given in Appendix A. During this visit, feasibility and study meetings were held with various repressentatives of industry and government. Meetings were held in the cities and towns of Accra, Kumasi, and Tarkwa.

\section{KEY FINDINGS}

As a result of this visit, the following findings related to the first four tasks outlined above are made: 
Task 1: Selection of Motor Centers

The facilities visited seemed to generally have the same level of technology and employee skills. Revenue income to repair facilities is small and highly variable. A rough estimate of the facilities visited places monthly gross total revenue at (US) $\$ 3000 \pm 80 \%$. The reason for this is the small motor population base that these facilities service. The rewind practices presently in use are inconsistent and can certainly be improved. In general, considerable potential exists for improving the present motor repair techniques that were observed during the tours. The suggested approaches will be discussed below. Certain facilities, such as the mining motor repair shops, have more space available. The quality and quantity of the repaired motors, however, does not significantly exceed that of the smaller shops. Instead of selecting four regional motor centers at this point in time, it is advisable that the government instead creates an environment conducive to free competition. With assistance from the government, this free enterprise system will result in the best run facilities having the best chance for survival.

\section{Task 2: Upgrading Repair Capability of the Selected Centers}

Ghanaian representatives expressed their intention to ORNL for improving their country's motor repair capabilities. A multi-faceted approach was envisioned, including the formation of partnerships with motor repair shops outside Ghana as well as encouraging foreign companies to build small-motor manufacturing facilities in Ghana. Dr. Hsu's recommendation is that instead of upgrading the repair capabilities of the selected centers, the upgrading should be conducted on a broader basis. After the trip, Dr. Hsu contacted several repair shops in the U.S. to inquire about their interest in investing in Ghana. None were interested because of the low level of revenues that repair shops in Ghana generate. Coupled with the large swings in anticipated monthly revenue, the expected payback would not warrant the required time, effort, and financial investment. Thus, it appears unlikely that investment from other countries will be forthcoming in this area.. It should be noted that in the U.S., shops that repair and rewind small motors tend to be small, privately owned operations that focus their attention on a specific local geographic area. The motor rewind business is an intensely competitive field and the profit margins are not large. Motors are rarely shipped over large distances and rewinds are generally limited to the larger-sized motors - over $50 \mathrm{hp}$ unless special fitting/mounting dimensions for installation requires the rewinding of small motors. One motor repair shop in Knoxville, Tennessee was visited and photographs as well as a brief description of the operations of this facility are included in Appendix B. This shop is fairly typical of motor repair shops in the United States.

In addition, the name of the following motor repair shop - an Allied Partner in the U.S. Department of Energy's Motor Challenge Program is included here: 
Brithinee Electric

620 S. Rancho Avenue

Colton, California 92324

Attention: Mr. Wallace P. Brithinee, President

Brithinee Electric has agreed to provide information and answer general questions on the rewinding of electric motors. You will need to contact them with specific inquiries. Mr. Brithinee, the company president, is very active in Electrical Apparatus Service Association, Inc. (EASA) and has contacts with several countries in the Caribbean area who, like Ghana, are in the process of improving their motor rewind capabilities. One suggestion Mr. Brithinee made when Dr. Jallouk spoke to him was in regard to an EASA convention that will be held at the Metro Toronto Convention Center in Toronto, Canada, from June 2730,1999 . A part of this convention is an exhibit hall with numerous representatives of motor repair shops and suppliers of material. It is strongly recommended that representatives from MOME or a motor repair leadership group in Ghana attend. This represents a significant opportunity to make direct first-hand contact with the major key suppliers and repair shops in North America. Additional information about this meeting, as it becomes available, may be obtained through EASA's web page on the Internet: www.easa.com.

The repair techniques used in the shops visited were generally inconsistent. Enclosed in Appendix $C$ is the latest copy of the EASA Standards used in the United States. Except for the differences in the voltage and frequency, the standards should be directly applicable to Ghana. A list of equipment needed for a rewind/repair shop is given in Appendix D. Also in Appendix E, information on the advantages and disadvantages of the four methods for motor winding removal are discussed.

There is a low inventory of materials in Ghana needed to repair electric motors. In addition, the established or traditional sources used today result in the importing of materials of inconsistent quality. This can have a significant impact on the consistency of a motor rewind and the resulting energy efficiency. To facilitate the timely availability of quality materials, it is suggested that contact be established with several reputable firms in the major manufacturing countries. A list of suppliers in the United States, who responded favorably to our requests for information, is included in Appendix F. Detailed quality specifications need to be written prior to going out on bids for these materials. In addition, a small effort needs to be set up to randomly test a fraction of the purchased materials to ensure that they meet quality standards. Supplies should be ordered in bulk to obtain most favorable pricing and, upon arrival, be located in a central supply area in Ghana. The delivery of high-quality materials to local repair shops can then be done, as needed, with a minimal turn-around time for a small incremental increase in price over the wholesale level. It is not necessary that this be a government undertaking, perhaps the repair shops in Ghana can form a cooperative association that can undertake this and similar tasks that can potentially benefit them all. Additional personal contacts can be made via trade shows such as the one mentioned above in Toronto this year. 
There is a significant dearth of testing equipment for electric motors in Ghana. Without such equipment, it is difficult to determine the present efficiency of the motors in use and how well motors are being rewound. In order to perform adequate motor testing, a minimal set of facilities, equipment and trained personnel are required. The different types of equipment that will be needed as well as the facilities are discussed under Task 4. In addition, a supply of technically qualified personnel and the corresponding training that will be needed are also discussed below under Task 4 .

\section{Task 3: New Motor Sales at Motor Centers}

It became clear in this study that too many motors are rebuilt (often several times) and too few new motor purchases are made. Although the U.S. may not represent a good source of $50 \mathrm{~Hz}$ motors, there are quality manufacturers in Europe whose motors could be purchased and tested, as necessary, to ensure performance is known. The U.S. has established, by law, minimum efficiency requirements for new motors sold domestically. The testing is for $60 \mathrm{~Hz}$ motors using IEEE Standard 112, Test Method B and would not be suitable for use in Ghana. However, Ghana should eventually establish its own test procedure and minimum efficiency standard for new motor sales.

Stocking new motors should be an important activity at central facilities and motor repair shops need to encourage new motor sales and draw upon the stock at the nearest central facility. In addition, new motor manufacturing in Ghana will certainly lead to greater increased new motor sales.

As with investments in motor repair shops, we received back a similar lack of interest from our contacts with U.S. corporations for setting up branches or subsidiaries in Ghana to manufacture motors for electric fans. Of the numerous letters sent out, only one possible interested party responded. This is presented in Appendix G. Climatic conditions and the low labor costs could result in a significant potential market for fans in Ghana. It is suggested that the Government of Ghana, through loan guarantees, aid in the startup of a total manufacturing enterprise for the production of fans. To minimize initial investment, it is suggested that surplus machine tools be located and imported from the United States or other countries with a significant manufacturing base. Raw materials can be supplied in a way similar to that suggested for motor repair - mainly by utilizing a central supply location. Once this manufacturing enterprise for the production of fans gets underway and is a financial success, it should stimulate the growth of other electric motor industries as well as the demand for electrical parts. This would place the central supply function on a surer footing and 'prime the pump' for additional economic growth in the electrical motor industry in Ghana. In this fashion, some of the motors sold in Ghana can be manufactured there. It is recommended that initially, only small horsepower units be manufactured. It should be noted that testing methods to determine the efficiency of these locally developed motors must be developed and that the local motor efficiencies must be comparable to imported units for such motors to be competitive. This will require that quality assurance procedures be instituted during manufacture. Assistance from international parties in setting up and operating such a facility will help ensure the success of such an undertaking. For example, 
assistance available through the United Nations (such as UNESCO) should be investigated. In addition, some organizations in the United States, such as the International Institute for Energy Conservation (IIEC), may be able to provide additional help or guidance in this area. Again, the best way to develop contacts with major suppliers in North America is through conventions such as the one in Toronto in 1999. Here, representatives from Ghana will be able to see firsthand the products that are available and initiate face-to-face contacts with sales representatives.

\section{Task 4: Value-Added Services Provided by the Motor Centers}

As the rural electrification program in Ghana expands, it is also natural that the demand for electrical equipment, including motors, will also expand. To help consumers select the proper equipment for their application, it is important that reliable information be available on the efficiency of the equipment being sold. Additional service tools should be available to help the customer apply performance optimization techniques to match his motor to the system's drive requirements. For developing performance optimization techniques it is recommended that a course be taken similar to the one prepared by Wisconsin Demand-Side Demonstrations, Inc., which uses the book entitled Performance Optimization Service Training Manual. This course was offered starting in 1994 in the United States. With regard to additional technical handbooks reference manuals and reports, a wide variety are available through EASA. A package, including a membership application for EASA is enclosed in Appendix H. Note that this package includes an "EASA Materials and Services Price List," which lists many publications available about electric motors. Also included in this package is the May 1998 issue of EASA's monthly newsletter "Currents." The centerfold of this publication contains information on EASA's "Used Equipment Trading Post" that serves as a conduit for the promotion of used, surplus, and reconditioned equipment for sale. While the Orlando convention took place earlier in the year, similar promotions can be expected to occur at the Toronto meeting. This is a relatively straightforward way to obtain equipment at a discount from retail price. It is recommended that EASA and EASA members be contacted for information on the availability of such equipment.

At present there is no adequate methodology established for motor efficiency evaluation in Ghana. Test methods from different countries and between major suppliers vary. In. addition, published data are often difficult to compare and required information is not easily available. Thus, it is recommended that testing procedures, similar to those established in the United States and other countries, be promulgated. Once in place, a trained staff will be needed to carry out or observe the testing procedures. In addition, one or more facilities are needed in Ghana where the efficiency of electric motors can be tested. Staffed by trained technicians, proper testing equipment, and clearly defined testing procedures, similar to Institute of Electrical and Electronics Engineers, Inc. [IEEE] 112 Test Method B, these facilities can represent national centers for motor testing efficiency. In addition, the methodology can serve as a first step for the formulation of policies and guidelines for the application of minimum standard efficiencies by the government as it relates to the import and local manufacture of electric motors. It is likely that, at least initially, such facilities be operated in conjunction with or at the site of major centers of higher learning. Such facilities 
are most likely to have the interest, training, and knowledge to properly undertake the needed testing. These facilities need to initially be certified by an agency of the government with respect to the availability of the necessary equipment to perform such tests. Additionally, the skilled technicians that perform the efficiency tests need to be certified to insure that they know the proper methods of efficiency testing. Finally, with both certification procedures in place, it will ultimately be necessary that both facilities and operators undergo recertification to insure that the proper procedures remain in use and skills are constantly updated. In the United States, the Department of Commerce, through the National Institute of Standards and Technology (NIST) administers the National Voluntary Laboratory Accreditation Program (NVLAP). NVLAP programs are established for public and private calibration and testing laboratories, including commercial laboratories, manufacturers' in-house laboratories and federal, state and local government laboratories. NVLAP accreditation is based on the evaluation of a laboratory's technical qualifications and competence for conducting specific test methods, measurements, and services in specified fields of calibration or testing. It is granted only after a thorough evaluation of the applicant has demonstrated that all NVLAP criteria have been met. A NIST memorandum on NVLAP is included in Fig. I-1 in Appendix I. Additional information on NVLAP can be found in NIST Handbook 150 and NIST Handbook 150-10. The front covers of both publications are shown in Figs. I-2 and I-3 respectively. The front cover of the IEEE Standard 112 is shown in Fig. I-4. ORNL has an NVLAP-approved motor testing facility on site. Photographs of this facility as well as another facility used to balance motors are presented in Appendix $\mathrm{J}$.

A central facility needs to be established for the leasing of equipment, tools, books, and instrumentation relating to motors and their efficiency. Due to the cost of many of these items along with the fact that no one facility can justify the purchase of much of this equipment due to its infrequent use, a central facility would well serve the needs of the motor repair and testing community. Needed portable equipment can be loaned out for short periods of time to the various users for a nominal fee. Such a facility would also be responsible for maintaining the equipment that is loaned out, insuring its timely return and calibrating the instrumentation to provide users with a degree of confidence. Photographs of the types of equipment needed for such an operating facility were also given in Appendix J.

In short, there is no doubt that the electric motor repair shops need to update their position with improved technology, as well as access to reasonably-priced materials. They also need standards to follow, equipment to test their products, facilities to improve their repair jobs, efficiency test beds, the ability to conduct value-added services, and the capability to replace old motors with high-efficiency motors. The government, helping to guide this effort, can be instrumental to its success. The private business sectors are, however, the fundamental players. The chart, shown in Fig. 1, outlines the elements needed to form the regional centers on the basis of a general improvement of all the repair shops. The government's role as a facilitator is suggested in the chart. 


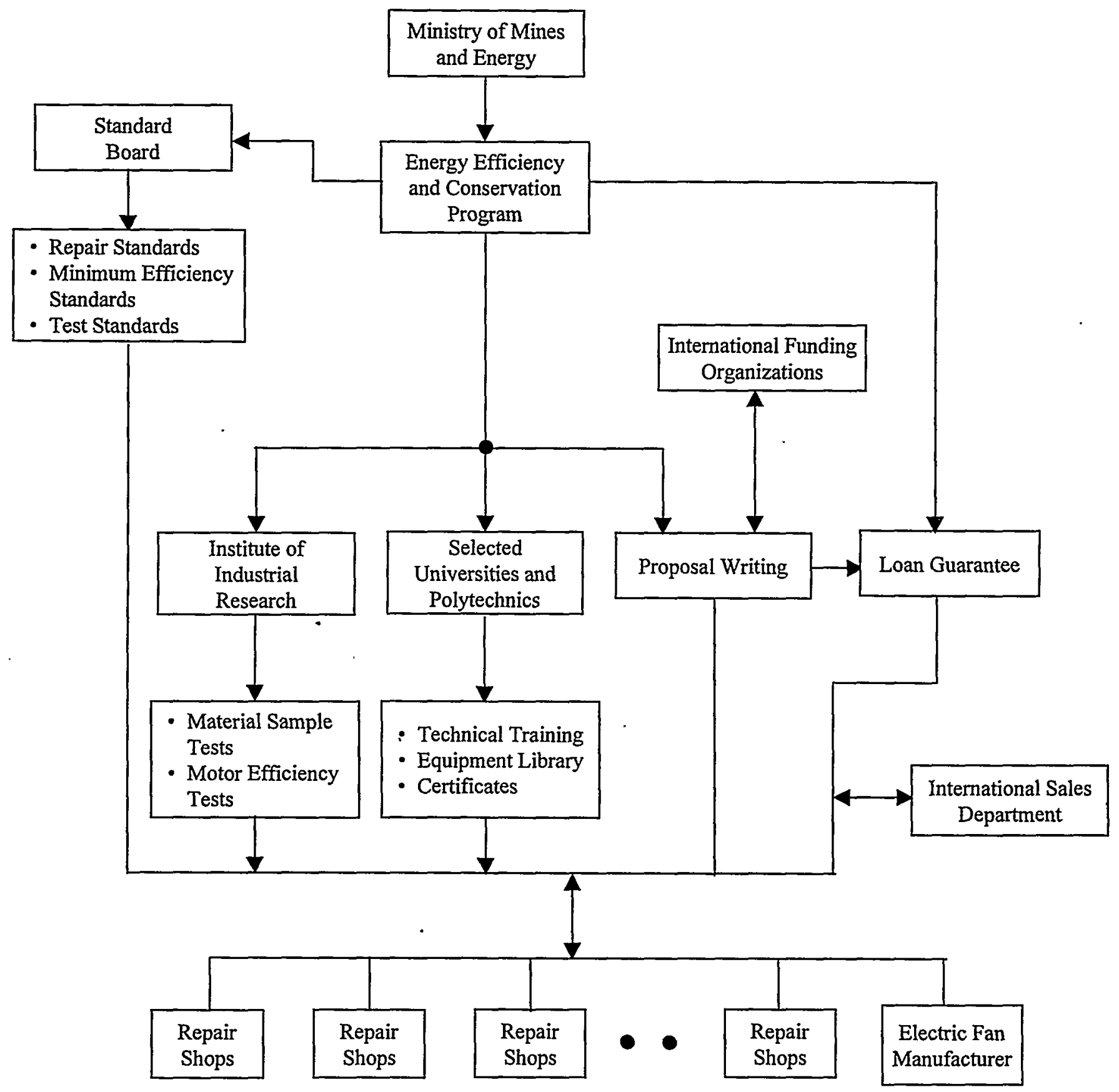

Figure 1

Suggested interactions among various Government Departments and Repair Shops 
Task 5: Seminar

As a final activity completing the ORNL study, a seminar or "Motor Repair Centers Workshop" was held in Accra, Ghana on September 15, 1999. A rapporteur assigned by the Energy Foundation provided the following summary (edited by ORNL):

\section{Electric Motor Improvement Project \\ Comments of Participants at Workshop for the Presentation of Consultant's Findings to Stakeholders}

\section{Motor-Testing Facility}

Dr. Ofosu-Ahenkorah, Executive Director of the Energy Foundation and organizers of the workshop held discussions beginning with a question regarding the typical/average cost of a motor stand (i.e., baseplate, refurbished dynamometer, etc.) from the USA. In response, the ORNL's representative (Mr. R. H. Staunton) indicated that the cost of basic equipment would depend very much on quality of materials, instrumentation, machine capacity, etc. However, he

put the average cost around $\$ 6,000-\$ 7,000$ for testing up to $100 \mathrm{hp}$ motors. In reaction to the ORNL representative's estimate of the average cost of a motortesting machine, a participant indicated that similar equipment used in Ghana is far more expensive than quoted.

The Principal of Ho Polytechnic, who participated in the workshop, indicated that the equipment for the Ho workshop which was donated by the French government cost about $£ 100$ million, which was over US $\$ 50,000$ at the time of purchase in 1996.

There was a general consensus that assistance (i.e., cash and otherwise) from the Energy Foundation and the Ministry of Mines \& Energy should be made available to facilitate acquisition of motor-testing machines for the motor repair centers. These machines should be able to calibrate motor testing instruments, measure rewound motor efficiency, etc. Specialized testing apparatus such as hand-held testers would be very useful. Supporting manuals for efficient use of .test machines/instruments were recommended. These can be provided by ORNL. Participants were informed about the existing collaboration between the Ghana Standards Board (GSB) and the CSIR - Instrumentation Unit for the calibration of test instruments. The participants were advised to contact the GSB or the CSIR for assistance, as needed.

\section{Motor Manufacturing Plant}

It became evident from the discussions that it was time for a local motor manufacturing plant to be established in Ghana to produce energy-efficient small to medium size motors for appliances such as fans, pumps, etc. Such a venture, if successful, would likely address the problem of reduced efficiencies due to frequent motor rewinds. Because of the hot climate, the importation of fans is likely to continue well into the future. 
The laudable move for a motor manufacturing plant notwithstanding, it was generally agreed that much emphasis must be placed on the quality of motors produced by the proposed manufacturing plant.

On the issue of duties on imported motors, the Honorable Member of Parliament, Mr. Thomas Yeboah, explained that motor repairers could enjoy tax (duty) exemption if the Ghana Standards Board develops efficiency standards for motors. These standards will facilitate the categorization of motors into those which are subject to duties and those which are not. It was revealed that the Energy Foundation was seeking a financial assistance package to facilitate the work of the GSB in developing the minimum efficiency standards.

\section{Motor Repairers' Association/Financial Assistance}

The fact that motor repairers need financial assistance for smooth running of their operations was emphasized and collectively agreed upon. There were suggestions advocating the Ministry of Mines \& Energy and the Energy Foundation to assist the motor repair centers by sourcing for funds for the centers. These funds could be managed by a financial institution (bank) selected by the Ministry or the Foundation. A revolving fund could also be set up for the same purpose.

It was also unanimously agreed that for the motor repair centers to have a much stronger bargaining power with the financial institutions, there is the need for them to pool resources through the formation of an association. The association is the surest solution to their capital investment problem.

A representative of the Banks (Agricultural Development Bank), who was present, informed the motor repairers about the readiness of the banks to finance energy-efficient projects since they are good investments. Similar statements have been made by other banks that attended workshops organized by the Energy Foundation in the past.

Welcoming as this message was, the general sentiment was that the Bank interest rates need to be reduced. There was also an appeal for streamlining procedures for loan approvals by the banks.

\section{Training}

Participants recommended periodic training programs for motor repair centers to refresh their knowledge and expose them to up-to-date technologies and practices in the trade. These programs are to be organized by the Foundation in such a way that they will benefit motor end-users too.

The GSB indicated that it conducts management programs for motor rewinders and performs laboratory accreditation too. After certification, the Board runs a surveillance program to ensure adherence to standards and regulations. 
On the issue of apprentice training, there was a suggestion the Polytechnics should be equipped so that they can train both apprentices for the motor repair centers and polytechnic graduates aspiring to work in such centers.

\section{Breakdown of Motors}

A number of factors, apart from age, that contribute to the breakdown of motors were cited. These are bearing failure, lack of under-voltage protection, inadequate maintenance, lack of overload protection (relays), humidity changes, etc. In the case of humidity changes, this can be addressed by phase heating. It was emphasized that motor end-users need to be educated on the importance and cost-effectiveness of preventive maintenance. The issue of soft starters for motors and applications that could benefit from their use should be addressed. It was noted that some motor end-users run their motors without starters.

It was generally agreed that the draft report prepared by ORNL is a good one.

The participants attending the workshop are provided in Table 1. 


\section{Table 1 Motor Repair Centers Workshop Attendees}

\begin{tabular}{|c|c|c|}
\hline Name & Company & Title \\
\hline Herbert Lutterodt & Germany & Student \\
\hline Patrick L. Abban & Takoradi Polytechnic & Student \\
\hline Albert Asante & Bert Rewinding Service & \\
\hline Winfried Odjidja & Electricity Company of Ghana & \\
\hline Michael Attua Obeng & Accra Polytechnic & \\
\hline Geoffrey D. & Rockland Elec. Eng. & \\
\hline Albert Oware & G.T.P. Tema & Elec. Eng. \\
\hline Theophilus Mohem & Resdem, Accra & Mech. Eng. \\
\hline George Asiedu Mantey & Ho Polytechnic, Box 217, HO & Elec. Eng. \\
\hline T. W. K. Agbadi & HO Polytechnic & Mech. Eng. \\
\hline Von Gaertner & C/O Agogo Hospital & Consultant \\
\hline Odame-Adame E. F. & Sonic Control \& Eng. Serv. & Director \\
\hline D. F. Bonnah & K. T. I. (Kumasi) & Motor Rewinding Instructor \\
\hline Danquah-Darko & Ghana Water Co. Ltd. & Head of Ops. \\
\hline I. K. Mintah & Mome & Tech. Director \\
\hline Ofosu-Ahenkorah & Energy Foundation & Exe. Director \\
\hline E.K. Annan & UST & Lecturer \\
\hline Emmanuel Amarquaye & Gilgal Agency & Director \\
\hline Kwame Ampofo & Energy Commission & Commissioner \\
\hline K. A. Kyeremeh & ECG & RD/SUBT \\
\hline Eng. A. T. Barfour & ECG & RD/ACCRA East \\
\hline W. K. Agyemang-Bonsu & EPA & PO/MID \\
\hline Hon. Thomas Yeboah & Parliament & Chairman-Mines/Energy Com. \\
\hline T. A. Okyere & ECG & SM/Protection \\
\hline J.C. T. Armah & GSB & $\mathrm{HD}$ \\
\hline F.S. Annorbah & Francis/Elec. & Manager \\
\hline \multicolumn{3}{|l|}{ Edward Baiden-Ghartey } \\
\hline P.K. D. Hedihon & Agric. Dev. Bank & Manager \\
\hline F. O. Kusi & Empretec GH. Foundation & Financial Ana. \\
\hline Peter Bismark Tetteh & Sam \& Frank Ltd. & O. M. \\
\hline \multicolumn{3}{|l|}{ Gershon Frank } \\
\hline E. Kwa-Kofi & Ghana Stds. Board & Scientific Office \\
\hline W. Kyeremateng & $\overline{\mathrm{ECG}}$ & DM/OPS \\
\hline G. M. Afeti (Dr) & HO Polytechnic & Principal \\
\hline P. K. Akomaning & $\begin{array}{l}\text { Nat. Board for AG.E.D. Small Scale } \\
\text { Industries }\end{array}$ & \\
\hline M. Addo-Ashong & SSNIT & Architect \\
\hline Dr. N. K. Smant Yeboah & Elec. Company of Ghana & Reg. Director \\
\hline Opuni Adomeko & Opuni Elec. & Manager \\
\hline Mr. S. K. Dayi & S. D. Electricals & Manager \\
\hline S. Ankrah & Ghana Consolidated Diamond & Manager \\
\hline Edward Awotwe & Centa Coasta & Manager \\
\hline A. Z. Mahama & Ghana Investment Prom. Ctr. & Officer \\
\hline Francis Baffoe-Ashun & SCIR-IIR & Head of Div. \\
\hline Frank Baidoo & Sam \& Frank Corp. & M. D. \\
\hline Issah Nikabs & Min. of Trade \& Industries & SIPO \\
\hline A. A. Dsane & Ghana Standards Board & S. O. \\
\hline E. A. Jackson & School of Engineering & Head of Dept. (Elec. Eng.) \\
\hline A. Sanful & G. C. D. Ltd. & Snr. Elec. Eng. \\
\hline Emmanuel M. Agbavior & CSIR-IIR & CTO \\
\hline Nick Kopesky & Nifes Consulting Group, UK & \\
\hline Kwasi Boateng & Stanconsult & Elect. Eng. \\
\hline
\end{tabular}




\section{APPENDIX A}

\section{TRIP ITINERARY}

March 24, 1998 Traveled from Oak Ridge to Frankfurt, Germany.

March 25, 1998 Traveled from Frankfurt, Germany, to Accra, Ghana.

March 26, 1998 Meetings with Mr. Isaac K. Mintah, Technical Director, Ministry of Energy \& Mines; Dr. A. K. Ofosu-Ahenkorah, Acting Chief Programme Officer;

Mr. Orison Mawumenyo Amu, Senior Programme Officer; Mr. Charles Anderson, Senior Program Officer; Prof. Fred Akuffo, Dept. Dean, School of Engineering, K.N.U.S.T, Kumasi; Mr. Michael Opam, Director, Bureau of Tarriff \& Economics, P.U.R.C.; and Mr. N. L. Hesse, Asst. Director (Laboratories), Ghana Standard Board.

March 27, 1998 Visited Golden Spoon Flour Mill, Ltd. and had meetings with Managing Director, Mr. E. K. Asare Amankwa and Production \& Engineering Director, Mr. Joseph Kwadjo Teye.

Traveled to Tema and visited Francis Electric Rewinding Works and met with the Managing Director, Mr. Francis Sekoh Annorbah.

Traveled back to Accra.

March 28, 1998 Saturday

March 29, 1998 Sunday

March 30, 1998 Traveled from Accra to Kumasi. Visited Ghana Consolidated Diamonds Ltd. and met with Chief Engineer, Mr. S. K. Ankrah.

March 31, 1998 Visited University of Science and.Technology, Kumasi. Talked to Prof. E. K. Annan.

Visited the Motor Repair Shop of the University.

Visited Lumber Mill.

April 1, 1998 Visited Centa Costa Motor Repair Shop.

Visited Opuni Electrical Works and met with the Managing Director, Mr. G. O. Adomako.

Traveled from Kumasi to Tarkwa.

April 2, 1998 Visited Sam \& Frank Rewinding Shop.

Visited Bert's Rewinding Service. 
Visited S. D. Electrical Repair Services and met with the Manager, Mr. S. K. Dayi.

April 3, 1998 Traveled from Tarkwa to Accra.

April 4, $1998 \quad$ Saturday

April 5, $1998 \quad$ Sunday

April 6, 1998 Traveled to Tema and visited Rockland Electrical Engineering Works.

April 7, 1998 Briefed Dr. A. K. Ofosu-Ahenkorah, Ag. Chief Programme Officer, on the status of this travel.

Met with Mr. Geoffrey Dedoo, Managing Director of Rockland Electrical Engineering Works.

Met with Dr. F. Addo Yobo, Cambridge Engineering \& Economic Research Consultants.

Met with Mr. Frank E. Y. Achampong, Managing Director of Facol Ltd.

April 8, 1998 Visited the Institute of Industrial Research CSIR and met with the Director, Dr. Kofi A. Owusu-Ansah and the Head of Applied and Industrial Physics Division, Dr. Samuel E. Quagraime.

Visited Mr. N. L. Hesse, Asstant Director (Laboratories), Ghana Standard Board.

Visited Ghana Investment Promotion Centre and met with Deputy Director, Dr. Peter Ankrah.

April 9, 1998 Briefed Dr. A. K. Ofosu-Ahenkorah, Acting Chief Programme Officer, about preliminary finding.

Met with Deputy Minister, Hon. Simon Abingya, MP.

Traveled from Accra, Ghana, to Amsterdam, Netherlands.

April 10, 1998 . Traveled from Amsterdam, Netherlands, to Oak Ridge, Tennessee. 


\section{APPENDIX B}

\section{A REWIND MOTOR FACILITY}

A set of pictures is included here from a motor rewind shop located in Knoxville, Tennessee. This facility is Southern Armature Works, Inc. located on 1721 Potter Street. They rewind electric motors in the horsepower range of less than one hp to several hundred hp. The company employs a staff of seven people of which six are directly involved in motor rewind. On average, the shop works 8 hours a day, 40 hours a week. Their estimates of the number of motors they are capable of rewinding is as follows:

- Fractional hp to $20 \mathrm{hp:} \quad 8$ motors/day;

- $20 \mathrm{hp}$ to $100 \mathrm{hp}$ :

2 motors/day;

- $100 \mathrm{hp}$ to $500 \mathrm{hp:}$

1 motor/day; and

- Greater than $500 \mathrm{hp}$ :

2 motors/week. 


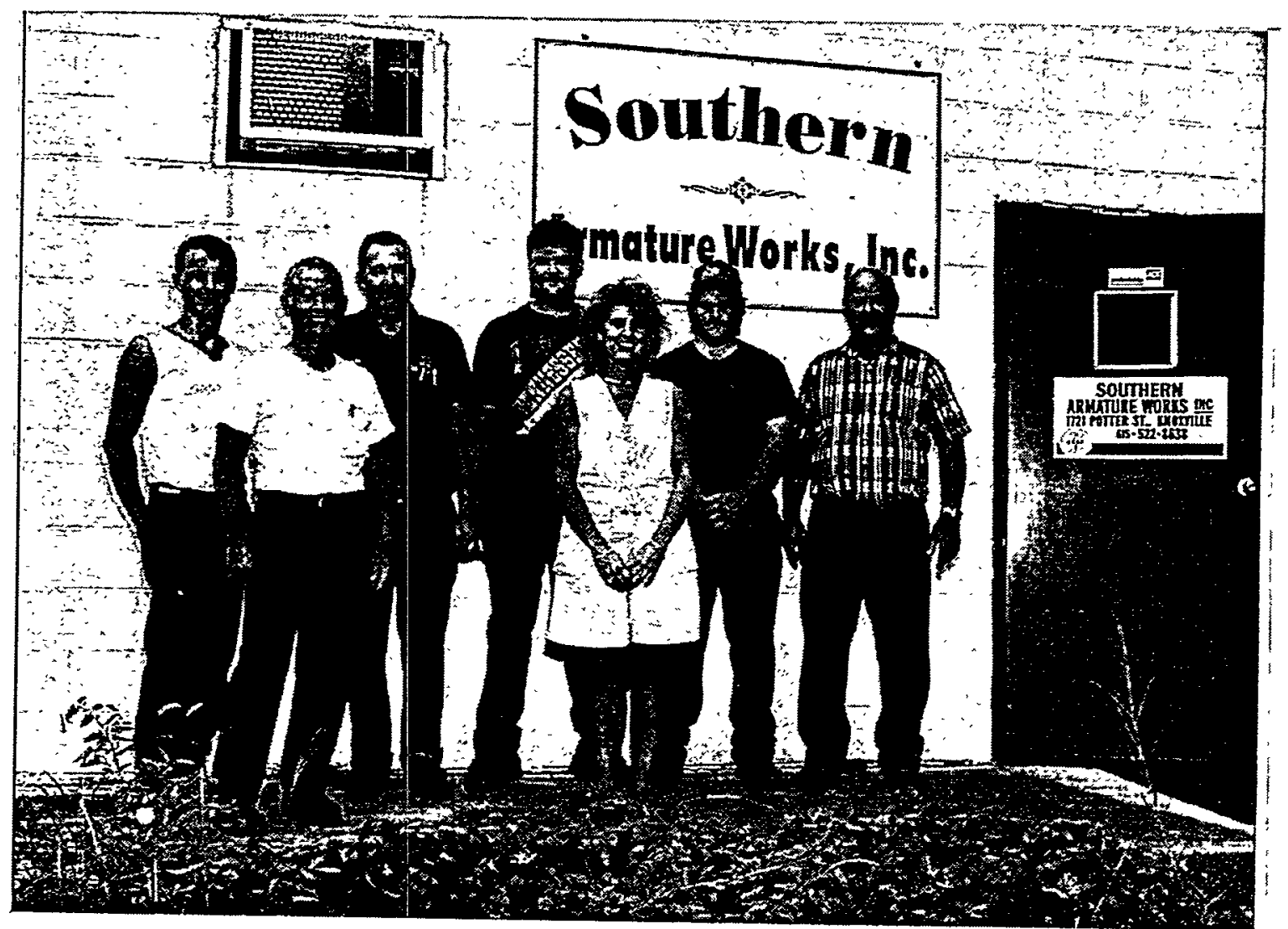

Figure B-1

Staff of Southern Armature Works, Inc 


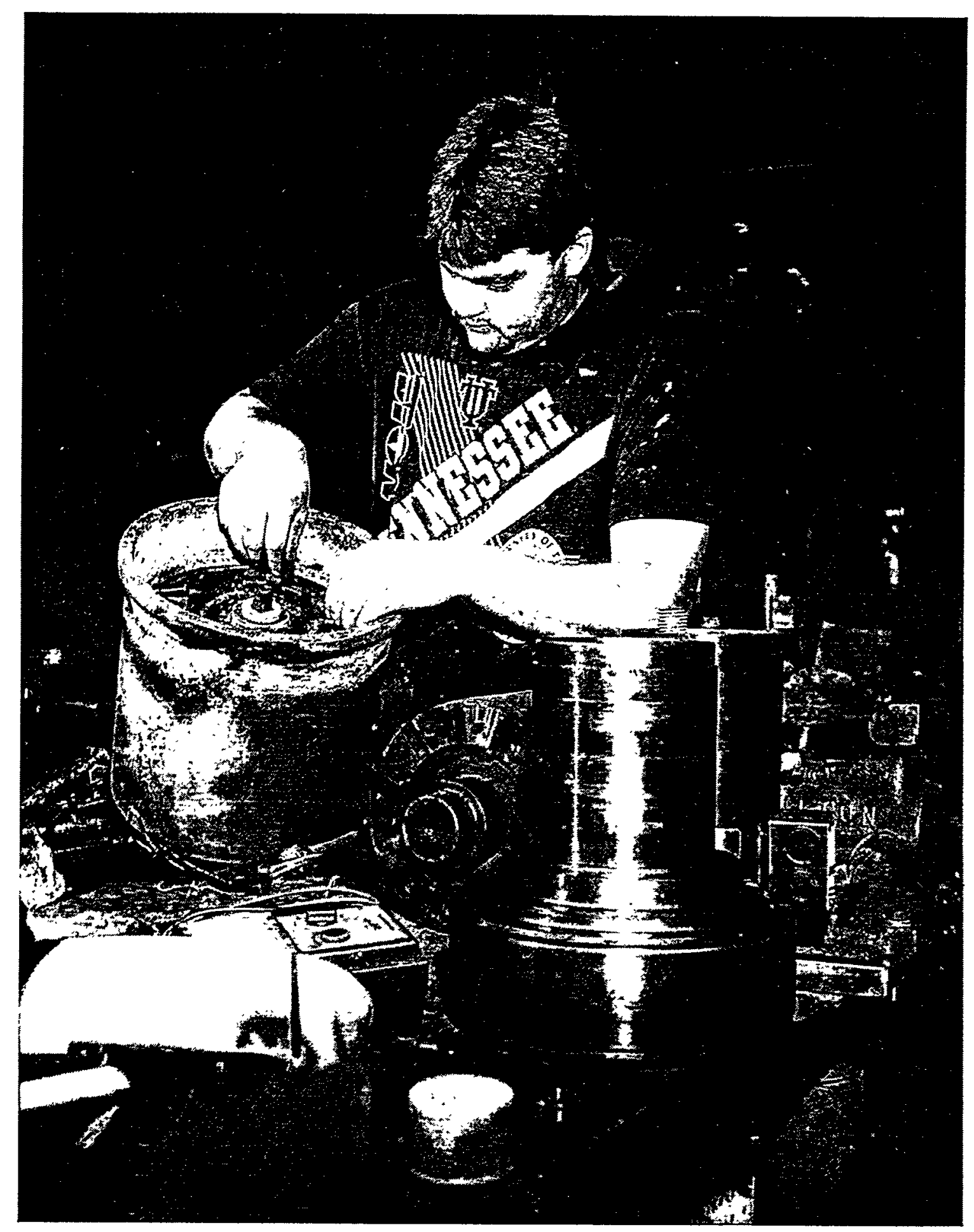

Figure B-2

Taking Parts Out of a Garbage Disposer Motor 


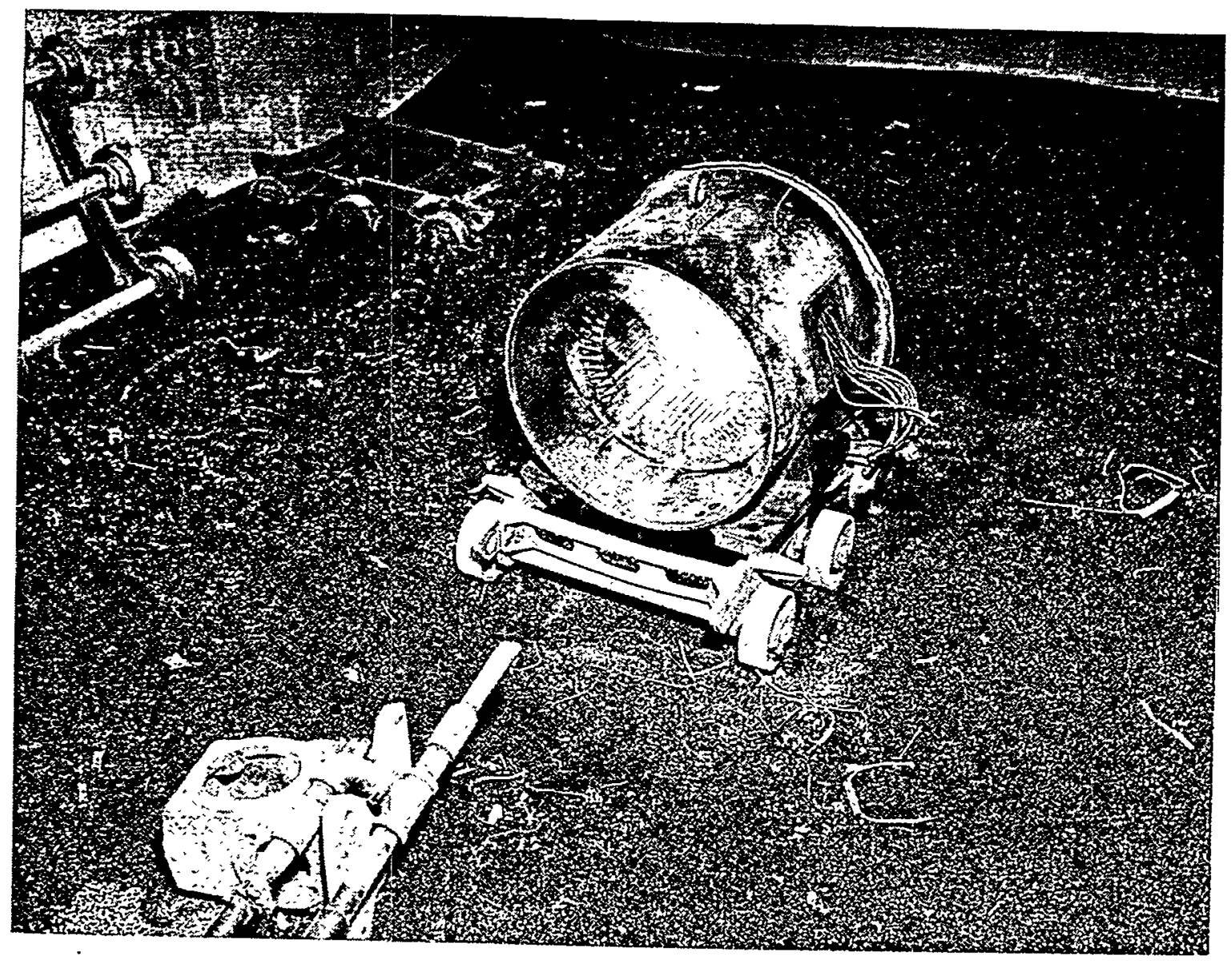

Figure B-3

Burning Off Old Resin Insulation 


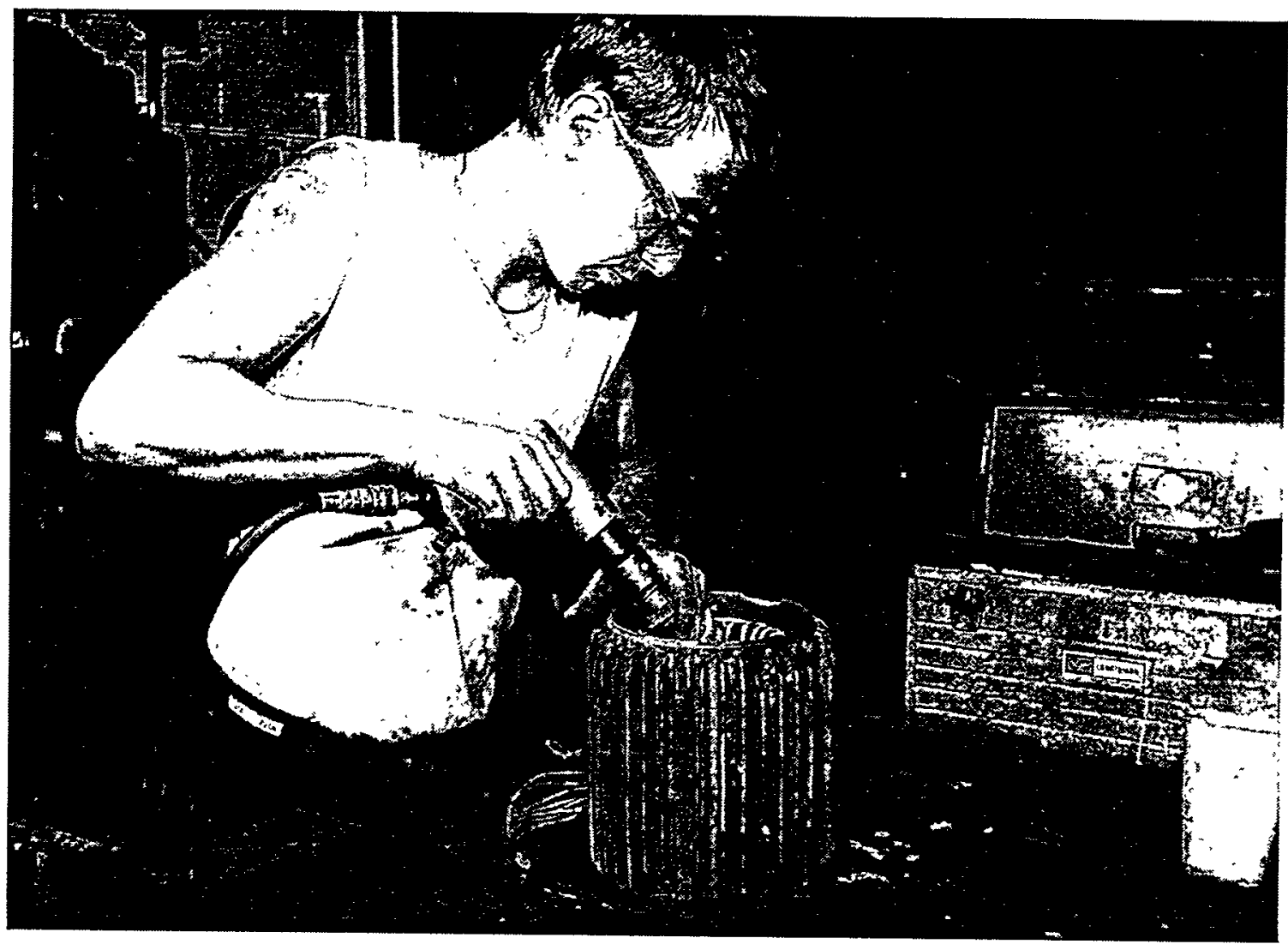

Figure B-4

Cutting Off End Windings With An Air Hammer 


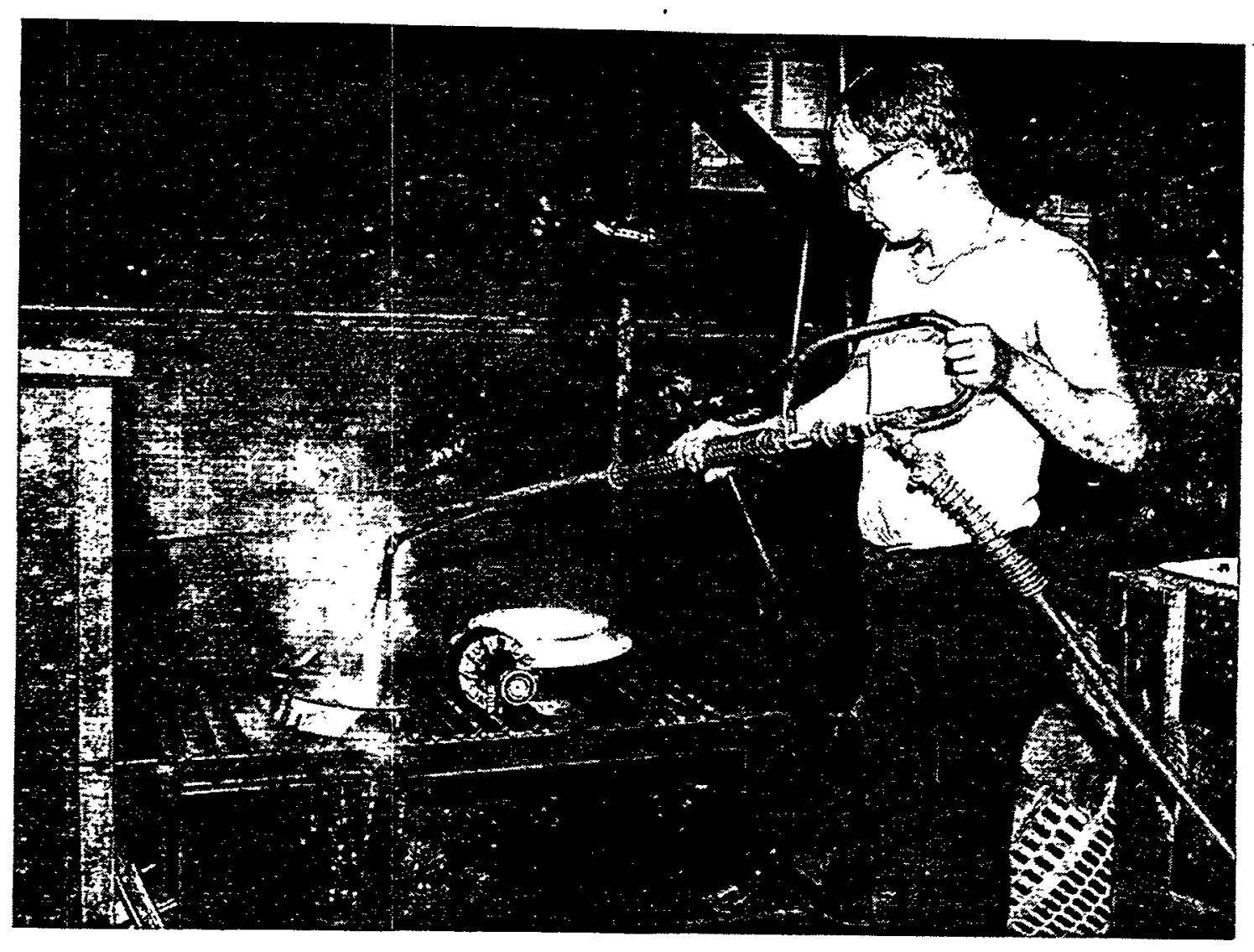

Figure B-5

Steam Cleaning of Motor Parts 


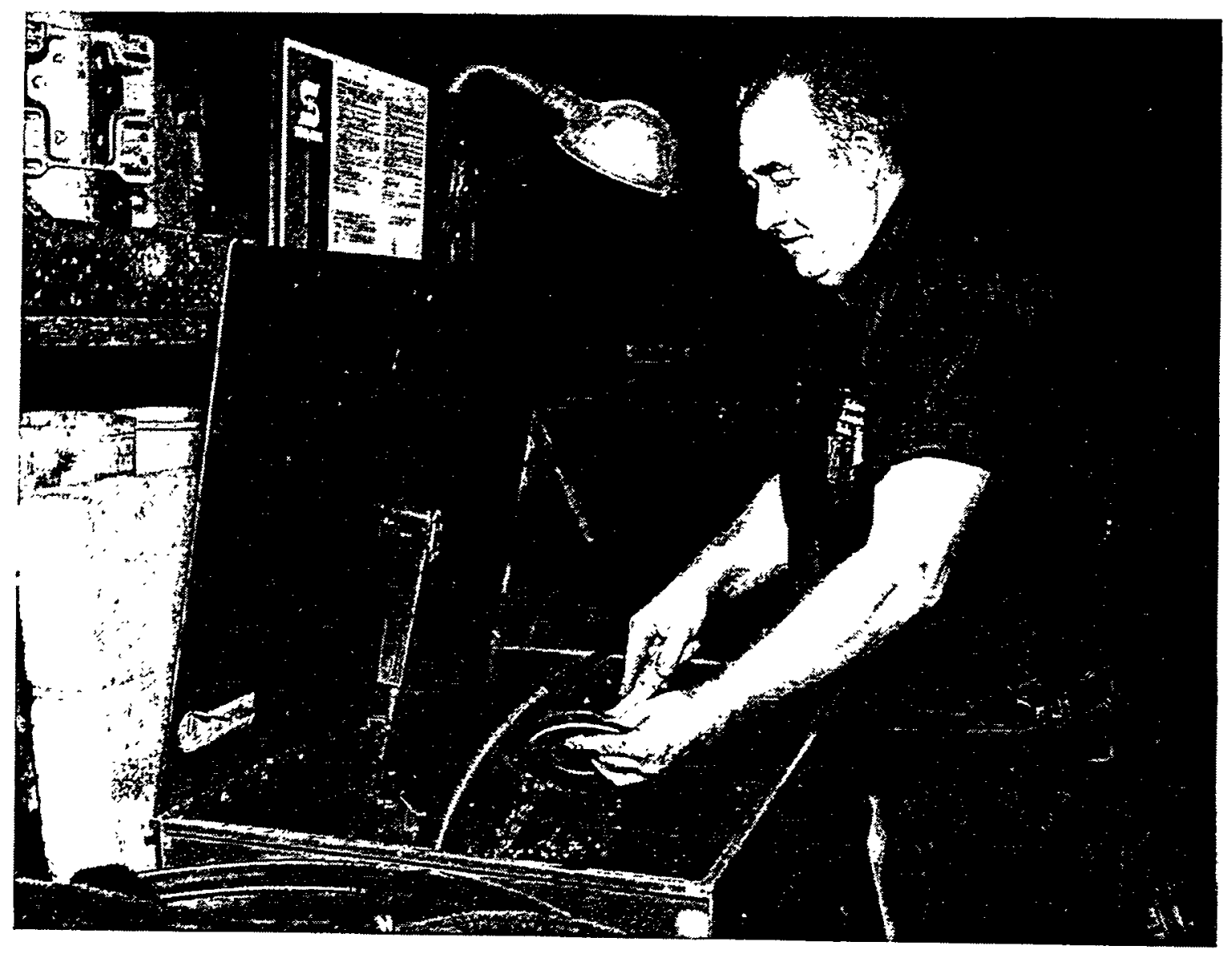

Figure B-6

Cleaning Motor Parts In a Solvent 


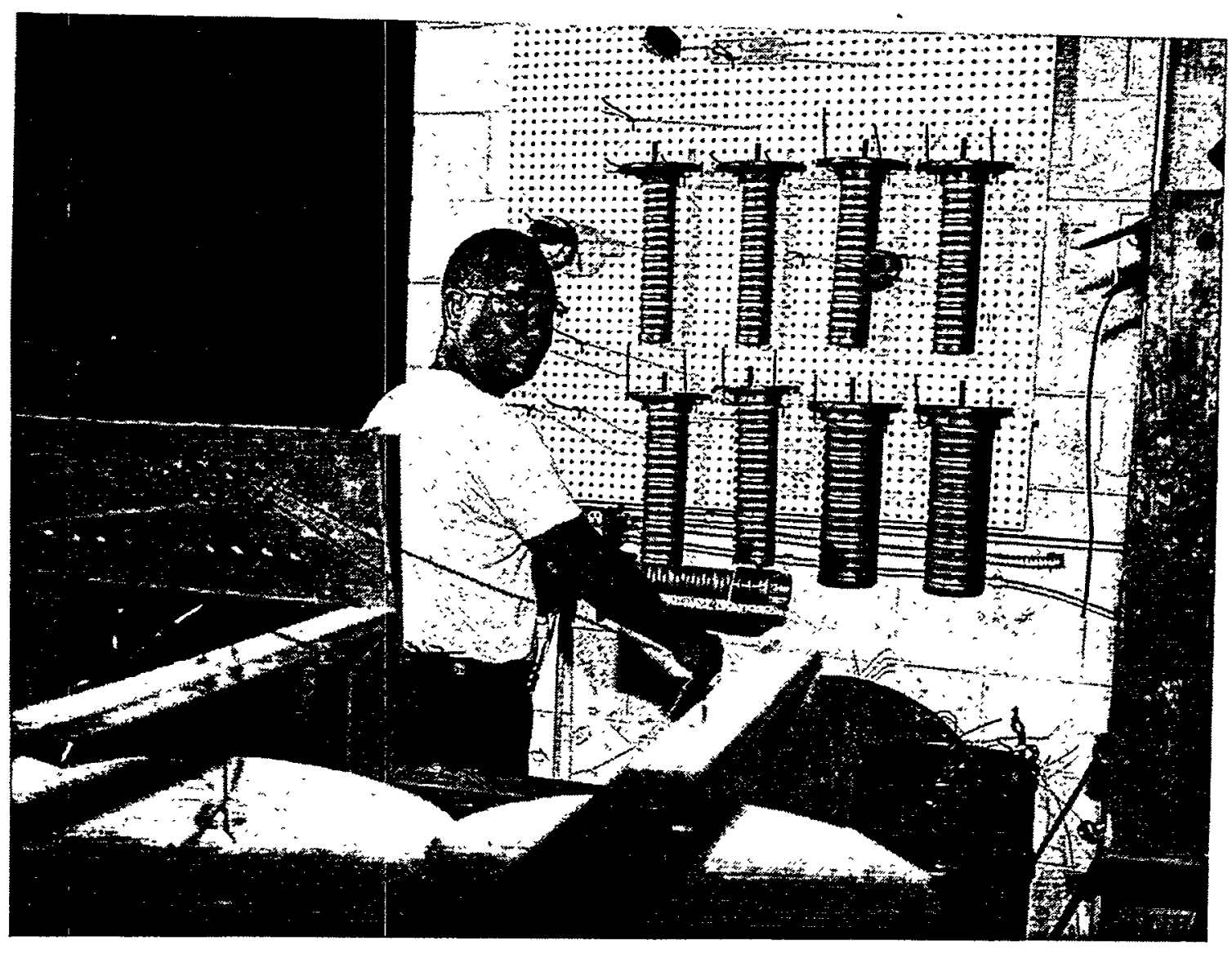

Figure B-7

Winding Coils 


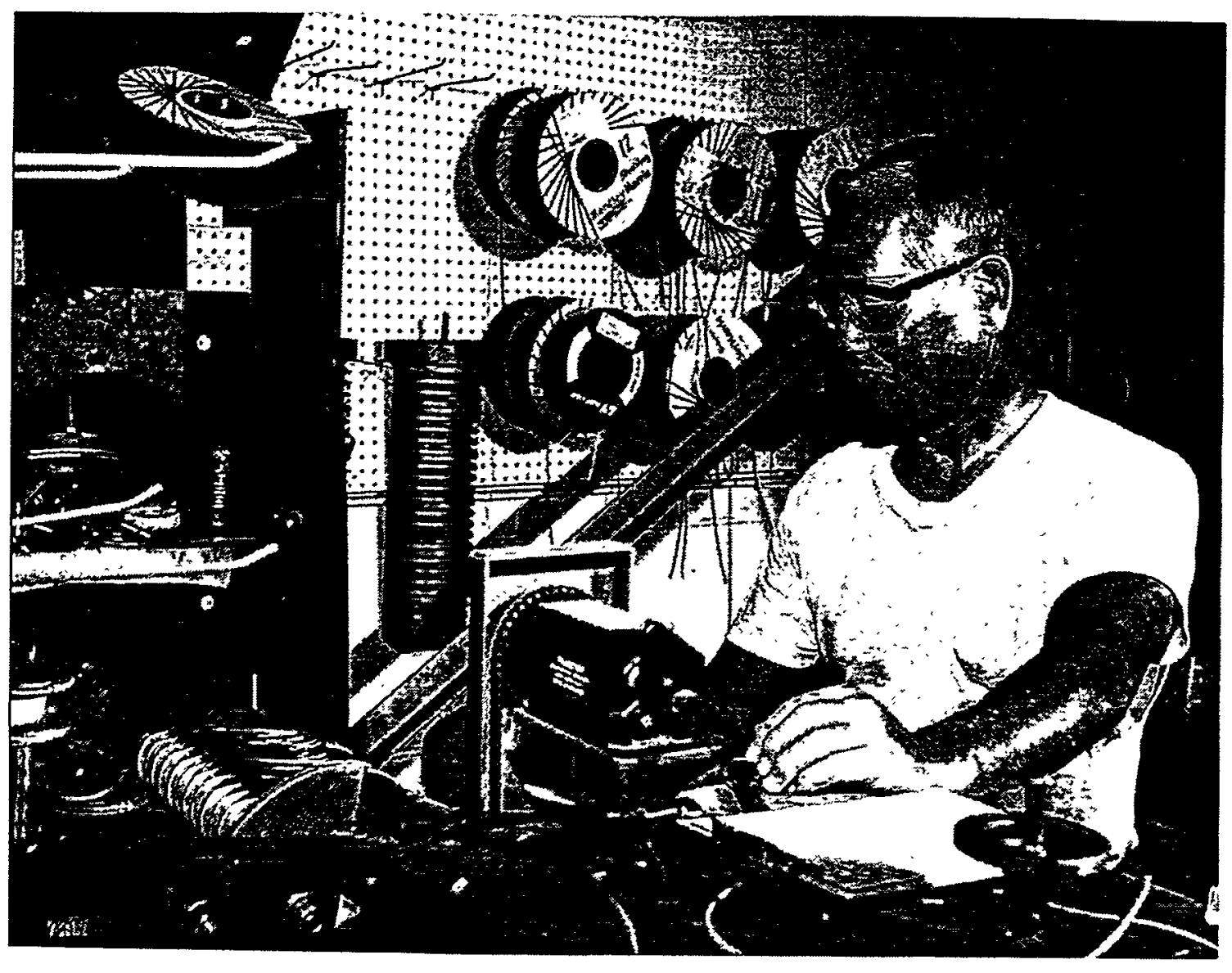

Figure B-8

Winding Coils 


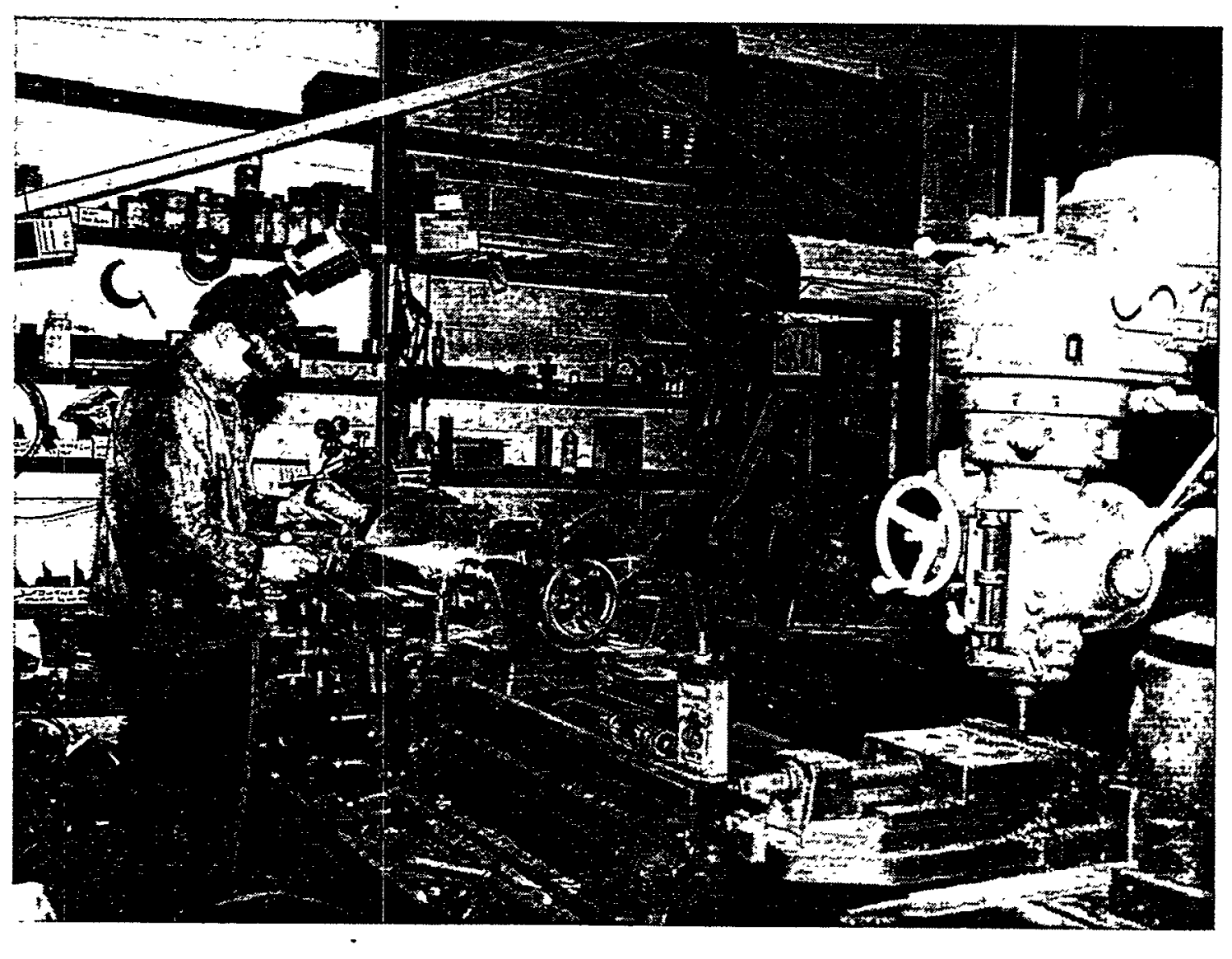

Figure B-9

Metal Spray for Shaft Repair 


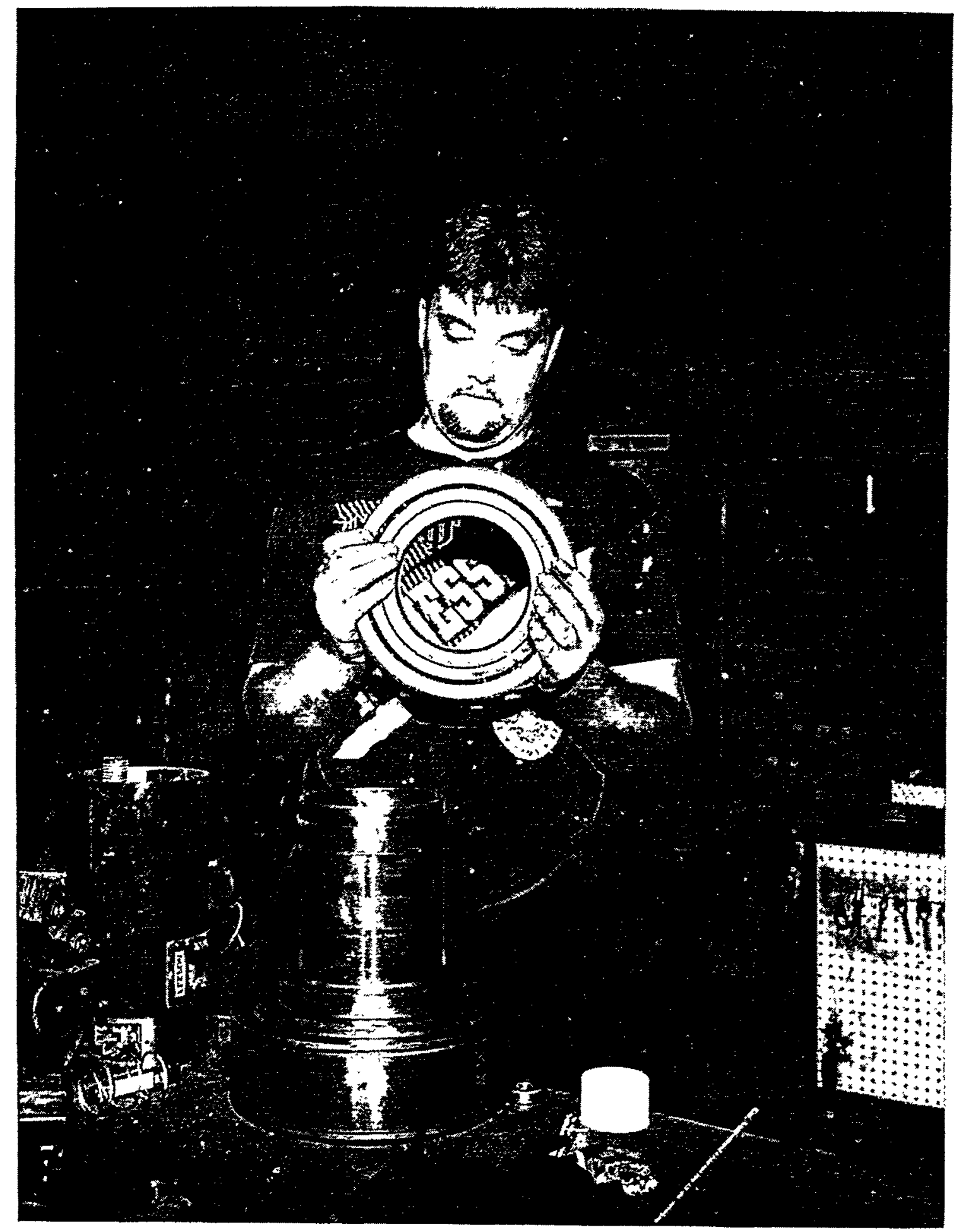

Figure B-10

Visual Inspection Of a Bearing 


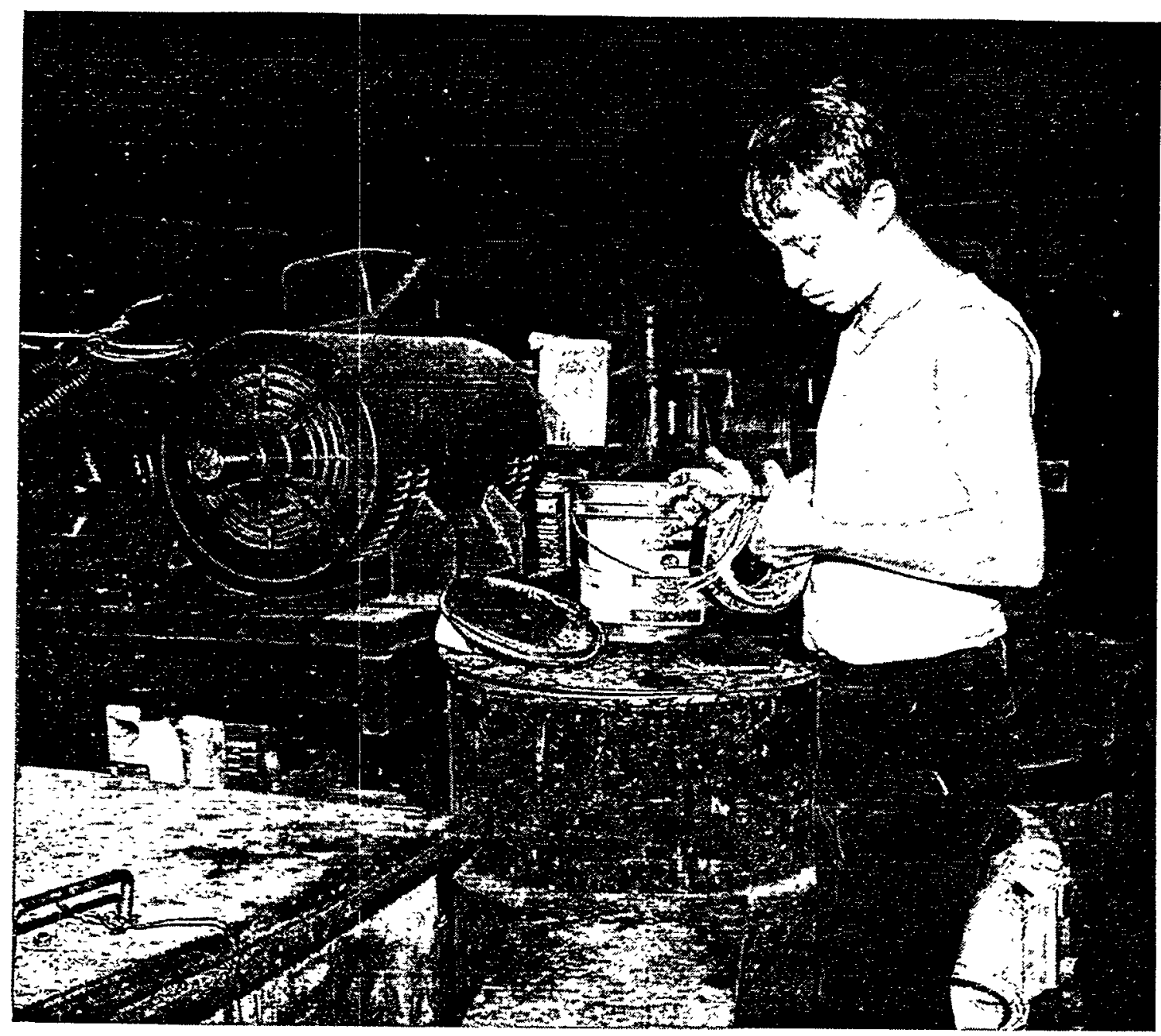

Figure B-11

Visual Inspection of Motor Part Prior to Dipping 


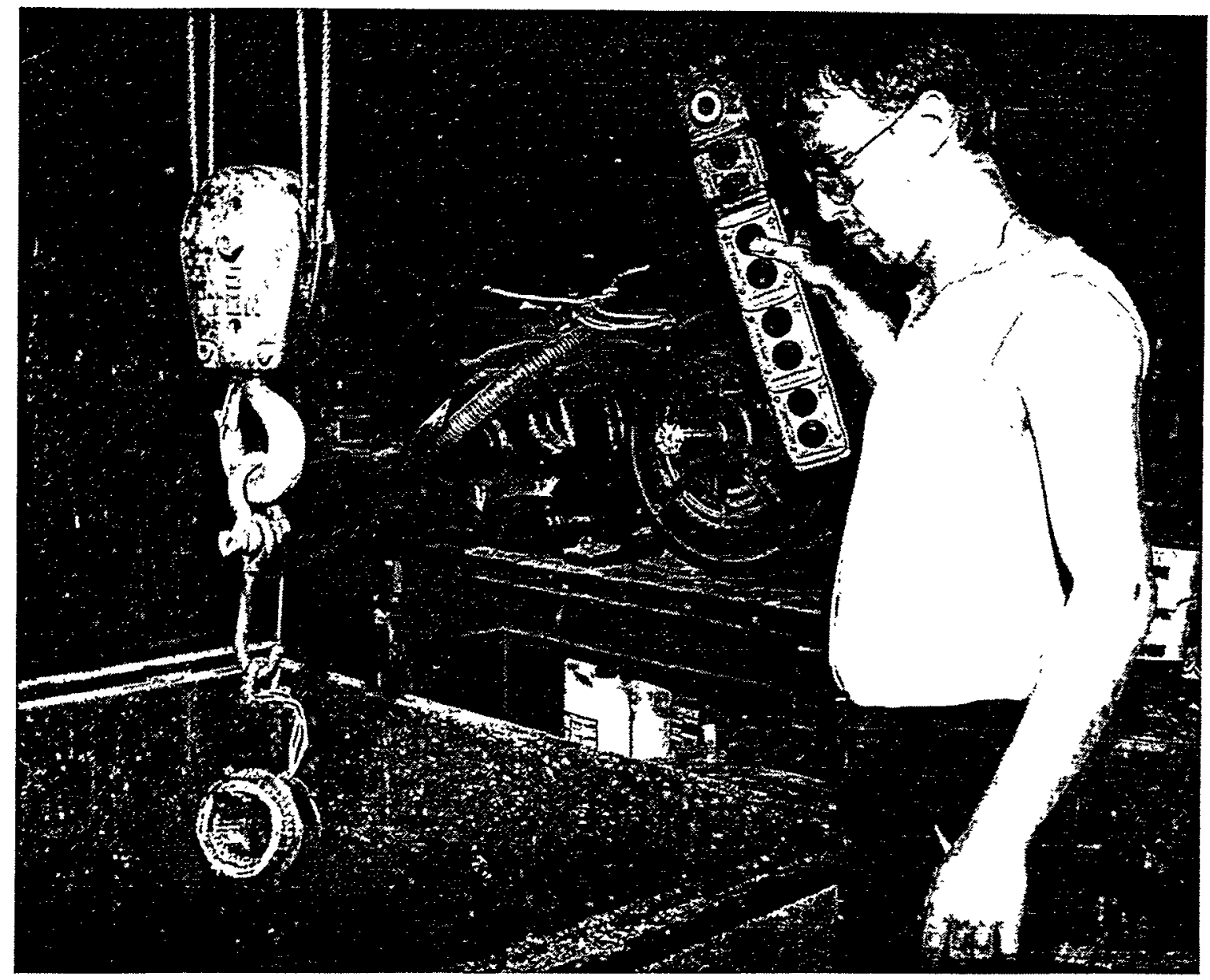

Figure B-12

Lowering of Small Motor into a Varnish Tank 


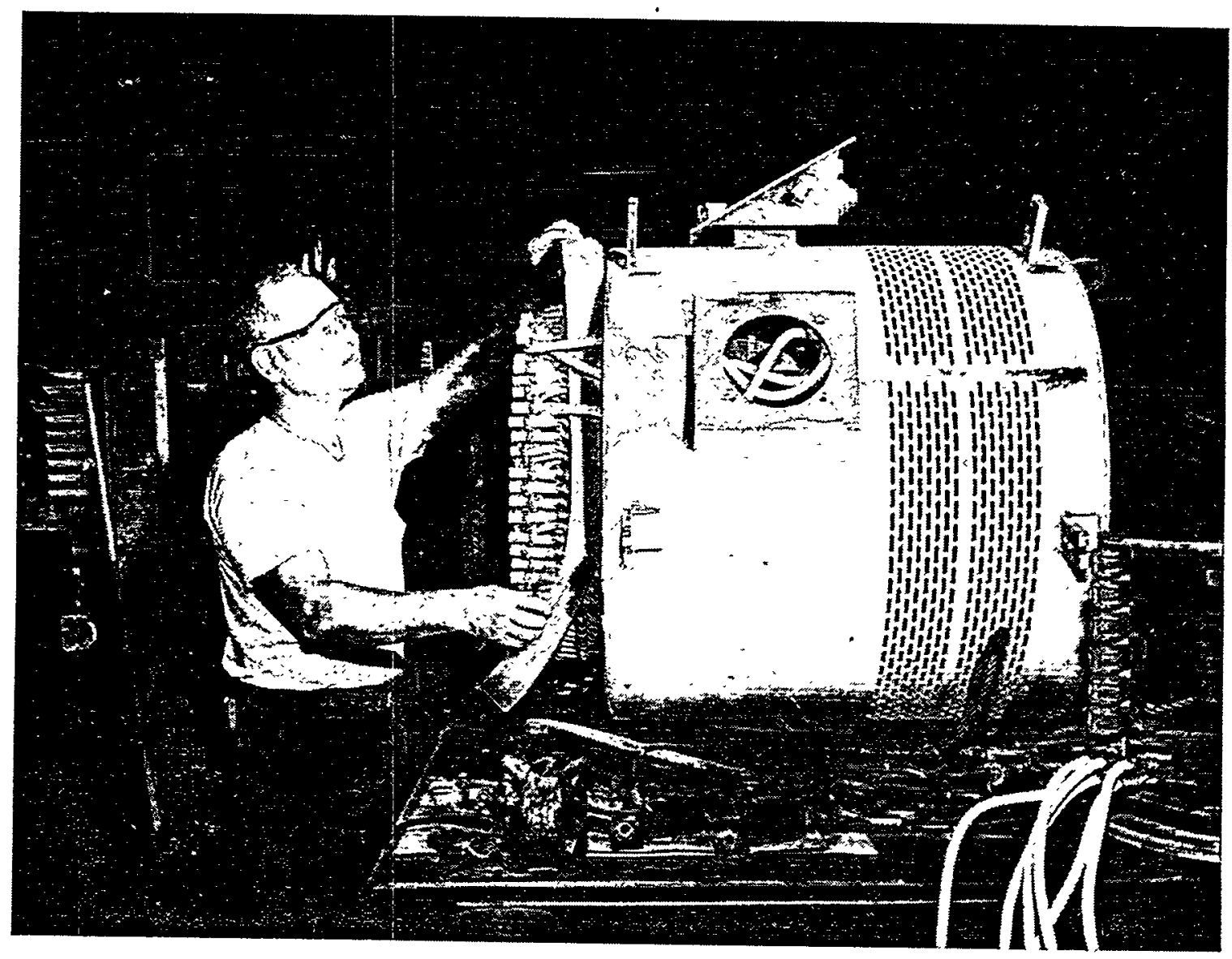

Figure B-13

Putting On End-Turn Insulation 


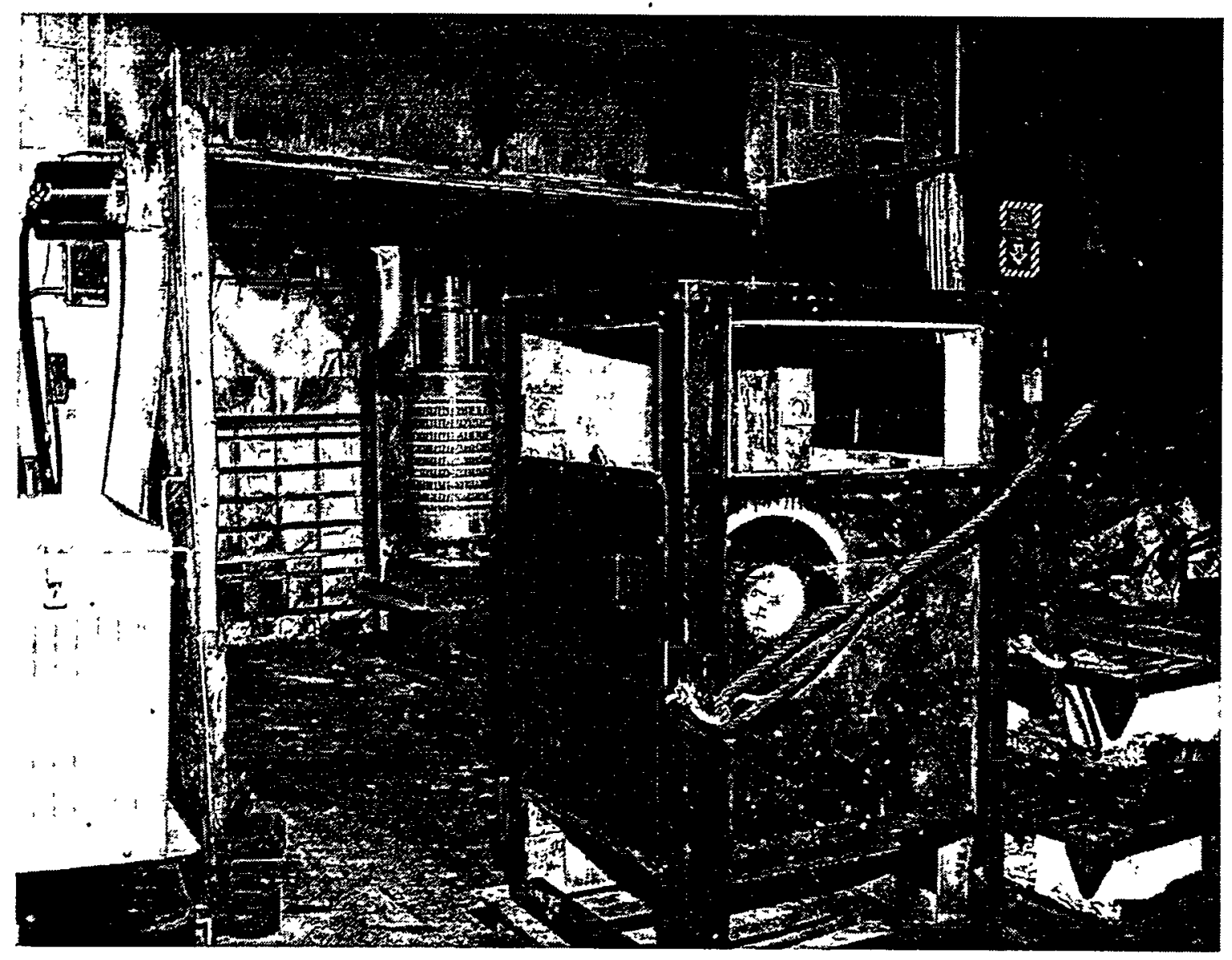

Figure B-14

A DC Rotor in A Baking Oven 


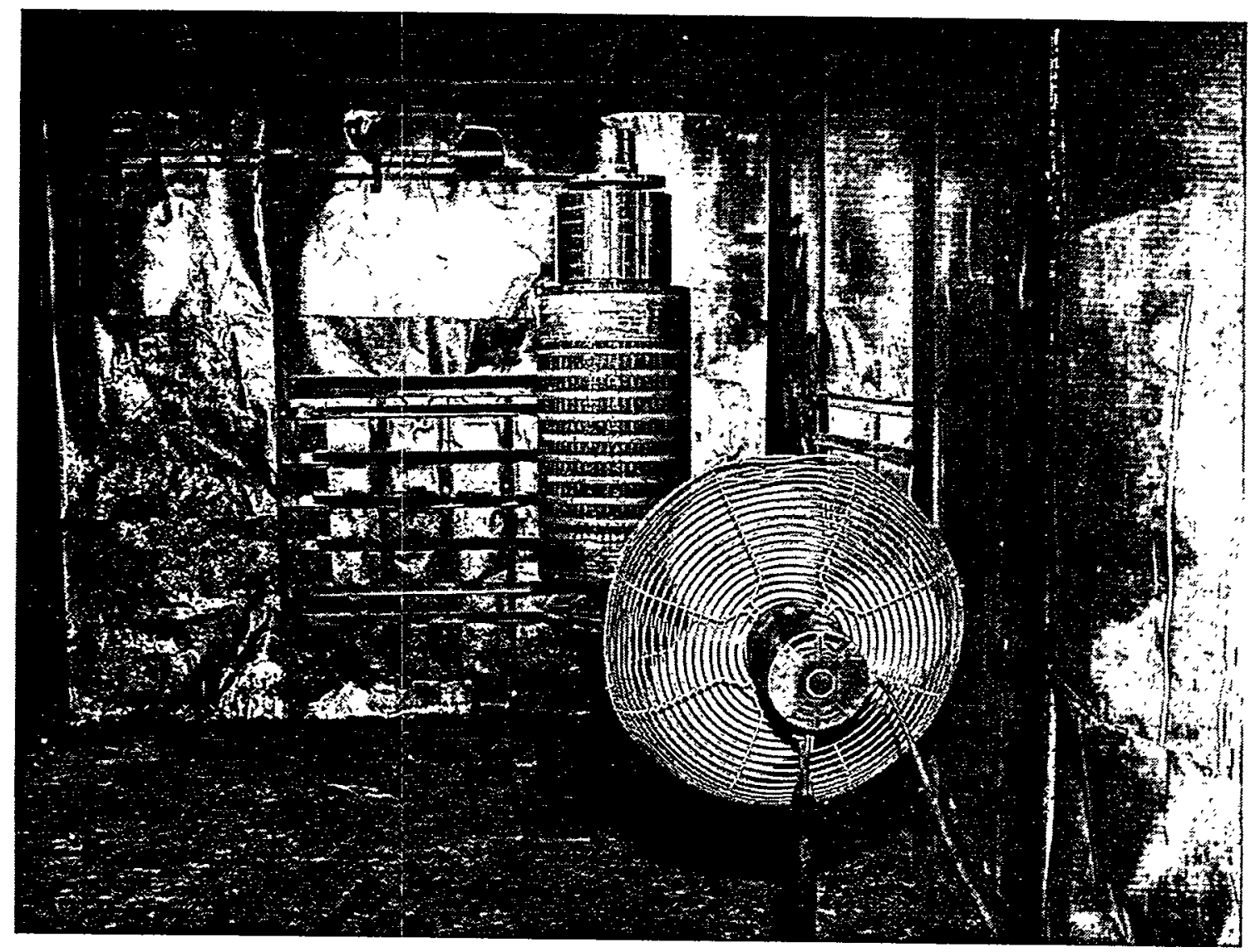

Figure B-15

A DC Rotor Coming Out Of The Oven 


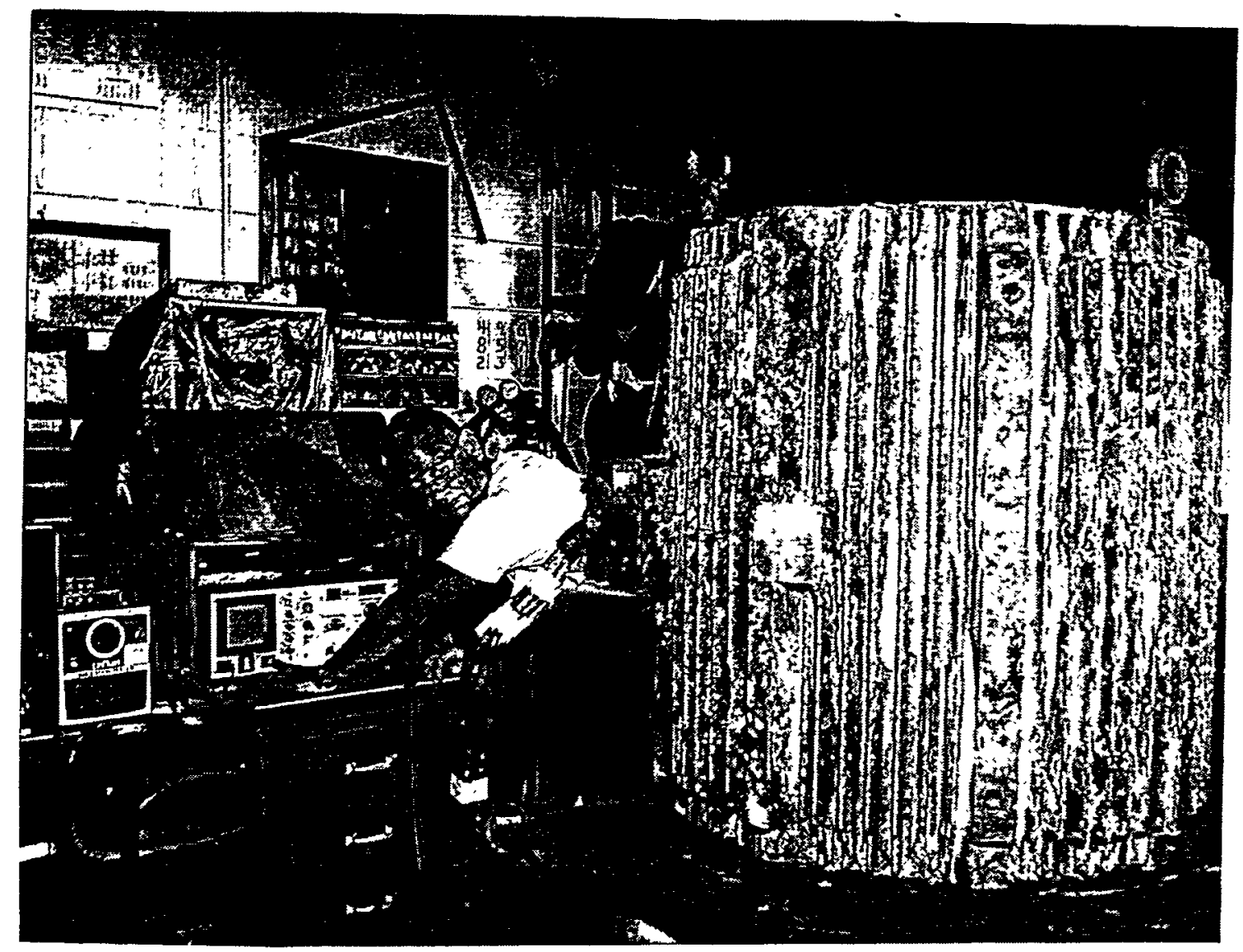

Figure B-16

Turn-To-Turn, Phase-To-Phase and Phase-To-Ground Test of Winding Using Baker Surge Tester 


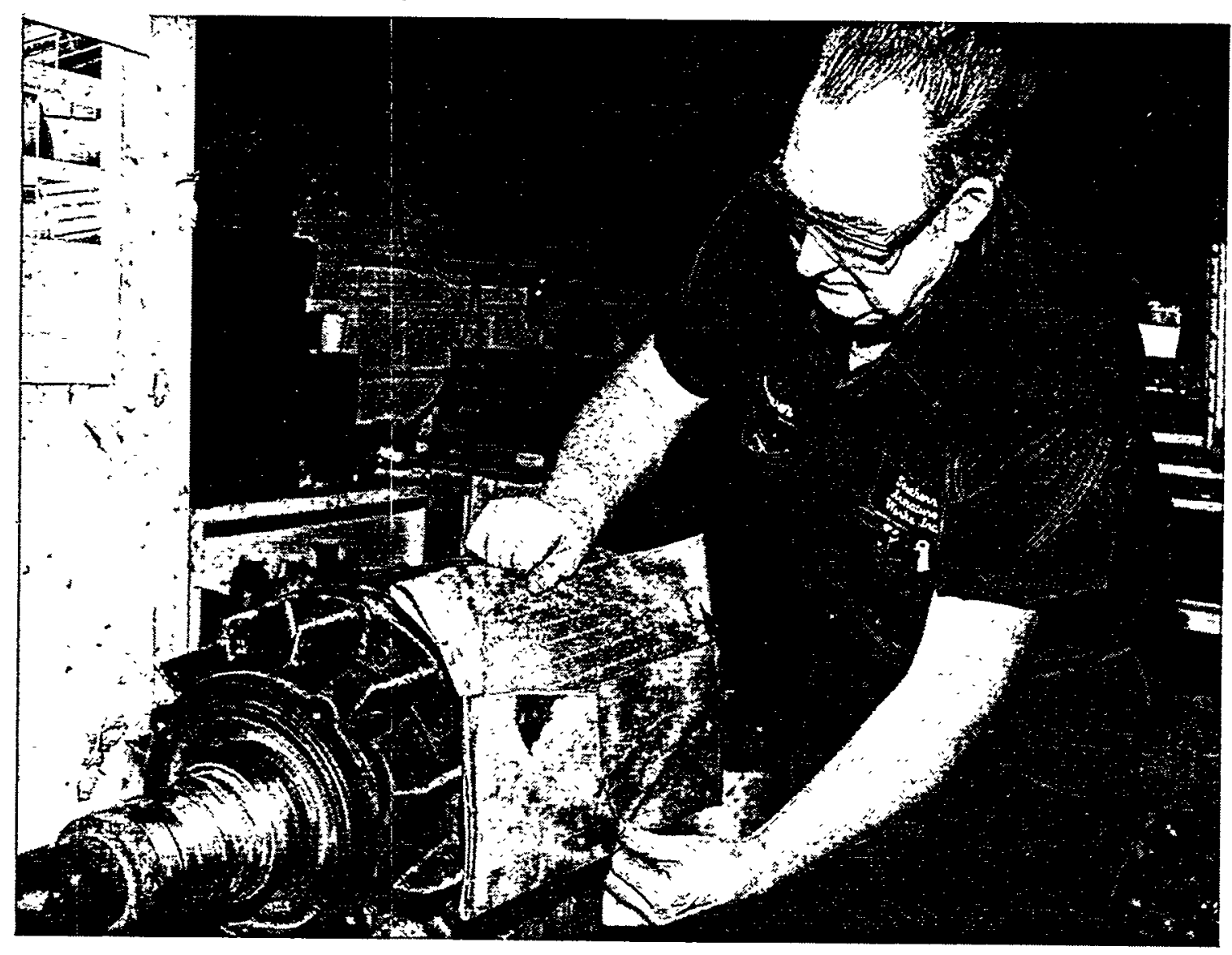

Figure B-17

Cracked Rotor Bar Test 


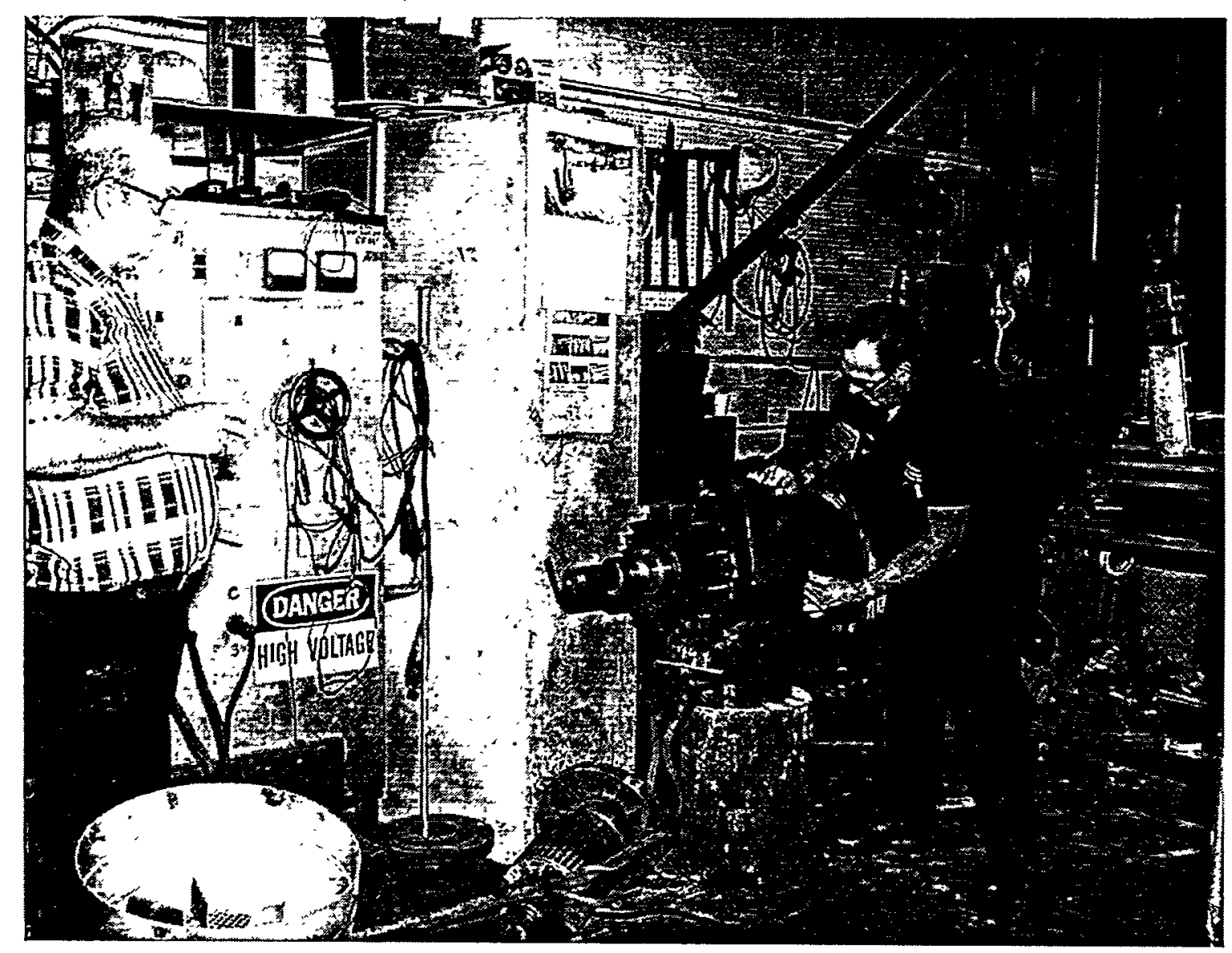

Figure B-18

Cracked Rotor Bar Test 


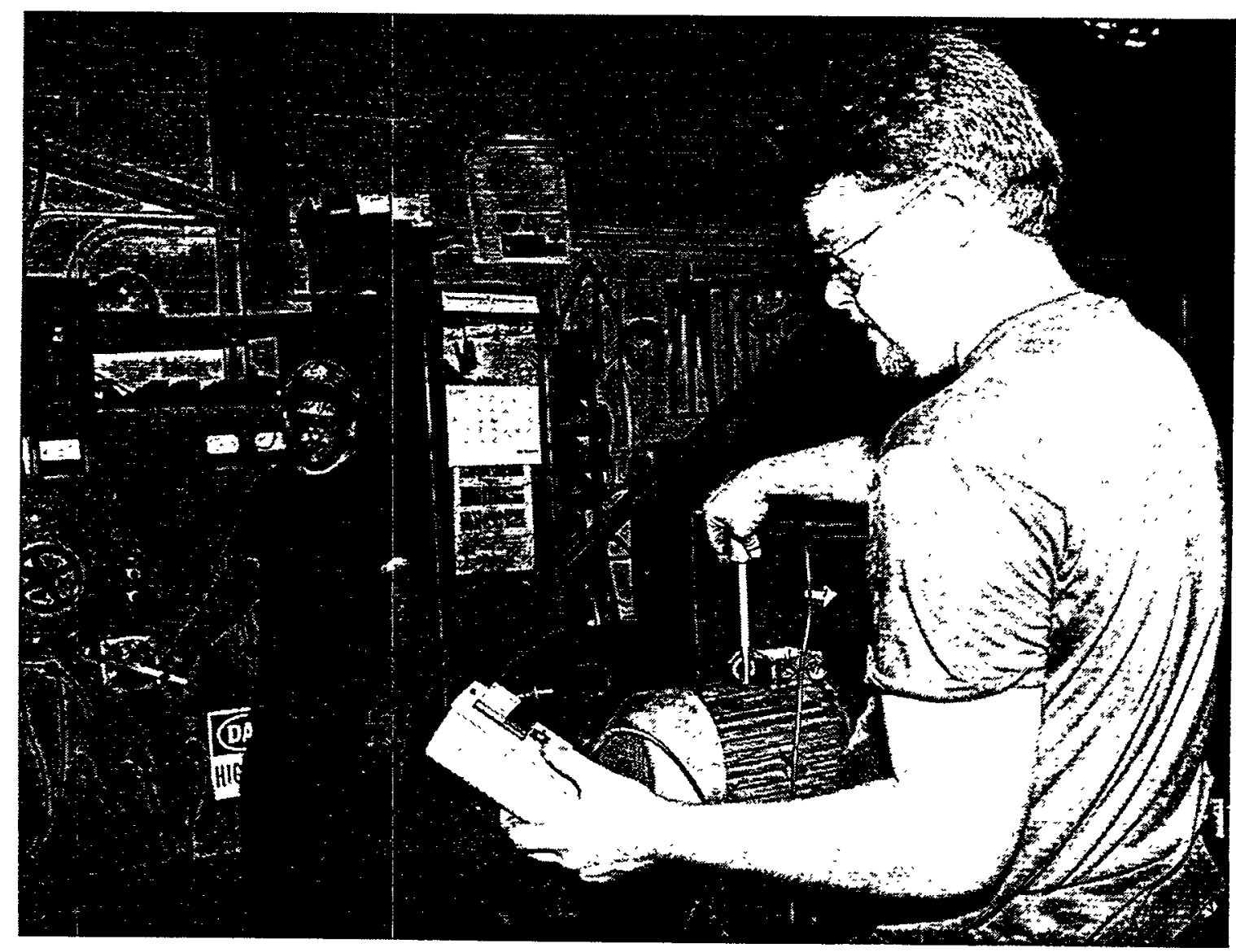

Figure B-19

Portable Vibration Test Meter To Check Rotor Balance 


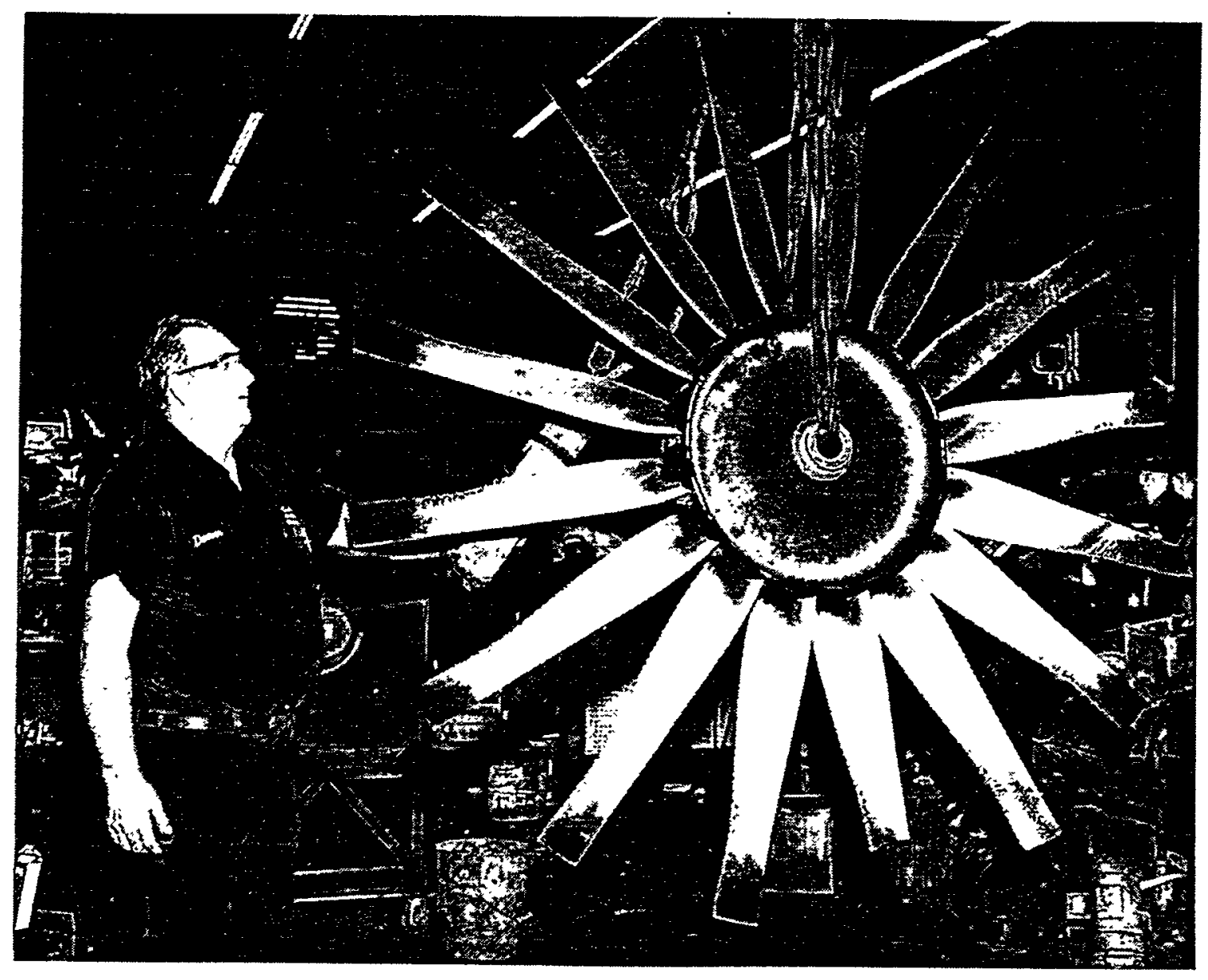

Figure B-20

Repairing Fan Blades 


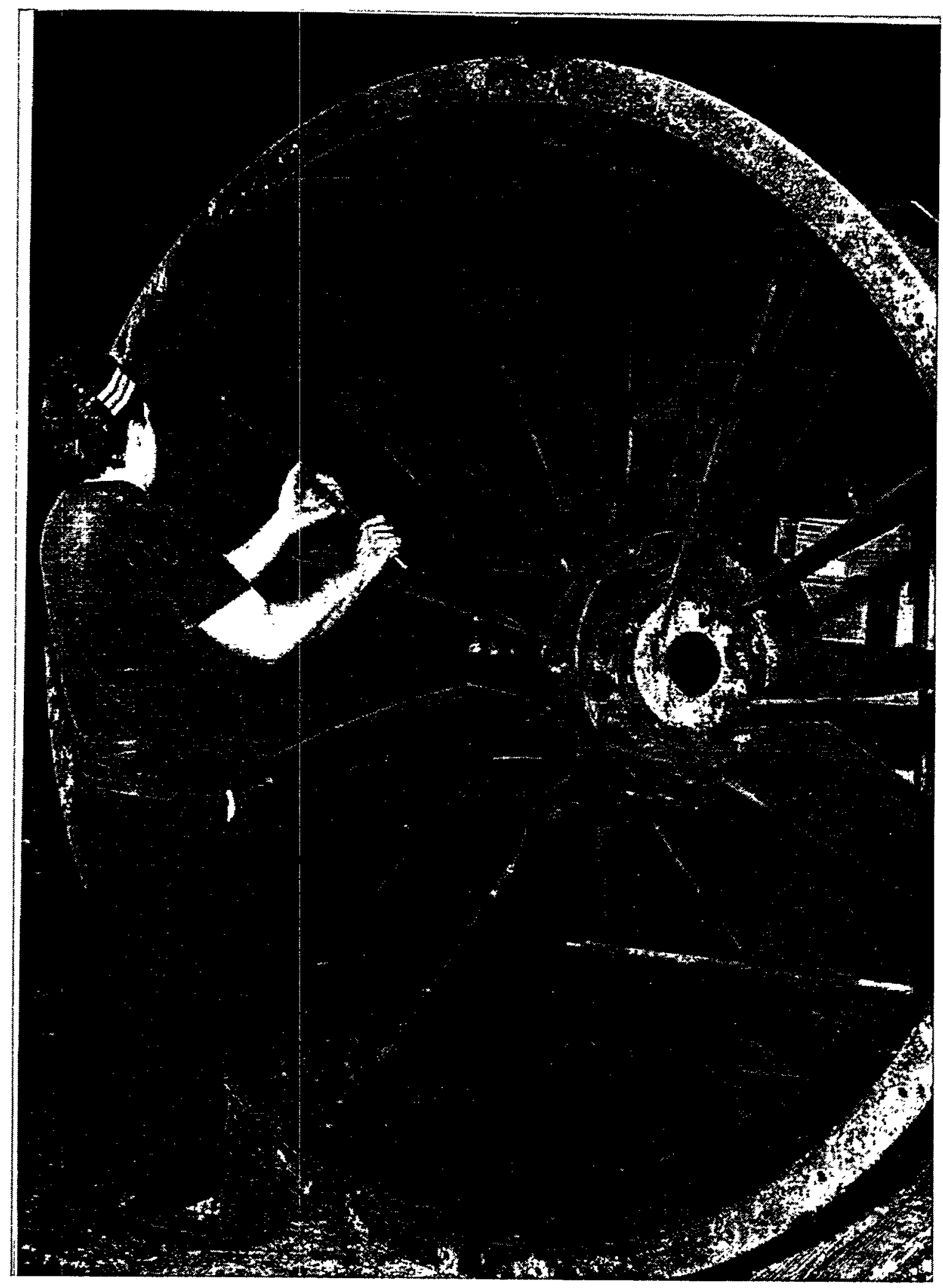

Figure B-21

Repairing A Fan 


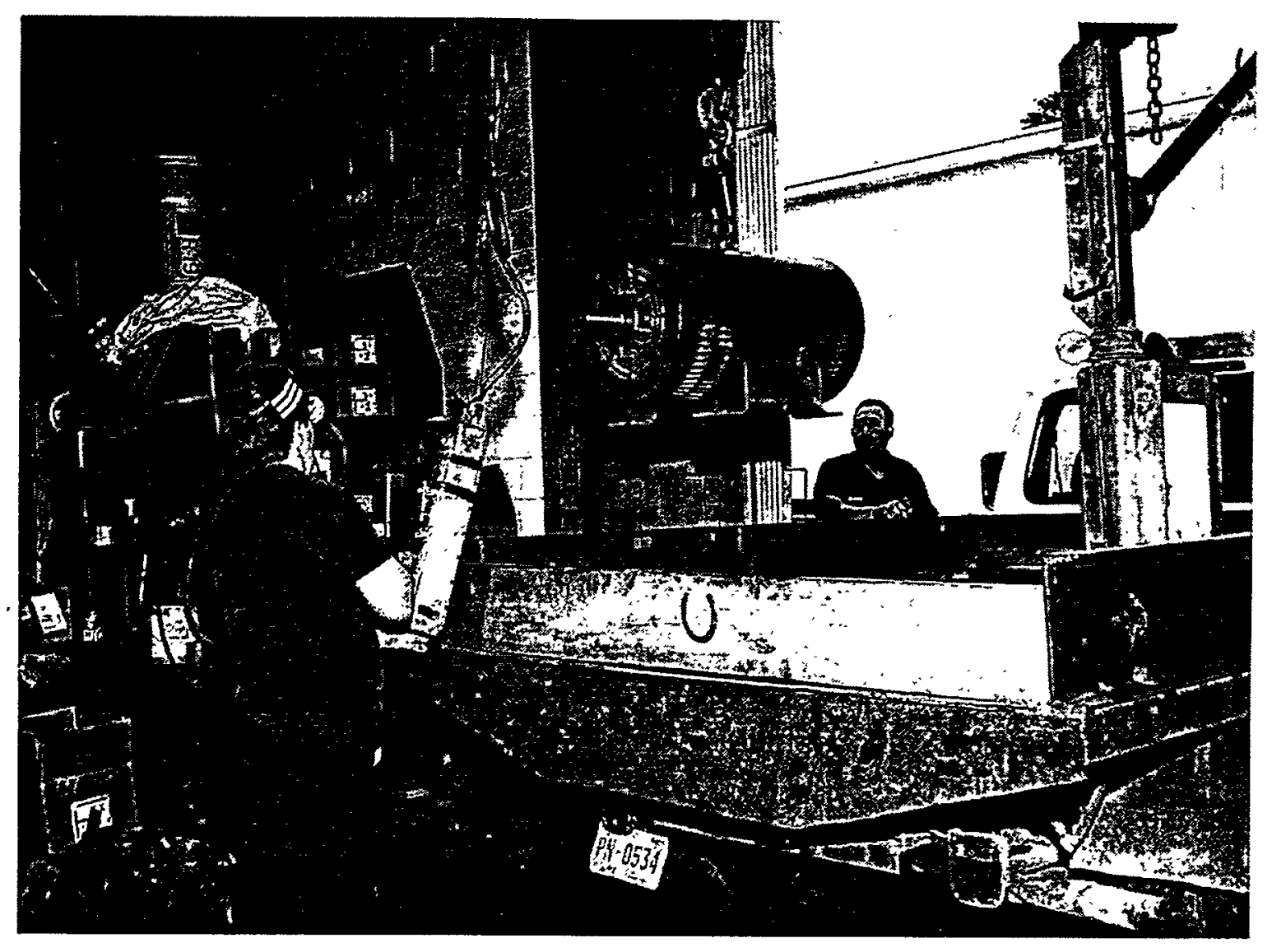

Figure B-22

Transportation of A Newly Rewound Motor 


\section{APPENDIX C}

\section{EASA STANDARDS}

Enclosed as an attachment to this document is the latest copy of the EASA Standard entitled: Recommended Practice for the Repair of Rotating Electrical Apparatus, EASA AR100-1998. This document contains the association's standards for the repair, rewinding and testing of rotating equipment. A section on Electrical Testing Safety Considerations is also included.

As indicated in Appendix H (i.e., Figure H-3), EASA was not able to permit ORNL to include the document in this report. However, the title page and table of contents are included in this appendix to provide an indication of the scope of information included. Once membership with EASA is obtained, additional copies of the complete document may be ordered as needed. 
EASA AR100-1998

RECOM M E DED

P R A C T I C E

FOR THE REPAIR OF ROTATING

ELECTRICAL APPARATUS

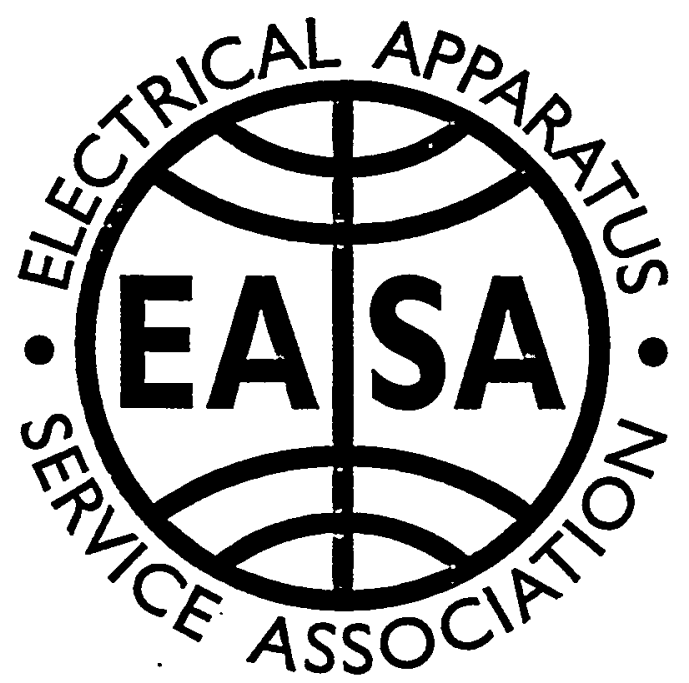

Reliable Solutions Today! 
Electrical Apparatus Service Association, Inc. 1331 Baur Blvd. • St. Louis, MO 63132

(314) 993-2220 - Fax: (314) 993-1269

Copyright $\odot$ 1998. All rights reserved.

$\mathrm{C}-3$ 


\section{TABLE OF CONTENTS}

\section{SECTION 1: GENERAL}

1.1 PURPOSE

1.2 SCOPE

1.3 IDENTIFICATION

1.3.1 Service Center Labeling

1.3.2 Records

1.3.3 Nameplate

1.4 CLEANING

1.5 TERMINAL LEADS

1.6 TERMINAL CONNECTORS

1.7 TERMINAL BOXES

1.8 COOLING SYSTEM

1.9 EXTERIOR FINISH

1.10 PACKAGING AND TRANSPORTATION

\section{SECTION 2: MECHANICAL REPAIR}

\subsection{SHAFTS}

\subsubsection{Shaft Extensions}

2.1.1.1 Diameter Tolerances

2.1.1.2 Permissible Runout

2.1.1.3 Keyseat (Keyway) Width

2.2 BEARINGS

Tolerances

2.2.1 Ball or Roller Bearings

2.2.2 Sleeve Bearings

2.2.2.1 Sleeve Bearing End-Thrust

2.2.2.2 Oil Rings

2.2.2.3 Seals

2.3 LUBRICATION

2.3.1 Grease

2.3.2 Oil

2.4 FRAME AND BEARING HOUSINGS

2.4.1 General

2.4.2 Mounting Surface Tolerances, Eccentricity and Face Runout

2.5 LAMINATIONS

2.6 BALANCING

2.7 SLIP RINGS

2.8 COMMUTATORS

2.8.1 Machining

2.8.2 Undercutting

2.9 BRUSHHOLDERS

2.10 BRUSHES

2.11 BRUSH SETTING FOR DC MACHINES.
2.12 AIR GAP MEASUREMENT OF DC MACHINES

\subsection{ACCESSORIES}

TABLES

2-1 Shaft Extension Diameter TolerancesNEMA Frame Size Machines

2-2 Shaft Extension Diameter Tolerances-IEC Frame Size Machines

2-3 PermissibleShaftExtension Runout-NEMA Frame Size Machines

2-4 Permissible Shaft Extension Runout-IEC Frame Size Machines

2-5 Shaft Extension Keyseat Width TolerancesNEMA Frame Size Machines

2-6 Shaft Extension Keyseat (Keyway) Width Tolerances-IEC Frame Size Machines

2-7 Sleeve Bearing Diametral Clearance GuideHorizontal Mounting

2-8 Labyrinth Seal Diametral Clearance Guide

2-9 Mounting Surface Tolerances, Eccentricity, and Face Runout-NEMA Type C FaceMounting Motors and Type D Flange-Mounting Motors

2-10 Mounting Surface Tolerances, Eccentricity, and Face Runout-NEMA Type P FlangeMounting Motors

2-11 Mounting Rabbet (Spigot) Diameter Tolerances-IEC Flange-Mounted Machines

2-12 Mounting Surface Eccentricity and Face Runout-IEC Flange-Mounted Machines

2-13 Brush-to-Brushholder Clearance

\section{SECTIÓN 3: REWINDING}

3.1 INSPECTION

3.1.1 Windings

3.1.2 Core Laminations

3.1.3 Thermal Protectors or Sensors .

3.2 REWINDING SPECIFICATION

3.3 STRIPPING OF WINDINGS

3.4 INSULATION SYSTEM

3.5 CONDUCTORS

3.6 STATOR, ROTOR, AND ARMATURE COILS

3.6.1 Random-Wound Coils

3.6.2 Form-Wound Coils

3.7 FIELD COILS

3.7.1 Stationary Coils

3.7.2 Rotating Coils

3.8 AMORTISSEUR AND SQUIRREL CAGE WINDINGS 


\subsection{THERMAL PROTECTORS OR SENSORS \\ 3.10 SHAPING AND LACING OF STATOR WINDINGS \\ 3.11 COIL CONNECTIONS \\ 3.11.1 Making Connections \\ 3.11.2 Insulating Connections \\ 3.12 WEDGES \\ 3.13 BANDING OF ROTORS AND ARMATURES \\ 3.14 IMPREGNATION OF WINDINGS}

\section{SECTION 4: TESTING}

4.1 SAFETY CONSIDERATIONS

4.2 INSULATION CONDITION TESTS

4.2.1 Inspection

4.2.2 Insulation Resistance Test

4.2.3 Polarization Index (P-I) Test

4.2.4 Insulation Power Factor Tests

4.2.5 Step Voltage Test

4.2.6 Turn-to-Turn Test

4.2.7 Interlaminar Insulation Test

4.2.8 Bearing Insulation Test

4.3 RECOMMENDED WINDING TESTS

4.3.1 Stator and Wound-Rotor Windings

4.3.2 Squirrel Cage Windings

4.3.3 Armature Windings

4.3.4 Shunt, Series, Interpole, Compensating and Synchronous Rotor Windings

4.3.5 Interconnection of Windings

4.4 HIGH-POTENTIAL TESTS

4.4.1 Windings

4.4.1.1 New Windings

4.4.1.2 Reconditioned Windings

4.4.1.3 Windings Not Reconditioned

4.4.2 Accessories

4.4.2.1 New Accessories

4.4.2.2 Accessories of Machines with Reconditioned Windings

4.4.2.3 Accessories of Machines with Windings Not Reconditioned

4.5 NO-LOAD TESTS

4.5.1 Speed

4.5.2 Current

4.5.3 Cooling System

4.5.4 Sound Level

4.5.5 Bearing Temperature

4.5.6 Vibration Tests
4.6 PERFORMANCE TESTS

4.7 INSTRUMENT CALIBRATION

TABLES

4-1 High-Potential Test Using AC-New Windings

4-2 High-Potential Test Using DC-New Windings

4-3 High-Potential Test Using AC-New Accessories

4-4 High-Potential Test Using DC-New Accessories

4-5 Unfiltered Vibration Limits-Resiliently Mounted Machines

\section{APPENDIX: ELECTRICAL TESTING} SAFETY CONSIDERATIONS

\section{A.1 PERSONAL SAFETY}

A.1.1 Training

A.1.2 Clothing

A.1.3 Supervision

A.1.4 First Aid

A.2 TEST AREA

A.2.1 Enclosure

A.2.2 Gates

A.2.3 Signs

A.2.4 Lighting

A.2.5 Safety Equipment

A.2.6 Test Unit Clearance

A.3 UNIT UNDER TEST

A.3.1 .Suitability for Test

A.3.2 Exclusive Attention

A.3.3 Grounding

A.3.4 Base

A.4 TEST PANELS

A.4.1 Construction

A.4.2 Voltages

A.4.3 Warning Lights

A.4.4 Disconnect

A.4.5 Safety Switch

A.4.6 Leads

A.4.7 High-Potential Ground Test

\section{BIBLIOGRAPHY}

\section{STANDARDS ORGANIZATIONS \& OTHER RESOURCES}

Note: Sections pertaining to the repair of liquid-filled and dry-type distribution transformers were withdrawn from this edition of EASA Recommended Practice for the Repair of Rotating Electrical Apparatus. . 


\section{APPENDIX D \\ LIST OF EQUIPMENT NEEDED FOR A REWIND/REPAIR SHOP}

A list of the equipment needed to properly rebuild electric motors was supplied by David L. Gebhart, PE, staff engineer with EASA. His letter is included herewith. 
We feel it is necessary to have the following equipment to properly rebuild motors:

1. An assortment of wrenches, hammers, screw drives, etc., hand or power operated, for dismantling and reassembling motors.

2. Hoists for unloading motors and lifting parts. The number and size will depend on the size of the plant and the largest motor you expect handle.

3. Equipment for moving parts between operations.

4. Pullers for removing bearings/couplings corroded to the shaft.

5. Equipment for cleaning the dirt and grease from the parts. This can be a chemical spray or sand blast equipment or both.

6. Equipment for stripping the old windings. This could be a burnout oven or chemical stripper. Do not use a torch or open flame. After the vamish is softened or burned off, you need coil cutters to cut off the coil on one end and coil pullers to remove the winding.

7. Winding machines for making coils, preferably that can layer wind.

8. Winding heads-you may want both three phase and single phase.

9. Coil racks for storing wire behind the winding machine.

10. Dereelers to keep the wire from becoming tangled.

11. Tension devices to apply tension to the wire while the coil is made. 
12. Dipping the wound stator in a tank of varnish and baking it in an oven is the most popular way to treating the windings. This procedure is used by manufacturers, as well as by repair companies. All stators should be given at least two dips and bakes. The Tickle Process and V.P.I Process are other methods.

13. Balancing equipment.

14. Test equipment such as volt meters, amp meters, ohm meters, dielectric test sets, core-loss testers, surge testers, etc.

15. Repairing shafts, frames, etc., requires metallizing equipment.

There is a magazine devoted exclusively to the repair and maintenance industry. There are many articles in each issue that would be of interest to you. The name of the magazine is Electrical Apparatus. It is published by Barks Publications, Inc., 400 North Michigan Avenue, Suite 900, Chicago, Illinois, 60611-4198. They also publish a yearly directory of manufacturers of material, shop equipment and test instruments. Their phone number is (312) $321-9440$.

If we may be of additional service, please advise.

Sincerely'yours,

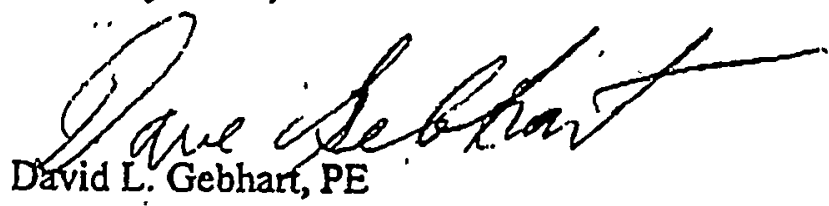

Staff Engineer

DLG:jw 


\section{APPENDIX E}

\section{MOTOR WINDING REMOVAL METHODS}

This appendix provides information on the advantages and disadvantages of the four methods for motor winding removal. This write-up, while still in rough draft form, should be of assistance to motor rewind facilities. 


\section{FAX COVER SHEET}

ATTENTION: Julie Van.Hemel

COMPANY: Hagler Bailly Consulting

LOCATION: San Francisco, CA

FAXNO.: $\quad 415.882 .1610$
FROM: David L. Gebhart, PE

Staff Engineer.

ENGR FAX: 314.993 .2998

DATE: . February 20, 1997

\section{MESSAGE}

SUBJECT: Fact Sheets on Motor Winding Removal Methods

The following are my comments on the four methods contained in your February 19 fax to Bruce Benes.

\section{Cold Stripping Chemical Method}

\section{Description:}

There is more than one type of chemical that can be used. Therefore, in your first sentence I suggest you drop "dichloromethane $\left(\mathrm{CH}_{2} \mathrm{Cl}_{2}\right)$ " and insert "a chemical". You can drop the word "chemically" before "soften". Drop your entire second sentence and replace it with "The time required would depend upon the size of the motor.

\section{Disadvantages:}

Add between your first and second sentence: "A given chemical may not attack all varnishes."

\section{Burnout Oven}

\section{Description:}

The material doesn't have to go completely to ashes. In the second sentence change "are turned to ash" to "have softened to the point where the winding and insulation can be removed." The last word in description should be "puller". 
FAX: Julie Van Hemel

February 20, 1997

Page 2

Disadvantages-Technical:

Some motors will not be damaged at $345^{\circ} \mathrm{C}$. I suggest you replace "exceeds the recommended $345^{\circ} \mathrm{C}$ " with "becomes excessive".

\section{Coil Puller with Gas or Propane Warming}

Title:

Drop "Coil Puller with" from the title. All methods use a coil puller

Descrintion:

First sentenco-I feel $10^{\circ} \mathrm{C}$ is too low. Reading some literature from Thumm (maker of this type of equipment) I believe a range of $25-50^{\circ} \mathrm{C}$ would be more accurate.

\section{Blow Torch}

I would prefer to drop the mentioning of this method altogether. I don't want to encourage its use. Just being mentioned may make some people think it is all right and would delay their investment in other methods.

If you do keep it in, then under Description drop "reduced to ash" and replace it with the above wording under burnout oven.

pc: Bruce Benes 


\section{FaX Cover SheET}

Hugler Bally Consulting, Inc. 455 Market Streot, Suile 1420

Phone: (415) 882-1602

San Franoisco, CA 94105

Pax: (415) 882-1610

Intcrnet E-Mail: jvanheme@habaco.com

To:

Bruce Benes, BASA

RAX No.: 314/993-1269

CC:

Bugenio Tellez

ENXNo.: 011-52-22-435-437

From:

Julie Van Hernel

DATE: February 19, 2997

SubJECr: Fact Sheets on Motor Winding Removal Methods

NUMBER OF PACRS (INCLUDING THIS COVER PAGE): 5

Missing puges or wreadahle copy? Call (415) 882.1602 and ask for: Angoln Bllimgs

Original documonts will 0 Noi be sent DFollow by:

Allached please find tho winding remnval fact kheets I spoke to you about on the phone a tiow minutes ago. for review by soincone familiar with the technical specirications for exch of theso methods. We basically want to mike sure we haven't missed any obvious or important advantages or disadvantages of each of these methods.

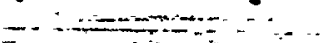

Pleaso let mo know if you bave any qucstions and thank you very inuch for agreeing to have someone take a look.

Best rogards,

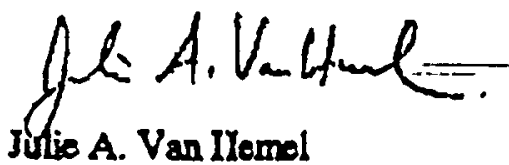

Iutie A. Van IXemel

Resourch Associate

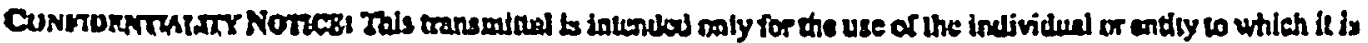

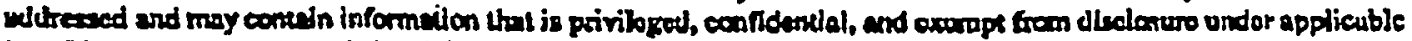

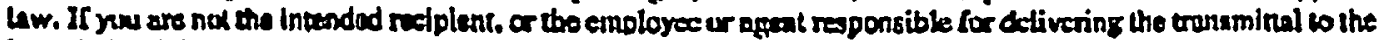
intended redpion, you are hereby nextifiod thes any disclosure copying, diututbution, or the taking of any sction in

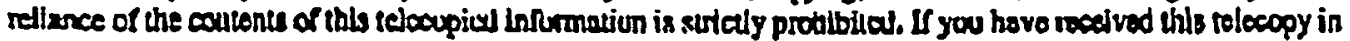

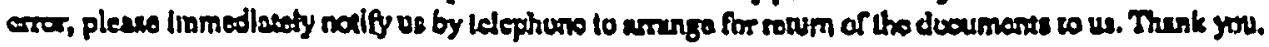




\title{
Cold Stripping ChFMICAL WINDING REMOVAL METHOD
}

\author{
Bact Shat \\ Drait of $2 / 1897$
}

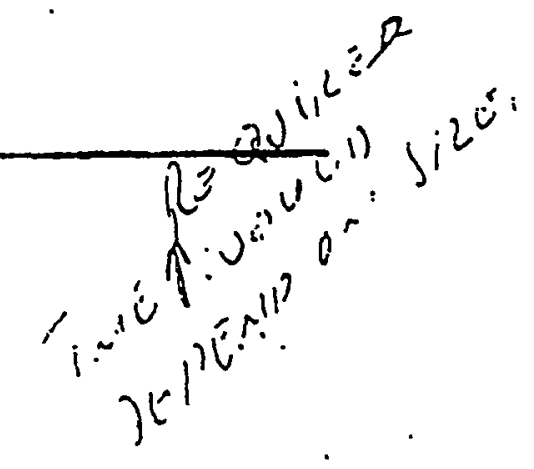

Descrintlen: This meltod of renoving motor windings tinvolves dipping the entire motor in

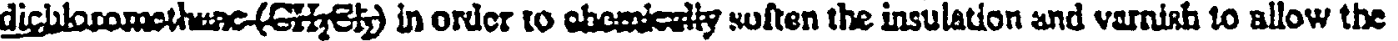

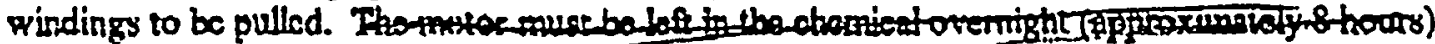

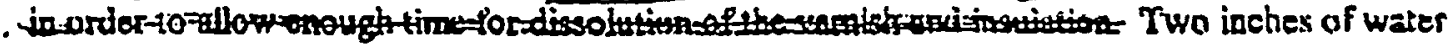
must cover the top of the Hquid to avoid ovaporation and haparthous fumer cescaping from the solution. After soaking, the motor must drip dry and then be washed using a pressurized washer 10 clenn the cherrical residuc from the motos stator. Then the motor must be dried ugain prtor to winding.

Cost: Approximately \$500. One drum of tho chomical will twe onough for approximately 50-100 rzotors, uepending on sire. The cost can be signifievently highter depending on the number of motors stripped cach year when viewed over a 10 to 20 year period.

\section{Adyantores:}

- Cost. Because this method is relattvely ixexpensive, it can be utilized by even the smallest rewind ithops. Bfficiency losses will be lower using this method than using the currost blow-loch roothed uxuplayed by most shops.

- Tumaround time. Multiple moton ean be immersed in chemical at oxce (depending on motor kize).

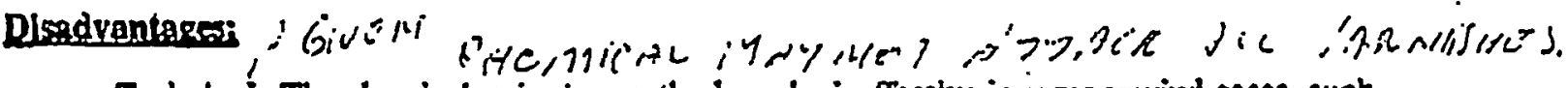

- Technical. The chemicul stripping method can be ineffective in some rewind cases, such as with overloaded statosi or excessively thick varnishes. If chemical rewidue is not completely washod and removed after dipping, residual chemical can damage new motor Insulution.

- Health. Tho usw of this chenical poses heallh risks if not handled property. Dungers incilucte inhalation, skio and cye irritation, and ingestion. Prolonged inbalation car causo dizzinevs, nnusea, headache and vomiting, as well ay stress to the cardiovencular system, eapecially in persons who smoke.

- Dispossal. Disposal of this chemical is an environmental concern. In the U.S., regulations require disposal through a licensed recluimer of incincration facility. If dirposed of improperly, tho vapors can collect in low arcas, and the chemical irself can cuntaminate ground and surfaco waters. Proper disposal of this chemieal may ulxo reyulre unanticjpated cxpenses for the rewind shop, whieh partially oflset the cost advuntuge. 


\section{BURNOUT OVEN WINDING REMoval METHod}

\section{- Fach Sheat \\ Druft of 2/18/97}

Deseriotion. The rotor staror is pluced in a burnout oven that is set for a maximum recommended tcmporature of $345^{\circ} \mathrm{C}\left(650^{\circ} \mathrm{Rj}_{\mathrm{f}}\right.$ I is kept at this temperature untll all of the vamish and insuluting malorials aroumpod to ash (B hours of nore, dopending on mocentive). The windings are then pulled using o wechenical or hydraulic pull $\pi_{1}$

\begin{tabular}{|c|c|c|c|c|}
\hline Approximato Molur Size & $400100 \mathrm{kT}$ & up $10200 \mathrm{kPR}$ & up to S00 HP & Apros Enede \\
\hline Dlmonsiunn & $100 \mathrm{~cm} \times 10 \mathrm{nmem} \times 112 \mathrm{an}$ & $100 \mathrm{~cm} \times 130 \mathrm{~cm} \times 112 \mathrm{~cm}$ & $130 \mathrm{~cm} \times 160 \mathrm{~cm} \times 142 \mathrm{~cm}$ & 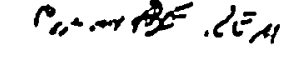 \\
\hline | Ininstullad cout" & $\$ \$ 18,750$ & \$ $\$ 19.75 n$ & $\$ 23,350$ & \\
\hline
\end{tabular}

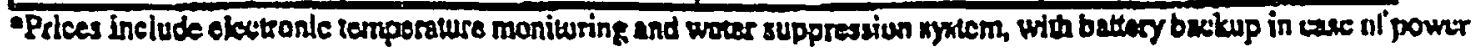
failure.

\section{Advantages:}

- Tumaround time. Mulingle motors can be fired at once (depending on the sitw of the motors).

- Health. No special handling or training is required for shops using this metbod.

- Endisnsoment. Tho Blectrical Apparatuy Service Associalion recommends this mothod as the standard for alsigping of motor winulings while mninteining imini offictoncy.

\section{Diondyantagre:}

$$
\text { Derimeit Exissive }
$$

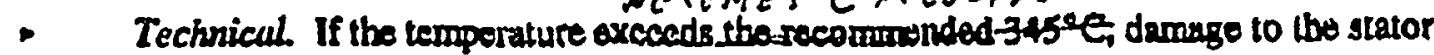

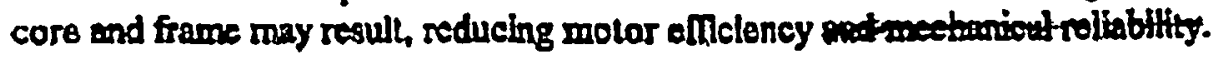

- Environmental. Gasces and other byproducts ars exhaunted through a smoke stack into the atmosphere.

- Cont. The bumout ovens may be prohibitively expensive for small rewind shops. Provision of financing may be required to encourage purchune of the bumout ovens by small- and medium-stead slops whose volume of businoss may not warrant such a largo capital investmont. 


\title{
GAS OR PROPANE WARMING WINDING REMOVAL METHOD
}

\author{
Faet Shest \\ Drafi of 2/I8/97
}

Dencription: Using natural gas- or propane-fired jets held $15.25 \mathrm{~cm}$ uway from the motor core, the buck iton and insulation is tharmod until the windingy become soll and pllable (oppraximaty

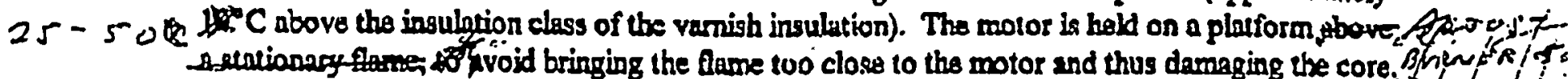

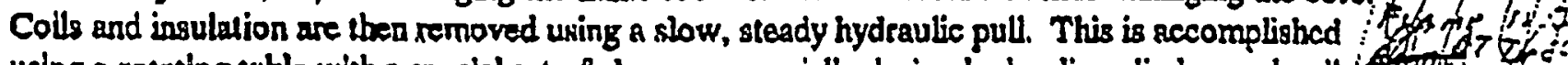
using a rotuting tahle with a special set of clamps, a speoially design hydraulic cylinder, and coil clamps. Stripping teniporature is kept below the ineling point of the Mylar in the slot paper Insulation.

Cost: \$5, 400-\$TBD (uninstulled). Includes platform for holding motors while wanned and pulled, hydraulic mechanism for pulling, and flame apparatus.

\section{Adyantages:}

- Technical leonporatures remain how, maintaining the original magnetic properties of the stutor tore and minimizing the risk of damage. Keeping temperatures below the malting point of tho insulation allows it to be remuved with the cuils, greally reducing cleuning thenc.

- Speed. This methad requires only 2.5 to 4 bours to complete.

- Enviroumental. There are no airborne byproduets or disposul problems.

- Cost. Though this method is inore expensive than the clemical method, it is far less expensive than the purohase of a burnout uver. Small shops could be offered financing or incentlves to purchose the upparatus.

- Health No special handling or training is required for shops using this method.

\section{Dlsudyantasegi}

- Technical. If the hydraulic pull method is not used cortectly or a mechanical pull in used instead, coro damage may rasult when core haminations are pulted apart.

- Tumaround time. Only one motor can bo warmed or pulled at once. However, larger shops may be able to purchase multiple assemblies in order to process several motors at a time. 


\section{BLOW TORCA} Winding Removal Method

Descetption: Using a propune-fired blow torch, insulation and varnish are burned out of the

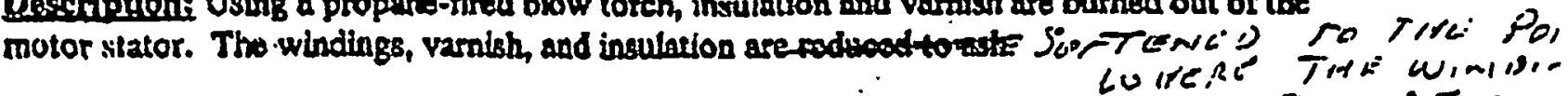

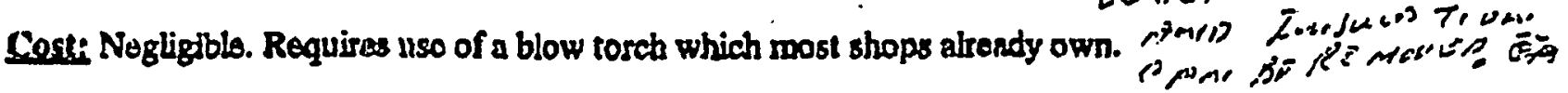

\section{Advontareas}

- Cost. Thls arethud is the most common used in shops today, and as such requiren no addlitonal investment in training or equipment.

- Speed. This method requires only 0.5 to 1 hour to completc.

Disadyantares:

- - - Technical. Hand-hold nulure of tho torch method causes uncontrolled and flucruating tersperulure in nwtur costu. High tamparatures and direct contact between flanis and stalor can cauro severe burning and damage to motor core, resulting in efficiency lossen in the rewound motor.

- Healsh. Use of this metbod causes cmission of toxic particles and gases hazardous to the huram rospiratory syctcm. Extreme heal makes motors unsafe for handling. 


\section{APPENDIX F \\ LIST OF MANUFACTURERS AND SUPPLIERS}

Manufacturers and suppliers of the following materials were contacted to determine the proper companies and subsidiaries that can provide materials to Ghana.

Companies were contacted to ascertain the sales of the following equipment to Ghana:

- Electrical Motors and Drives - a sample letter is shown in Fig. F-1;

- Magnet Wires - a sample letter is shown in Fig. F-2; and

- Electrical Insulation for Low-Voltage Motors - a sample letter is shown in Fig. F-3.

The letters sent to manufacturers and suppliers netted six responses. These responses and the associated literature sent are listed below:

1) GE International - See letter in Fig. F-4.

2) $3 \mathrm{M}$ International Business - See letter in Fig. F-5. From $3 \mathrm{M}$ were included catalogs of their complete line of electrical products. These catalogs are included with this report. The catalogs are:

- 3M Electrical Products;

- 3M Electrical, Electronic and Specialty Tapes;

- Scotch $^{\mathrm{TM}}$ Brand Polyester Film Tapes;

- 3M Heat-Shrinkable Molded Shapes; and

- $3 \mathrm{M}$ Scotchlok ${ }^{\mathrm{TM}}$ Terminals and Tools.

3) H. P. Reid Company, Inc. - See letter in Fig. F-6. From H. P. Reid we received the following catalog;

- H.P. Reid Precision Engineered Wire.

4) Essex Group, Inc. - See letter in Fig. F-7.

- Essex Magnet Wire Product and Application Data; and

- Essex Magnet Wire Engineering Data.

5) Western Filament, Inc. - See letter in Fig. F-8. From Western Filament, we received the following catalogs:

- Stator Lacing Tapes and Cords;

- Expandable Sleeving Products; and

- Western filament Distributor Pricing List.

6) MagneTek sent three electric motor and drive catalogs. They are:

- MagneTek Commercial-Industrial Motor/Drive Catalog. Bulletin 943, Spring 1997;

- MagneTek IEC and NEMA 3 Phase Induction Motors; and

- MagneTek Replacement Motor Manual 497. 
April 30, 1998

Baldor

Attn: Sales Manager

P.O. Box 2400, Dept. TR

Fort Smith, Arizona 72902

Dear Sir or Madam:

\section{Sales of Electric Motors and Drives in Ghana}

Under a contract between the Oak Ridge National Laboratory and the Government of Ghana, Africa, I spent nearly three weeks in Ghana conducting feasibility studies for improving electric motor service centers. The hope among Ghanaian people toward the United States is genuinely high.

One important function that the motor service centers will have to do is promote the replacement of old drives with higher-efficiency motors or adjustable-speed drives. It seems that there is not a single sales - representative of any American motor company available in Ghana.

Please let me know the answers to the following questions:

How would a dealer in Ghana buy electric motors and adjustable-speed drives from your company? What are the terms of payment for your exported motors and adjustable-spieed drives to Ghana? and Is it possible for you to send me two sets of your electric motor and adjustable-speed drive catalogs (the three-phase line voltage is 415 volts and the frequency is $50 \mathrm{~Hz}$ in Ghana)?

Thank you for your early reply to the questions.

Yours truly,

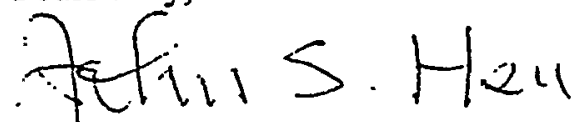

John S. Hsu

JSḦ:pja

Enclosure

c: D. Adams

M. Olszewski

File-NoRC : 
April 30, 1998

Westinghouse Electric Corporation

Attn: Sales Manager

Westinghouse Building

11 Stanwix Street

Pittsburgh, Pennsylvania 15222

Dear Sir or Madam:

\section{Sales of Magnet Wires in Ghana}

Under a contract between the Oak Ridge National Laboratory and the Government of Ghana, Africa, I spent nearly three weeks in Ghana conducting feasibility studies for improving electric motor service centers. The hope among Ghanaian people toward the United States is genuinely high.

One important need for the motor service centers in Ghana is to improve the accessibility of quality copper magnet wires at reasonable prices. It seems that there is not a single sales representative of any American magnet wire company available in Ghana.

Please let me know the answers to the following questions:

How can a dealer in Ghana buy magnet wires from your company?

What are the terms of payment for your exported magnet wires to Ghana? and

Is it fossible for you to send me two sets of your magnet wire catalogs?

Thank you for your early reply to these questions.

Yours truly,

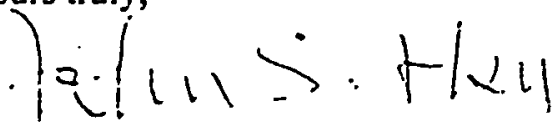

John: S. Hsu

Enclosure

JSH:pja

c: D. Adams

M. Olszewski

File-NoRC

Figure F-2 
April 30, 1998

Acton Technologies, Inc.

Attn: Sales Manager

101 Thompson Street

Pittston, Pennsylvania 18640

Dear Sir or Madam:

\section{Sales of Electric Insulation for Low-Voltage Motors in Ghana}

Under a contract between the Oak Ridge National Laboratory and the Government of Ghana, Africa, I spent nearly three weeks in Ghana conducting feasibility studies for improving electric motor service centers. The hope among Ghanaian people toward the United States is genuinely high.

Orie important need for the motor service centers in Ghana is to improve the accessibility of quality electric insulation at reasonable prices. It seems that there is not a single sales representative of any American electric insulation company available in Ghana.

Please letme know the answers to the-following questions:

How can a dealer in Ghana buy electric insulation from your company?

What are the terms of payment for your exported electric insulation to Ghana? and

Is it possible for you to send me two sets of your electric insulation catalogs?

Thank you for your early reply to these questions.

Yours truly,

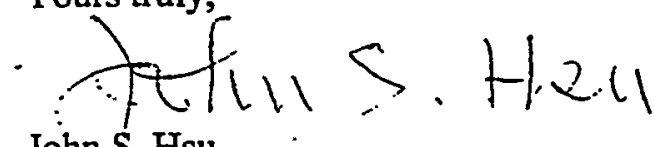

John S. Hsu

Enclosure

JSH:pja

c: D. Adams

M. Olszewski

File-NoRC 


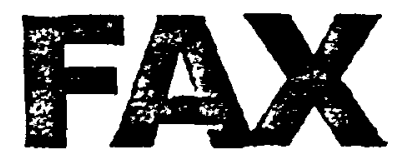

TO: OAKRIDGENATIONALLABORATORY From: SHERIF MARZOUK - GE CAIRO

\begin{tabular}{lll}
\hline Atth: MR.JOHNHSU & CC: & MR. WAFIKRAMSEY \\
\hline Faxe $423-241-6124$ & Date: June 1, 1998 \\
\hline
\end{tabular}

Ro: SALES OF ELECTRIC INSULATION FOR LOW VOLTAGE MOTORS IN GHANA

Dear Sir,

Thank you for your letter of April 30/98 addressed to GE Fairfield, Connecticut which I received on May 13/98. The following companies are manufacturing and selling motor insulation.
1) Essex Brownell
Tel: $800-774-4643$
Fax: $219-461-4444$

2) Ha Hoiden

Tel: $800-328-4662$

3) Electrical Ins. Supply - Tel: 513-771 4073

Fax: 612-577-5550

Kindly call one of these suppliers for the subject project in Ghana.

Thanks \& Best Regards,

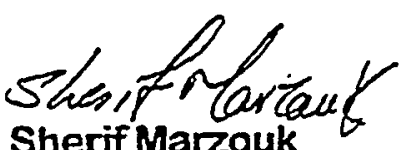

Sherif Marzouk

AREA SALES MANAGER

GE-CAIRO/dK

Tel: $\quad 202-305-5470 / 2$

Fax: 202-305-9626
**NEW ADDRESS**

General Electric Intemational Operations

Industrial Control Systems

TEL: 202-305-5470 or 72 / FAX: 202-305-9626

54 LEBANON STREET - 11TH FLOOR

MOHANDESEEN, CAIRO - EGYPT

Figure F-4 


\begin{tabular}{|c|c|c|c|c|}
\hline $\begin{array}{l}\text { Phone } \\
\text { Fax Phone }\end{array}$ & $\begin{array}{l}\text { JOHN HSU } \\
\text { OAK RIDGE NATIONAL } \\
\text { LABORATORY } \\
\\
423 / 241-5045 \\
423 / 241-6124\end{array}$ & . & FROM: & $\begin{array}{l}\text { KRISTINE OLESON } \\
\text { 3M INTERNATIONAL BUSINESS } \\
\text { DELELOPMENT } \\
\text { 3M COMPANY } \\
2860 \text { BANKERS INDUSTRLAL DR } \\
\text { ATLANTA, GA } 30360\end{array}$ \\
\hline$C C:$ & & $\because-\ldots=\cdots$ & $\begin{array}{l}\text { Phone } \\
\text { Fax Phone }\end{array}$ & $\begin{aligned} & 770-242-2418 \text { or } 800 / 243-3636 \times 4 \\
- & -\quad-770-242-2407 \text { or } 800 / 932-0274\end{aligned}$ \\
\hline
\end{tabular}

|REMARKS: $\square$ Urgent $\square$ For your review $\quad \square$ Reply ASAP $\square$ Please Comment

MR. HSU,

IN RESPONSE TO YOUR PHONE MESSAGE, THE FOLLOWING IS THE CONTACT NAME AND COMPANY NAME FOR OUR DISTRIBUTOR OF ELECTRICAL PRODUCTS IN GHANA:

CONTACT: FIDEL JONAH CITLAND INTERNATIONAL - : DANKWA CIRCLE OSU ACCRA GHANA

PHONE - 021-761185

MR JONAHMOBILE PHONE - 024-345156

PLEASE CONTACT TREVOR KING OF CITLAND HERE IN THE UNITED STATES FIRST, HOWEVER, AS HE WOULD LIKE TO SPEAK WITH YOU CONCERNING QUANTITY AND OTHER ASPECTS OF YOUR REQUTREMENTS. MR KING IS THE PRESDENT OF CITLAND AND HIS OFFICE IS LOCATED IN ATLANTA, GA AND HE CAN BE REACHED AT 770/955-1655. HE OPENED THE GHANA DISTRIBUTORSHIP FOR 3M ELECTRICAL PRODUCTS AND HAS THE ABILITY TO STOCK INVENTORY OF 3M PRODUCTS IN GHANA SHOULD YOU SO DESIRE.

I AM SENDING YOU OUR COMPLETE LINE OF ELECTRICAI PRODUCTS (TWO SETS) PER YOUR REQUEST AND PLEASE DO NOT HESITATE TO CONTACT ME SHOULD YOU HAVE ANY QUESTIONS!!

BEST REGARDS, ENCLOSED: $\%$

KRISTINE 
May 5, 1998

Mr. J. S. Hsu

OAK RIDGE NATIONAL LABORATORY

P. O. Box 2009

Bldg. 9102-1, MS-8038

Oak Ridge, TN 37831

Ref: New HP Reid Catalog

Dear Mr. Hsu :

We are pleased to send you a copy of our new catalog that describes HP Reid's capabilities for manufacturing fine and ultrafine diameter precision wire. Also included in the catalog are convenient technical reference charts for NEMA Standards, Voice Coil wire, gold plated copper wire, bonding wire, and Resistance wire. We hope that you will find this reference information useful to you in your work.

We are also in the process of setting up a website (uww.hpreid.com) with this same technical reference information. Targeted date for being on-line with the website is May 15, 1998.

HP Reid is proud of its 16-year history of assisting customers in advancing the state-of-the-art in their fields of technology. Now that HP Reid is part of the worldwide Sandvik group of Companies, we are better able to support our customers with leading edge research capabilities and investment in new production capabilities.

Please contact me to discuss how HP Reid can help on your next program which involves specialty custom wire.

Very Best Regards,

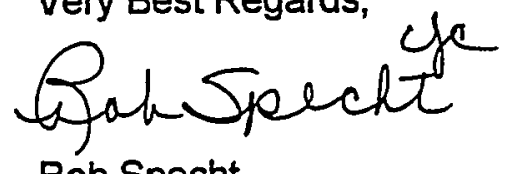

Rob Specht

Vice President Marketing

RS:cjc

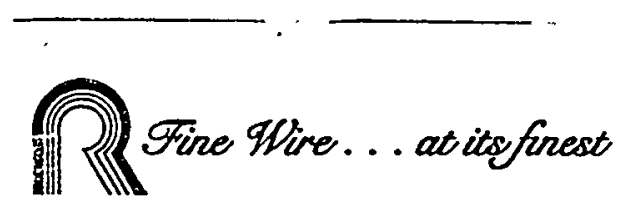

ROBERT C. SPECHT VIC PRESIDENT OF MARKEING

H.P. REID CO., INC. 1 COMMERCE BLVD. - P.O. BOX 352440 PALM COAST. FL 32135-2440 (904) 445-2000 • (800) 772-9473 FAX. $(904) 46-2244$ EMAL: Rob.SpechtoHPReid.com 
May 5, 1998

Mr. John S. Hsu

Oak Ridge National Laboratory

Building 9104-2, MS-8038

Post Office Box 2009

Oak Ridge, TN 37831-8038

Dear John:

Thank you for your letter dated April $30^{\text {th }}$ with your inquiry about magnet wire availability in Ghana. I am pleased to provide the following answers to your questions:

1) We currently do not have a sales representative or distributor to handle sales of magnet wire in Ghana. However, we do have an international sales person here in our corporate offices in Fort Wayne, Indiana who handles all international type inquiries. Her name is Ms. Dee Torrez. Her direct telephone number is $219 / 461-4444$, and her fax number is $219 / 461-4531$. All inquiries for magnet wire information, pricing; specifications, and other issues can be directed to Dee. We will handle all orders for Ghana from here. We would need the appropriate freight forwarder and containerazation information prior to shipping.

2) The terms of payment for companies outside of the United States without a formal credit approval would be cash in advance or letter of credit from an authorized banking institution.

3) I am pleased to provide two copies of our Magnet Wire catalogs as well as two engineering handbooks on Magnet Wire. If you desire more of these, please let me know:

Thanks for your interest in Essex Magnet Wire, and we look forward to being of service to you and the companies in Ghana in the future.

Sincerely, Essex Group, Inc.

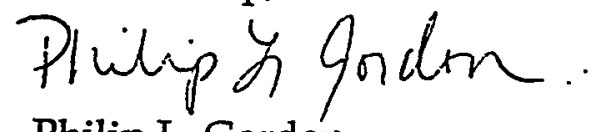

Philip L. Gordon

Magnet Wire Marketing Mgr.

Cc: D. Torrez 


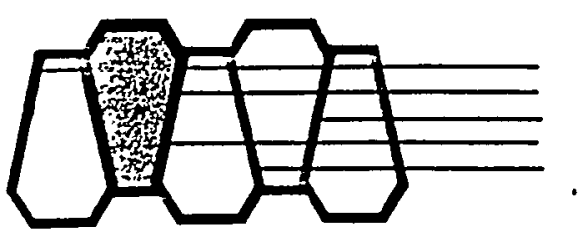

FAX: $970-241-8682$

\section{western filament, inc.}

630 HOLLINGSWORTH DRIVE - GRAND JUNCTION, COLORADO 81505

$5 / 15 / 98$

John S. Hsu

Oak Ridge National Laboratory

Building 9104-2, $15-80.38$

Post Office Box 2009

OE.k Kid.Ee, TN 37831-8038

Dear Mr. Hsu:

Thenk you for your interest in our products. Most of our products we produce are for lacing and tying. We also sell expandable eleevings. I am including two sets of brochures for your use. Please let me-know if you have eny questions regarding our produsts.

We would be wilizing to eell to you directly. Our terms would be check or bank transfer in advance. Again, I thank you for your interest and I look forward to serving you in the future.

Best Regards,

"inutioth Vecontia

Charlotte Vecchia

Inside Sales

Figure F-8 


\section{APPENDIX G \\ MANUFACTURING ELECTRIC FANS IN GHANA}

As mentioned earlier in this report, contact was made with numerous companies in the United States to assess any interest in regard to manufacturing electric motors in Ghana. An example of the letter sent is given in Fig. G-1. Only one response requesting additional information was received. This response is given in Fig. G-2.

G-1 
April 27, 1998

Action-Aire, Inc.

Attn: Managing Director

66 Grant Avenue

Carteret, New Jersey 07008

Dear Sir or Madam:

\section{Manufacturing Electric Fans in Ghana}

Under a contract between the Oak Ridge National Laboratory and the Government of Ghana, Africa, I spent nearly three weeks in Ghana conducting feasibility studies for improving their electric motor service centers. The hope among Ghanaian people toward the United States is genuinely high. Ghana is a relatively stable country, English is the official language, the minimum wage is less than one U.S. dollar a day, the estimated unemployment rate is above 30 percent, and public schools are tuition free up to the university level. Althougn Ghana has only 18 million people, it is a reasonably good business location for the African market. There are a lot of imported electric fans in the market but it seems that there is not a single ceiling fan and table fan manufacturer in Ghana.

My study concludes that there is a need for Ghana to start establishing a basic electric motor manufacturing industry. Because of the market potential, manufacturing electric fans may be the first step to meet this need. The Ghanaian Government is very keen on attracting foreign companies to invest in Ghana. Incentive tax breaks are part of the package.

Please let me know if you are interested in getting more information for establishing a manufacturing branch of electric fans in Ghana.

Yours truly,

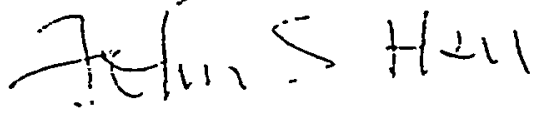

John S. Hsu

JSH:pja

Enclosure

c: D. Adams

M. Olszewski

File-NoRC

Figure G-1

OH WI - Bringing Science to Bife 


\section{Grant Avenue Carteret, NJ 07008}

Tel: 732-541-4441 732-969-9494 Fax: 732-541-5121 732-969-3905

October 22, 1998

Oak Ridge National Laboratory

Building 9104-2, MS-8038

P/O Box 2009

Oak Ridge, Tn 37831-8038

Attn: John S. Hsu

Dear Mr. Hsu,

The correspondence (of April $27^{\text {th }}$ ) you sent us regarding Ghana arrived at my desk yesterday. Yes, we are interested in receiving additional information. Kindly mail to my attention.

Yours truly,

Qeer

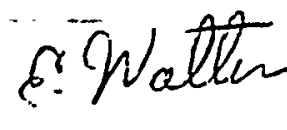

Allen E. Walters

Vice President

Figure G-2

G-3 


\section{APPENDIX H}

EASA PACKAGE AND BROCHURES

AND

ADDITIONAL CONTACTS WITH EASA

Included is a large folder from EASA describing the organization, its functions as well as an application for membership. Note that EASA is the main organization in the US representing the electrical apparatus sales and repair industry.

Contact was made with EASA. on behalf of Ghana via two letters dated April 29, 1998, and May 18, 1998. These are shown in Figs. H-1 and H-2, respectively. Specific request was made to make request the use of EASA training materials (especially EASA training films). EASA's reply is shown in Fig, H-3, indicating the availability of EASA materials to members only. A list of the EASA training films is provided in Fig. $\mathrm{H}-4$. 
April 29, 1998

Ms. Linda Raynes

Acting Executive Vice President

Electrical Apparatus Service Association, Inc.

1331 Baur Boulevard

St. Louis, Missouri 63132

Dear Ms. Raynes:

\section{Electric Motor Service Centers in Ghana}

Under a contract between the Oak Ridge National Laboratory and the Government of Ghana, Africa, I spent nearly three weeks in Ghana conducting feasibility studies for improving their electric motor service centers. The facility and equipment in their service centers are poor, there is no standard to follow for repair work, and the low revenue of service centers also prevents advancement. However, the hope among Ghanaian people toward the United States is genuinely high.

I have talked to Mr. David Gebhart and understand that the service centers in Ghana can join EASA as a member. Please let me know the answers to the following questions.

The current level of the service centers in Ghana is low; does EASA have a certification requirement? No Is it all right for the Ghanaian Government to use EASA's training material and to certify those who pass beared

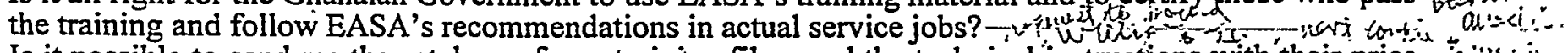
Is it possible to send me the catalogs of you training films and the technical instructions with their price lists?

I also learned from Mr. Gebhart that EASA has a list of recommended facility and equipment for service service centers. Is it possible to send me a copy of this list?

I also would like to study the EASAMexico training program that was mentioned by Mr. Gebhart and see what may be applicable for Ghana. Is it possible to send me a copy of that program?

Thank you for your early reply to these questions.

Yours truly,

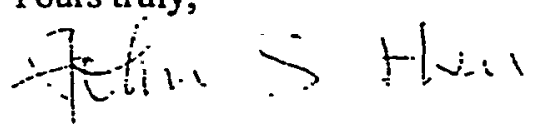

John S. Hsu

JSH:pja

c: D. Adams M. Olszewski

File-NoRC 
May 18, 1998

Ms. Linda Raynes

Acting Executive Vice President

Electrical Apparatus Service Association, Inc.

1331 Baur Boulevard

St. Louis, Missouri 63132

Dear Ms. Raynes:

\section{EASA training materials to be used in Ghana}

Under a contract between the Oak Ridge National Laboratory and the Government of Ghana, Africa, I spent nearly three weeks in Ghana conducting feasibility studies for improving their electric motor service centers. The facility and equipment in the service centers of Ghana are poor. There is no standard to follow for repair work, and the low revenue of service centers also prevents the advancement of service centers in Ghana. However, the hope among Ghanaian people toward the United States and the industrialized countries is genuinely high. I was impressed about how hard the Ghanaian people have to work in order to improve their living standards. They need technical assistance.

I wondered whether you would grant permission to the Ghanaian Government to use EASA's training materiais. The governinent may certify those who pass the training and follow EASA's recommendations in actual service jobs.

Thank you for your early reply to this inquiry. Should you need additional information, please don't hesitate to call.

Yours truly,

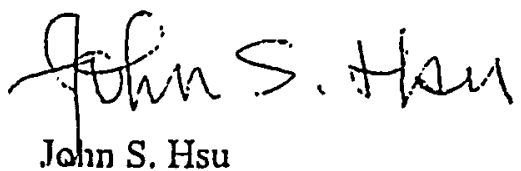

JSH:pja

c: D. Adams

M. Olszewski

File-NoRC

Figure $\mathrm{H}-2$

Qullit - Bringing Science to Bife 
Via Fax, Page 1 of 1

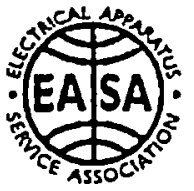

Fax \#: $423-241-6124$

October 21, 1998

Dr. John S. Hsu

Building 9102-1, MS-8038

Post: Office Box 2009

Oak Ridge, TN 37831-8038

Dear Dr. Hsu:

I tried call you but have had no success yet. I thought I would send this fax and ther attempt to contact you again. My sincere apologies for the tardiness in response to your inquiries; we thought that a letter had been sent to you immediately after the 1998 June convention in Orlando, but were not able to locate it. Apparently this is something that slipped through the cracks. Again, our apologies for the unfortunate oversight.

Your letter of May 18, 1998 was brought in front of the EASA Board of Directors at thieir June meeting. While there was müch empathy for the Ghanaian people's need for technical expertise and after.much discussion, the Board of Directors felt they could not violate EASA Association's bylaws regarding supplying EASA materials to nonmembers. The Board suggested that the government of Ghana apply for EASA's Allied membership, which would enable the government to receive all EASA materials at member prices.

A membership packet will be sent to you via mail. We hope that this is helpful.

Sincerely,

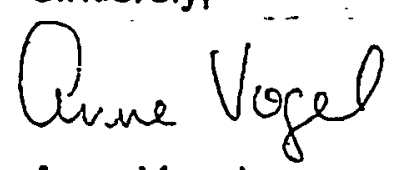

Anne Vogel

Executive Secretary

Figure H-3 


\section{EASA TRAINING FILMS}

1. Taklng Winding Data From A Threo-Phase Inductlon Motor.

Teaches how to determine type of connection, number of parallel circuits, tums per coll, wire

size, span and groups. Shows step-by-step way to propenty record all information. $\{27: 38\}$

2. Dlsassembly of A Throe-Phase induction Motor.

Shows step-by-step disassembly of a TEFC motor with the proper tools to use, how to mark paris tor proper reassembly, how to remove ball bearings from shaft. Details things not to do.

boes not include strippling. $(22: 13)$

3. Machine Winding Three-Phase Random Wound Colls.

Teaches procedures for winding dlamond and round-nosed coils. Includes determining coil dimensions from a bare core and winding multiple groups at one time. (17:30)

4. Winding A Three-Phase Stator.

Teaches step-by-step proper insertion of three-phase winding. What tools and insulation to use, including proper positioning of center sticks, wedges, phase insulation and fillers. Points out improper methods of winding. $(25: 55)$

5. Assembly of A Throo-Phase Induction Motor.

Step-by-step method of assembling the motor. Describes the tools used and those not used. Shows how to align parts as marked in disassembly, Includes installation of ball bearings to the shaft. $(29: 50)$

7. Manufacturing Form Coils.

Shows how to determine loop dimensions, winding the loop, insulating it and spreading the coils, along with determining the dimensions of the spread coil. $(25: 50,21: 29)$

8. Winding Stators With Formed Colls.

Describes the procedures for Insenting a formed coil into a stator. Shows proper tools and various wedging methods. Includes connecting the colls and insulating the conniectlons. (20)

9. Taking Data From A SIngle-Phase Stator.

Shows step-by-step procedure for properly determining and recording the type of connection, number of parallel creuits, turns per coil, wire size, span and groups, and how to distlnguish between running and starting windings. (16)

10. Disassembly of A Singlo.Phase Capacitor Motor.

Step-by-step disessembly of a capacitor motor, both ball bearing and slesve bearing. Includes bearing removal (both types), plus operation and replacement of various types of starting switches and governors. Stripping not included. (12:33)

11. Winding Single-Phase Concentrlc Colls.

Shows method of winding concentric coils, which includes determining the coil width for the various size coils within each group, how to set the concentric winding head and select the proper grooves for winding the coils. Also shows how to wind coils using the Holden Headi 25

12. Winding A Single-Phase Stator.

Shows proper procedures for inserting concentric colls Into a single-phase stator. Shows tools and insulations and points out relationship between running and starting winding colls 11

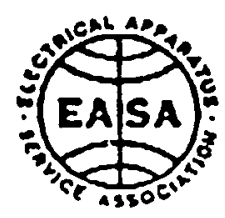

(Continues on reverse side.)

Figure $\mathrm{H}-4$

H-5 
13. Assembly of A Single-Phase Capacitor Motor.

Step-by-step assembly of a capacitor motor including:Installation of both ball and sleeve bearings. Shows tools needed and how to align parts marked during disassembly. $(23: 30)$

14. Taking Data From A Hand-Wound D.C Armature.

Describes the correct procedure for taking data from hand-wound d-c armatures. Shows how to record the data on typleal d-c data sheets, and explains the terminology used describing d-c data. Points out differences between lap and wave windings. $(26,50)$

15. Hand-WInding A D-C Armature.

Provides step-by-step instructions on winding a d-c armatura, including how to Install end fibres and slot liners; how to wind and shape the armature coils and how to make the commutator connections.

16. DIsassembly of A D-C Machine.

Shows step-by-step disassembly of a d-c motor and the tools to use. Demonstrates how to mark parts, and how to label and record connectlons for use in assembly. Also explains how to check for shorts or opens in field and armature windings, how to test run the motor, and how to inspect parts for damago and wear. (19)

17. Assembling A D.C Machine.

Step-by-step procedure for assembling a d-c motor. Includes field coll insertion, connection and polarity checks. Also shows how to install bearings, how to seat brushes and set the neutral position, how to check windings with a megohmmeter, and how to make connections.

18. Random-Winding D.C Fleld Colls.

lliustrates procedures for manufacturing random-wound interpole and main field colls for $d-c$ machines. Covers everything from removing old coils and taking data to installing and connecting new coils, including how to construct winding forms and jigs, how to shape coils to conform with the curvature of the field frame and how to insulate field coils. Both "wet" and "dry" winding techniques are lllustrated. "(19)

19. Layer-Winding D-C :Field Colls.

Covers all necessary steps; for layer winding d-c field coils, how to layer-wind a shunt field coil, how to reinsulate an interpole fleld coil, and how to install large field coils in the frame.

20. Testing Three-Phase A-C Motors Ratad 600 Volts Or Less.

Outlines the basic steps and procodures commonly used for testing three-phase, a-c motors rated 600 volts or less, including preliminary insulation resistance, continuity and:no-load tests, as well as the single-phase test for.rotors. Aso explains how to test components once the motor has been disassembled; these procedures include surge-comparison, polarization index, growier and d-c high-potential tests, as well as the "loop" test for stator cores. Additionally, examines periormance of final insulation resistance, no-load, vibration and dynamometer tests on repaired or rewound motors. (22:50)

21. Testing D-C Machines.

Pan 1 deals with "Initial Inspection \& Preliminary Testing"; Part 2 concentrates on "Used Armature Windings"; and Part 3 covers "Cores, Commutators \& Rewound Armatures." Parts 4 and 5 explain how to test "Field Windings" and how to perform "Final Tests." (46:50, 31:50)

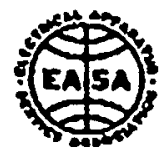

8BPEABC

Electrical Apparatus Service Association, Inc. 1331 Baur Blvd. - St. Louls, MO 63132 - (314) $993-2220$

Figure H-4 (cont'd) 


\section{APPENDIX I \\ INFORMATION ON NVLAP \\ AND \\ IEEE STANDARD 112}

Information is presented on the NVLAP Program in the US. The Department of Commerce, through NIST administers NVLAP. NVLAP programs are established for public and private calibration and testing laboratories including commercial laboratories, manufacturers' in-house laboratories, and federal, state, and local government laboratories. NVLAP accreditation is based on the evaluation of a laboratory's technical qualifications and competence for conducting specific test methods, measurements, and services in specified fields of calibration or testing. It is granted only after a thorough evaluation of the applicant has demonstrated that all NVLAP criteria have been met. A 1996 NIST memorandum on NVLAP is included in Fig. I-1. Additional information on NVLAP can be found in NIST Handbook 150, Procedures and General Requirements and NIST Handbook 150-10, Efficiency of Electric Motors. Both documents are available for sale through the Superintendent of Documents, U.S. Government Printing Office, Washington, D.C. 20402-9325. The front covers of both publications are shown in Figs. I-2 and I-3, respectively.

The front cover of IEEE Standard 112 is shown in Fig. I-4. This report, entitled IEEE Standard Test Procedure for Polyphase Induction Motors and Generators was issued in 1996. A correction sheet for this report was issued on January 20,1998. Copies of this document and other IEEE standards can be purchased. International callers can inquire by calling 1-908-981-0600. To order by fax, call 1-908-981-9667. IEEE standards information can be accessed via the World Wide Web at: http://standards.ieee.orgl. 
January 22, 1996

MEMORANDUM for

From
NVLAP customer laboratories and potential customers

James L. Cigler, Chief

Laboratory Accreditation Program

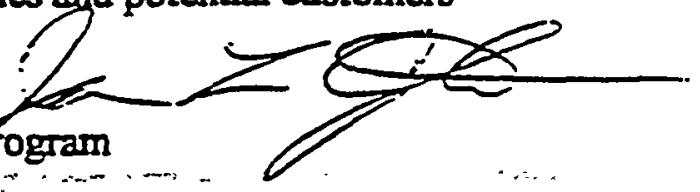

Subject: Use of Accredited Calibration Laboratories To Achieve Traceability of Measurements

NVLAP is instituting a policy to bring traceability of measurements into line with international practices and to require that testing and calibration laboratories obtain traceability of measurements either directly from a national laboratory or through other accredited calibration laboratories. This will facilitate and promote broad acceptance of valid calibration and test results and thereby avoid barriers to trade. Use of accredited calibration laboratories is an integral component of mutual recognition agreements.

The National Institute of Standards and Technology administers the National Voluntary Laboratory Accreditation Program (NVLAP) under regulations found in Part 285 of Title 15 of the U.S. Code of Federal Regulations. These regulations are implemented in NIST Handbook 150. NVLAP accreditation is available to commercial calibration and test laboratories, manufacturers' in-house laboratories, university laboratories, and federal, state and local government laboratories. Laboratories located outside the United States may also be accredited if they meet the same requirements as domestic laboratories, with additional specified fees and requirements regarding language and export licenses.

NVLAP offers a series of laboratory accreditation programs (LAPS) which are established on the basis of requests and demonstrated need. Each LAP includes specific calibration fields and associated parameters and/or test standards and related methods and protocols assembled to satisfy the unique needs for accreditation in a field of calibration and/or testing. NVLAP is currently negctiating with the European Cooperation for Accreditation of Laboratories (EAL), Australia, New Zealand, Hong Kong, Canada, Mexico, and India for mutual recognition agreements. These agreements will recognize equivalency of the laboratory accreditation programs of these countries based on implementation of ISO/IEC Guide 25 (or equivalent) in the accreditation of testing and calibration laboratories, and compliance with the requirements of ISO/IEC Guide 58 (or equivalent) as accrediting bodies. 
Reliable and accurate testing depends critically on the use of appropriate laboratory instruments that are accurately calibrated. The dependability of calibration relies on measurement raceability to national laboratories (NIST in the United States); this must be demonstrated through calibration by the national laboratory itself or by a calibration laboratory whose traceability to the national laboratory has been validated through an accreditation process. Successful completion of this chain of events can lead to consummation of mumai recognition agreements with other counrries. It will be NVLAP's accredimation policy to require this sequence of traceability.

All calibration and testing laboratories desiring to be accredited by NVLAP after December 1 , 1996, must demonstrate compliance with these traceability requirements. All calibration and testing laboratories currently accredited by NVLAP must demonstrate compliance with these traceability requirements by the end of December 1997.

This policy will be reflected in the next revision of NIST Handbook 150, NVLAP Procedures and General Requirements, dated March 1994. All comments and/or questions related to the implementation of this policy should be addressed to: Chief, National Voluntary Laboratory Accreditation Program, National Instiute of Standards and Technology, Building 820, Room 282, Gaithersburg, MD 20899, telephone muber (301) 975-4016, fax mimber (301)
926-2884. 


\section{National \\ Voluntary \\ Laboratory \\ Accreditation \\ Program}

\section{Procedures and \\ General \\ Requirements}

James L. Cigler and Vanda R. White, Editors

March 1994

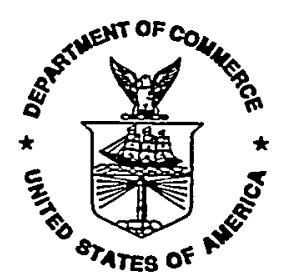

U.S. Departiment of Commerce

Ronald H. Brown, Secretary

Technology Administration

Mary L. Good, Under Secretary for Technology

National Institute of Standards and Technology

Arati Prabhakar, Director

Figure I-2 


\author{
National \\ Voluntary \\ Laboratory \\ Accreditation \\ Program
}

\title{
Efficiency of \\ Electric \\ Motors
}

Lawrence S. Galowin, NIST

Walter J. Rossiter, Jr., NIST

Wiley A. Hall, Retired, NIST

August 1995

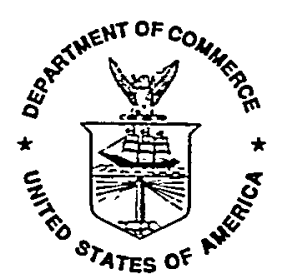

U.S. Department of Commerce Ronald H. Brown, Secretary

Technology Administration

Mary L. Good, Under Secretary for Technology

National Institute of Standards and Technology Arati Prabhakar, Director

\section{Figure I-3}

I-5 


\section{IEEE Standard Test Procedure for Polyphase Induction Motors and Generators}

$7-7-200$ (1) Circuits and Devices.

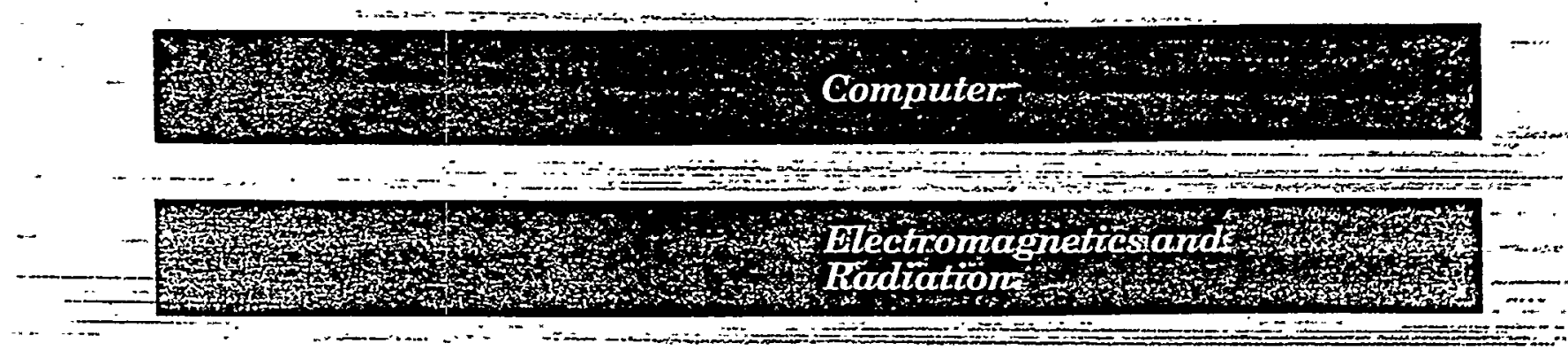

\section{IEEE Power Engineering Society}

Sponsored by the -....... Sponored by the
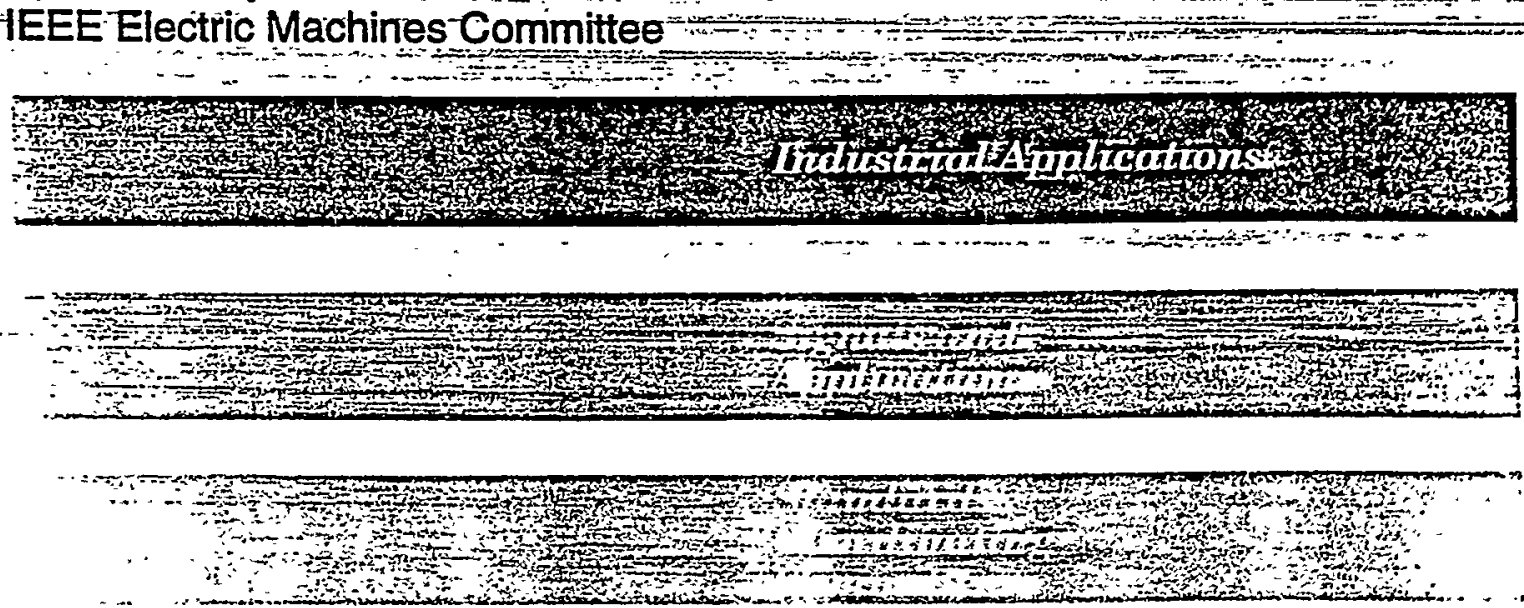


\section{APPENDIX J}

\section{ELECTRIC MACHINERY SYSTEMS TEST CENTER AND ROTOR BALANCING FACILITY AT THE OAK RIDGE NATIONAL LABORATORY}

The Electric Machinery Systems Test Center is an NVLAP-accredited motor testing facility located in Building 9104-1 at ORNL. This facility is capable of measuring the efficiency of electrical motors ranging from fractional horsepower up to $500 \mathrm{hp}$. The NVLAP Certificate of Accreditation is shown in Fig. J-1. Two of the stands in use are shown in Figure J-2. The one in the foreground uses an $\mathrm{AC}$ generator to place a load on the motor and an in-line torque cell to measure the torque output of the motor. It is capable of testing motors in the range of fractional horsepower to $10 \mathrm{hp}$. Here, the motor being tested is on the left and the $\mathrm{AC}$ generator is on the right. The in-line torque cell is in the cage between the motor and generator. The test stand that uses a water-cooled eddy current dynamometer is shown in the background. In Fig. J-3, that stand is more clearly seen. The motor to be tested would be located in the empty space on the left while the dynamometer is on the right. This stand is capable of testing motors of up to $100 \mathrm{hp}$. In Fig. J-4, a motor testing stand that also utilizes a water-cooled eddy current dynamometer is shown. This facility is capable of testing motors up to $500 \mathrm{hp}$ in size. Here, the motor is on the right and the dynamometer brake is on the left. Another view of this facility is shown in Fig. J-5. The torque cell on the $500 \mathrm{hp}$ test stand is shown in Fig. J-6. The two tanks, that supply cooling water to the three stands, are shown in Fig. J-7.

The control room for the motor test facility is shown in Fig. J-8. At the heart of the control room is the PC-based data acquisition system shown in Fig. J-9. Here, signals from the various stands are displayed, stored, and analyzed. The commercially available software package, LabVIEW ${ }^{\mathrm{TM}}$, is used as illustrated in Fig. J-10. A screen representing how data can be displayed in numerical or graphical form using a LABVIEW ${ }^{T M}$ program developed at ORNL is shown in Fig. J-11. The Electric Machinery Systems Test Center Rules of Operation, shown in Fig. J-12, are displayed in the control room.

The three-phase Variac voltage control center is shown in Figs. J-13-J-15. Here, the voltages to each of the three phases of the motor being tested can be set. The microprocessor voltage controller is seen in Fig. J-14 while the Variacs themselves are better shown in Fig. J-15. The resistance divider box, shown in Fig. J-16, is part of the equipment used to measure phase-tophase and phase-to-neutral voltages. Voltage readouts are displayed as shown in Fig. J-17. Readout devices, such as the Clarke-Hess Phase Meter shown in Fig. J-18, are used to record the phase angle difference between the current waveform and the waveform obtained from a current transformer (CT) in order to obtain data for transducer calibration. In determining total power, the phase angle (or power factor) is used as required by the derivation. Three hall sensors, one for each phase, are shown in Fig. J-19. They are used to measure the current and are generally more accurate than most conventional CTs. The clamp-on CTs, shown in Fig. J-20, are rated for $1000 \mathrm{amps}$ and are used for non-intrusive current measurements for each of the three phases. 
Other measuring devices in use are shown on Fig. J-21. The device on the left is a digital readout of the temperature from different types of thermocouples. The temperature readout device on the right is an infrared temperature-measuring device. Accelerometers used to measure the vibration level of a motor in operation are shown in Fig. J-22. The accelerometers are mounted on a motor as illustrated in Fig. J-23. The instrument in Fig. J-24 is a strobe light for measuring motor RPM. The instrument in Fig. J-25 is Fluke 41B Power Harmonics Analyzer. It can measure the power, current, voltage, and phase angle. In addition, it can record the harmonic content of the current and voltage signal for later off-line analysis.

In addition to the Electric Machinery Systems Test Center in Building 9104-1, there exists a Rotor Balancing Facility in Building 2018. This facility dynamically balances motor rotors as illustrated in the following photographs. Figure J-26 is an overall view of the balancing facility. In Fig. J-27, a rotor is being prepared for balancing. Here, a drive belt is attached to the rotor causing it to spin at speeds of from 600 to $900 \mathrm{rpm}$. The drive motor used to spin the rotor being balanced is shown in the lower right hand part of Fig. J-28. The amount of imbalance is recorded on the instrumentation shown in Figs. J-29 and J-30. During a balancing test, the drive end is first balanced, then the opposite end. This equipment can detect small vibrations, enabling rotors to be balanced to within $\mathrm{a} 3 / 4$ mil displacement. 


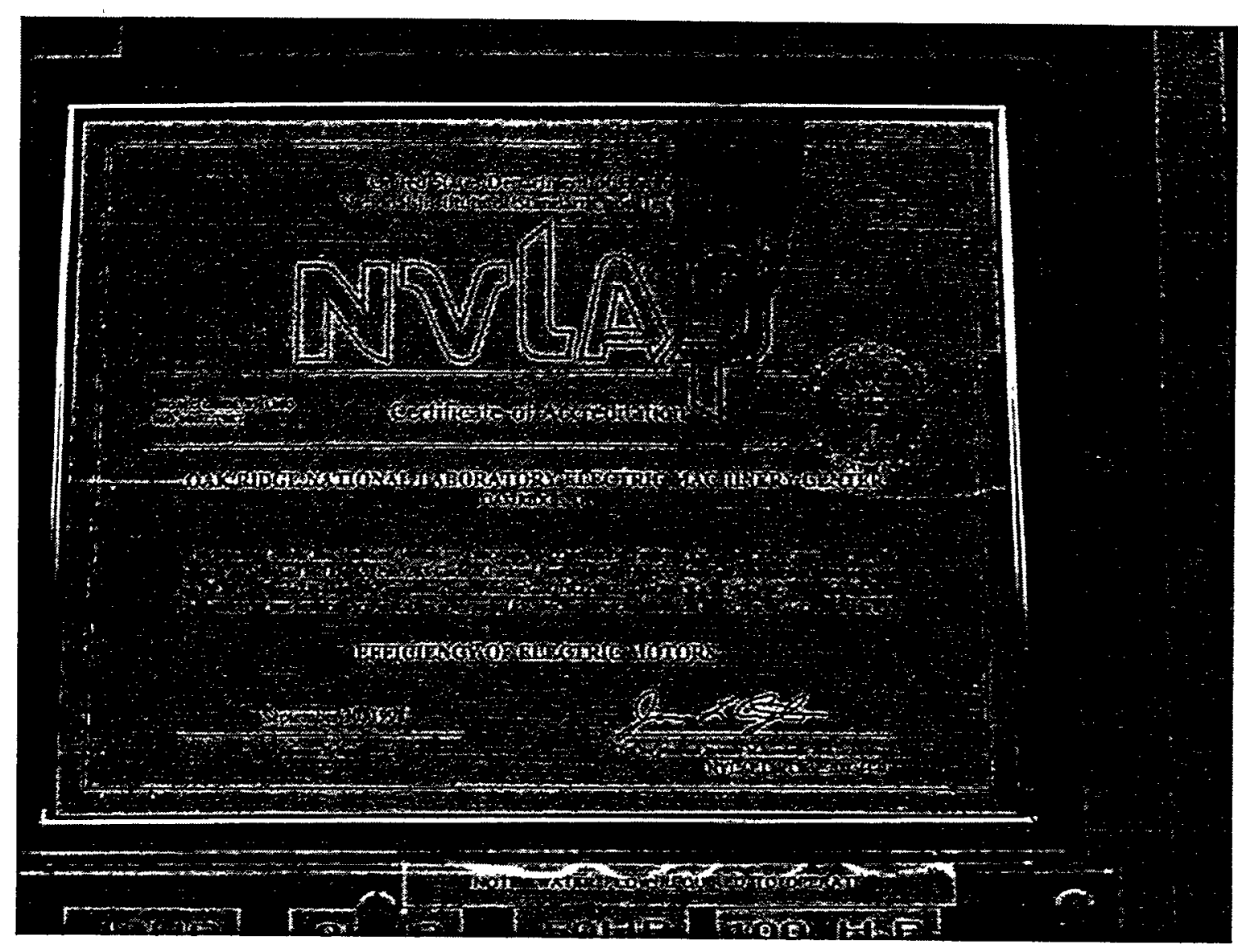

Figure J-1

NYLAP Certificate of Accreditation 


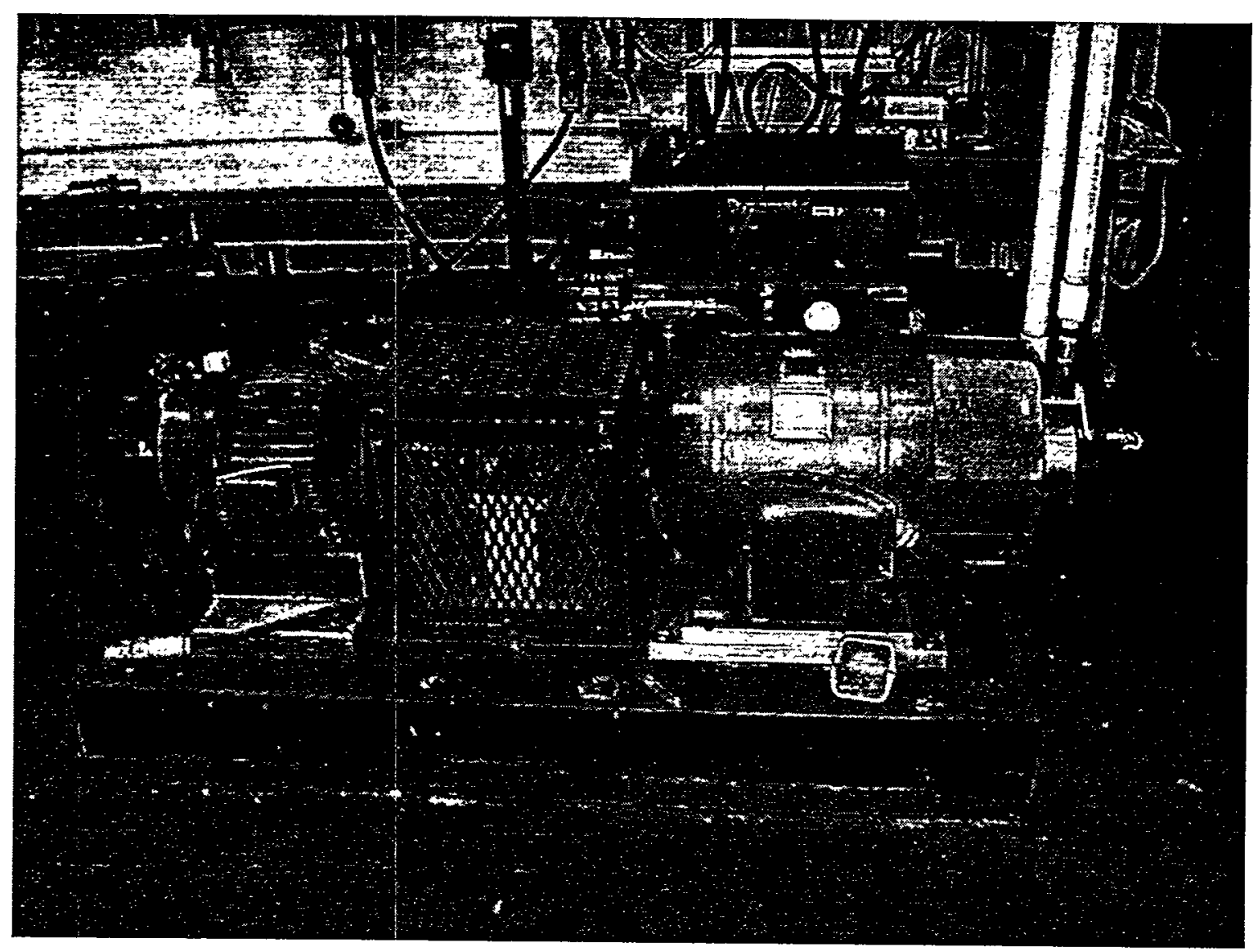

Figure J-2

Two Motor Test Stands

Foreground - Up to $10 \mathrm{HP}$

Background - Up to $100 \mathrm{HP}$ 


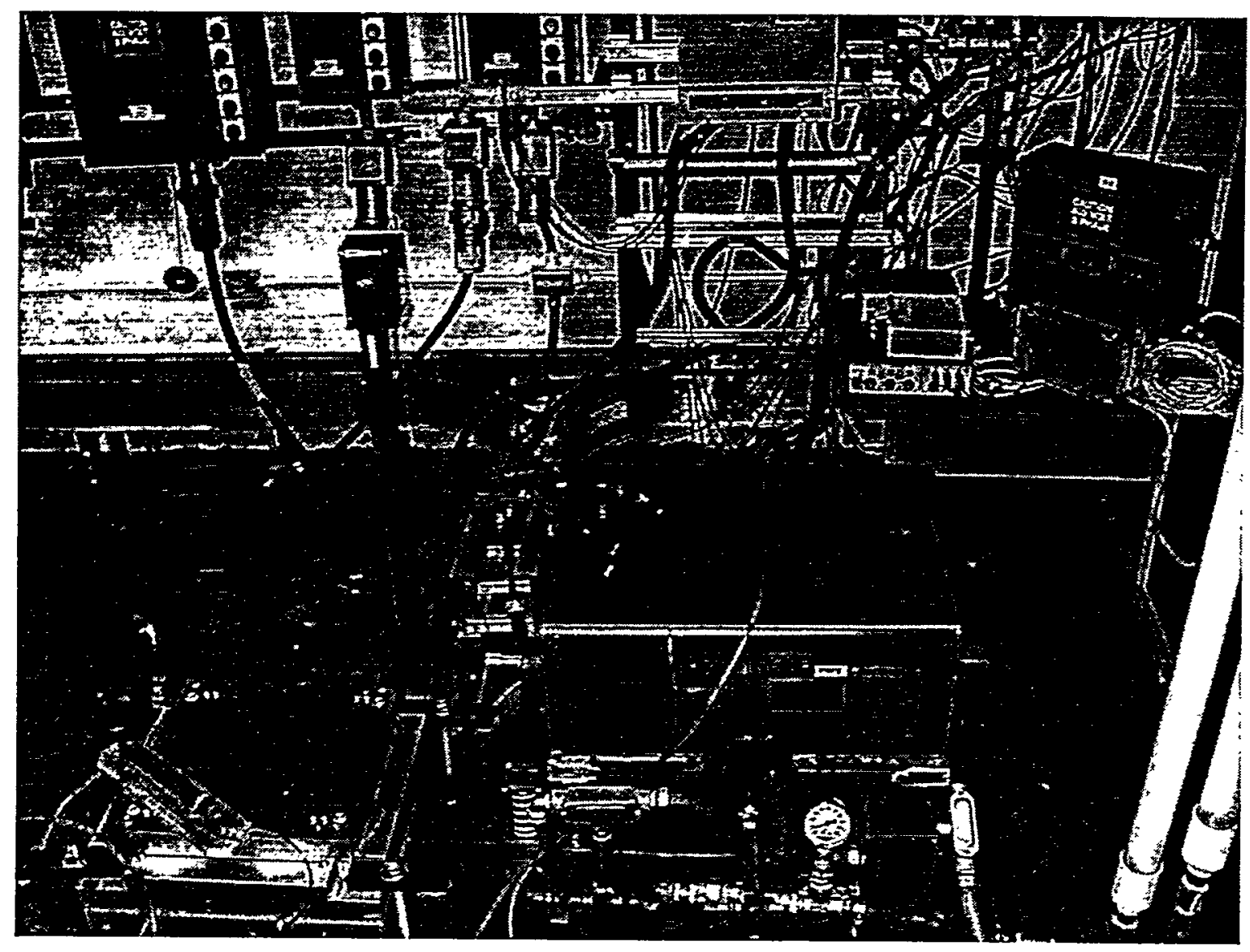

Figure J-3

Motor Test Stand with Water Cooled Eddy Dynamometer Up to $100 \mathrm{HP}$ 


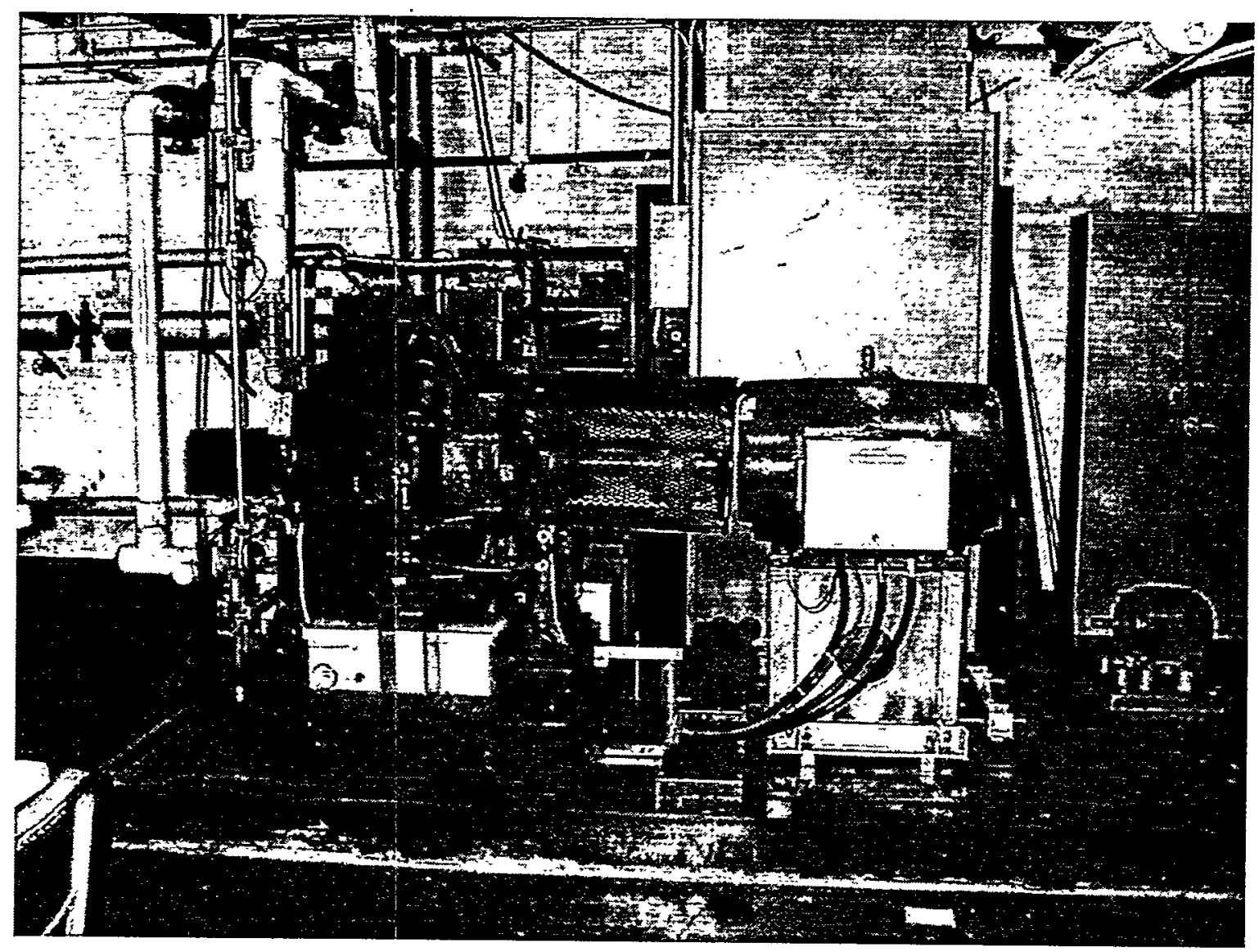

Figure J-4

Motor Test Stand with Water Cooled Eddy Dynamometer -

Up to $500 \mathrm{HP}$ 


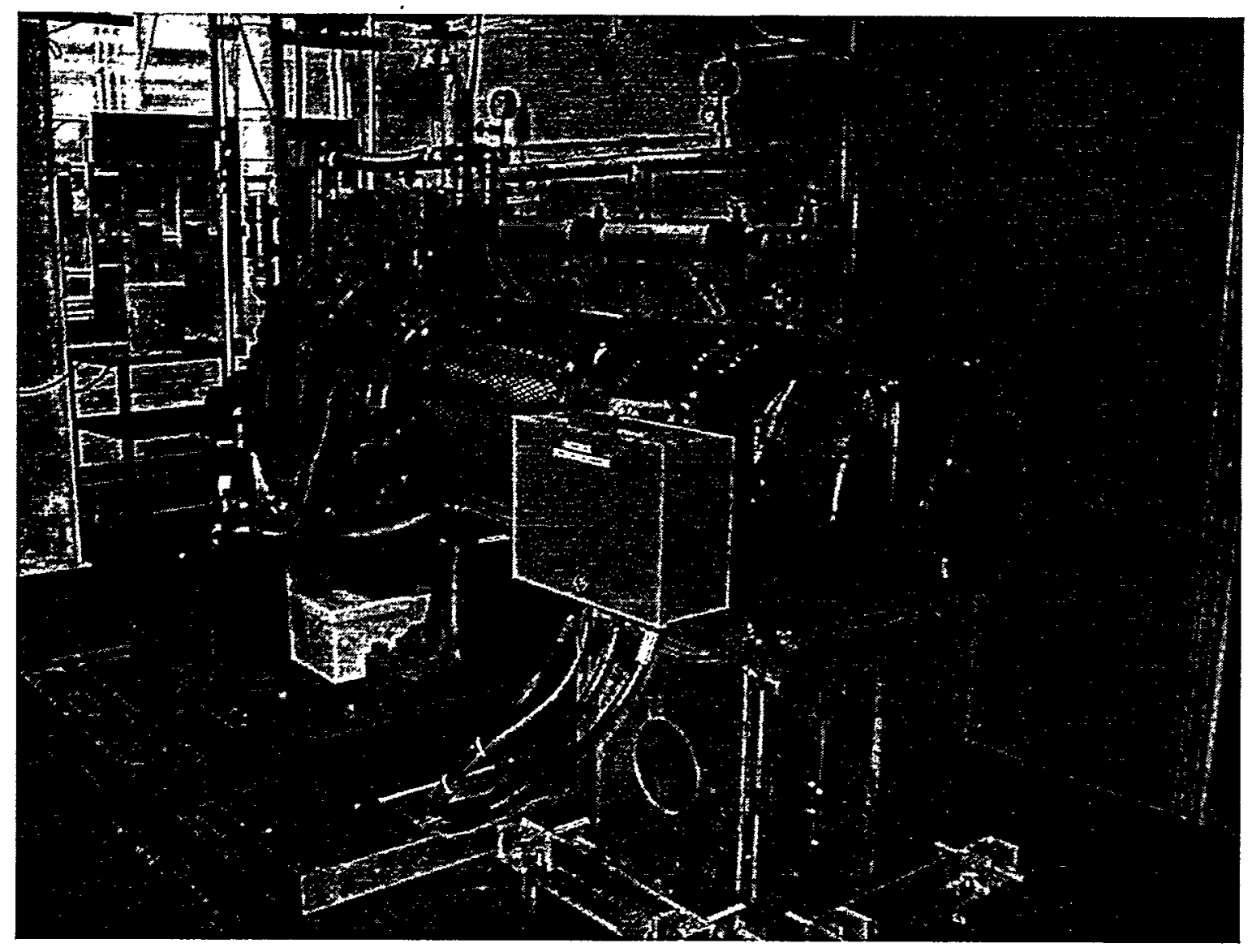

Figure J-5

Another View of Motor Test Stand with Water Cooled Eddy Dynamometer Up to $100 \mathrm{HP}$ 


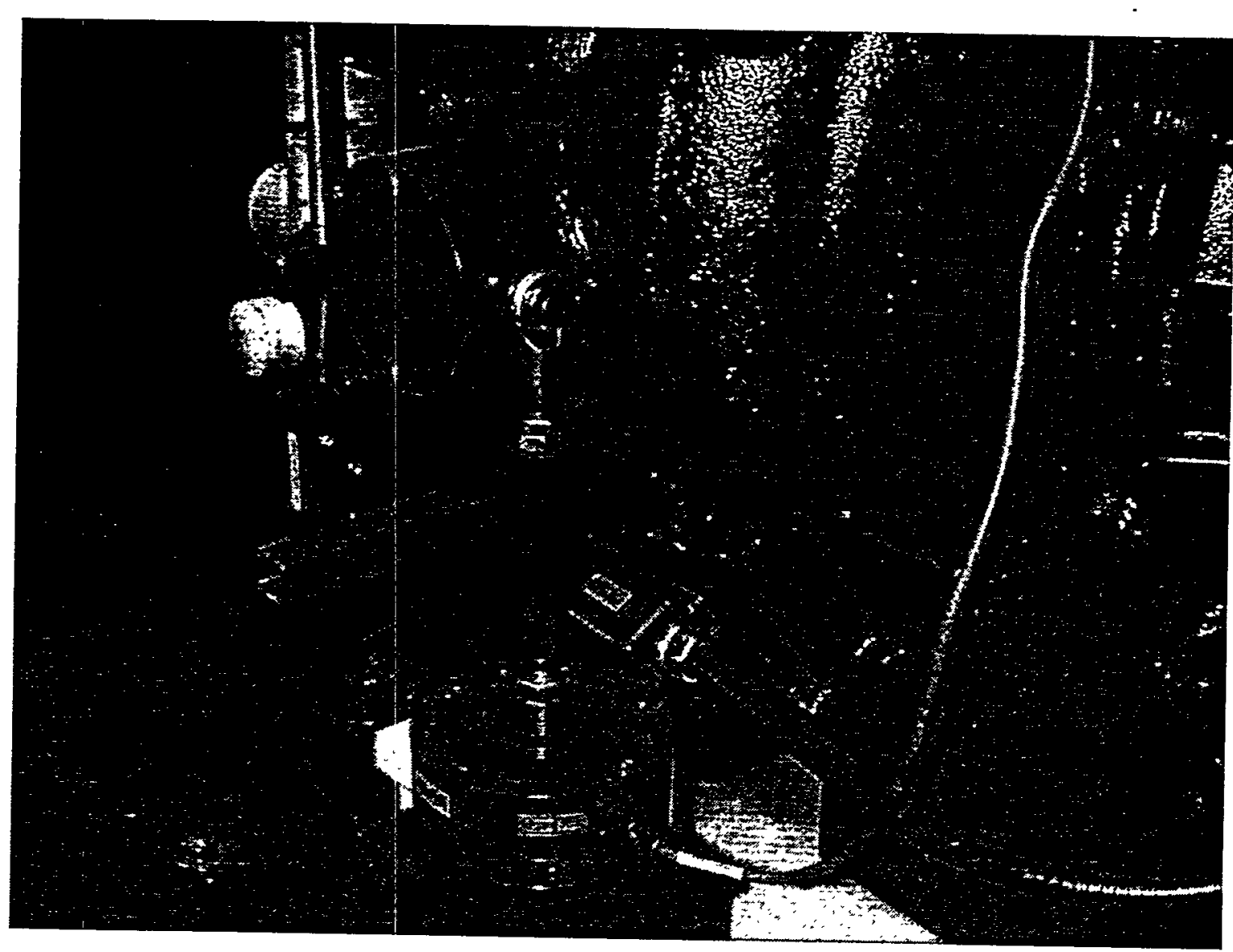

Figure J-6

Torque Cell on the 500 HP Test Stand 


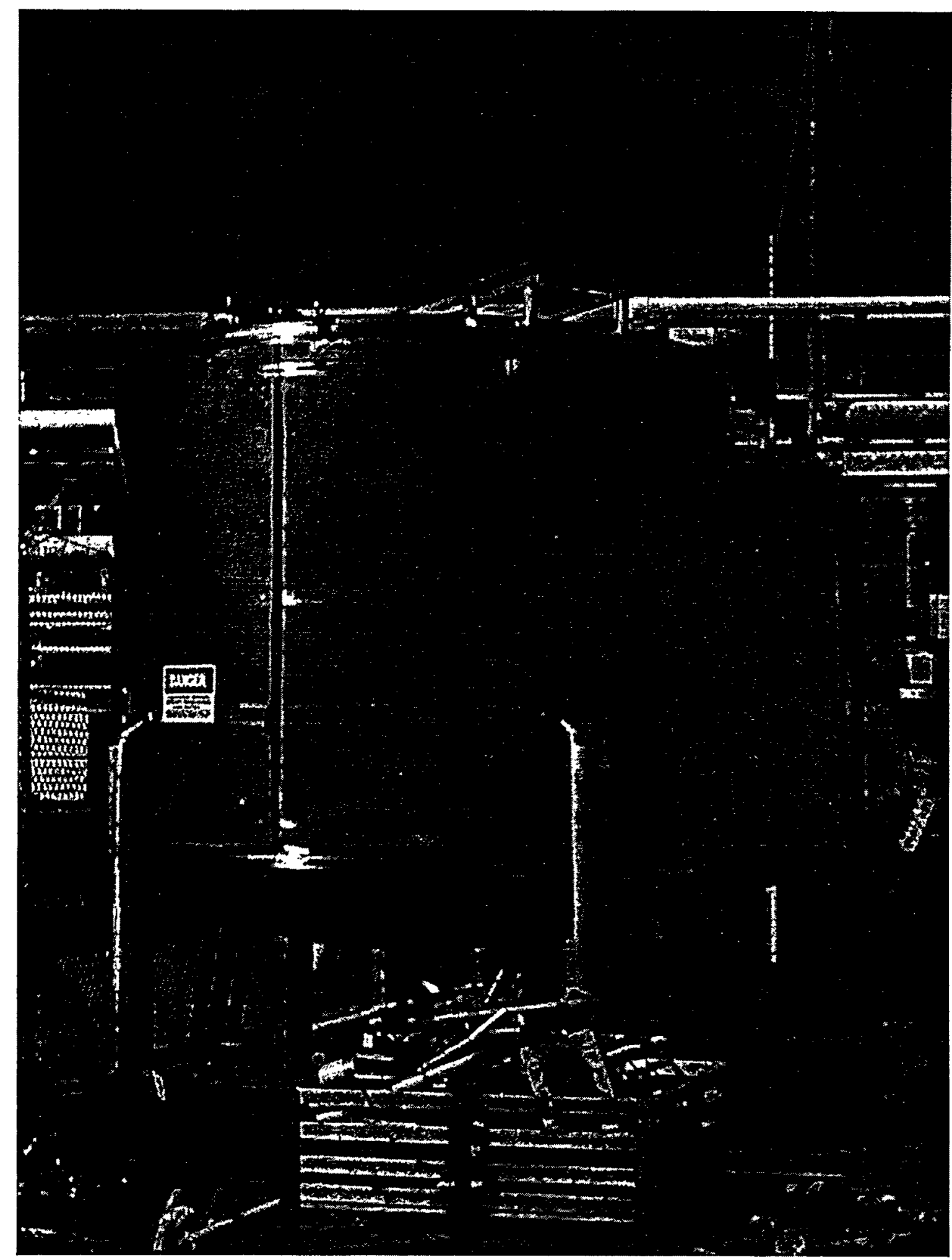

Figure J-7

Two Storage Tanks For Cooling Water Supply 


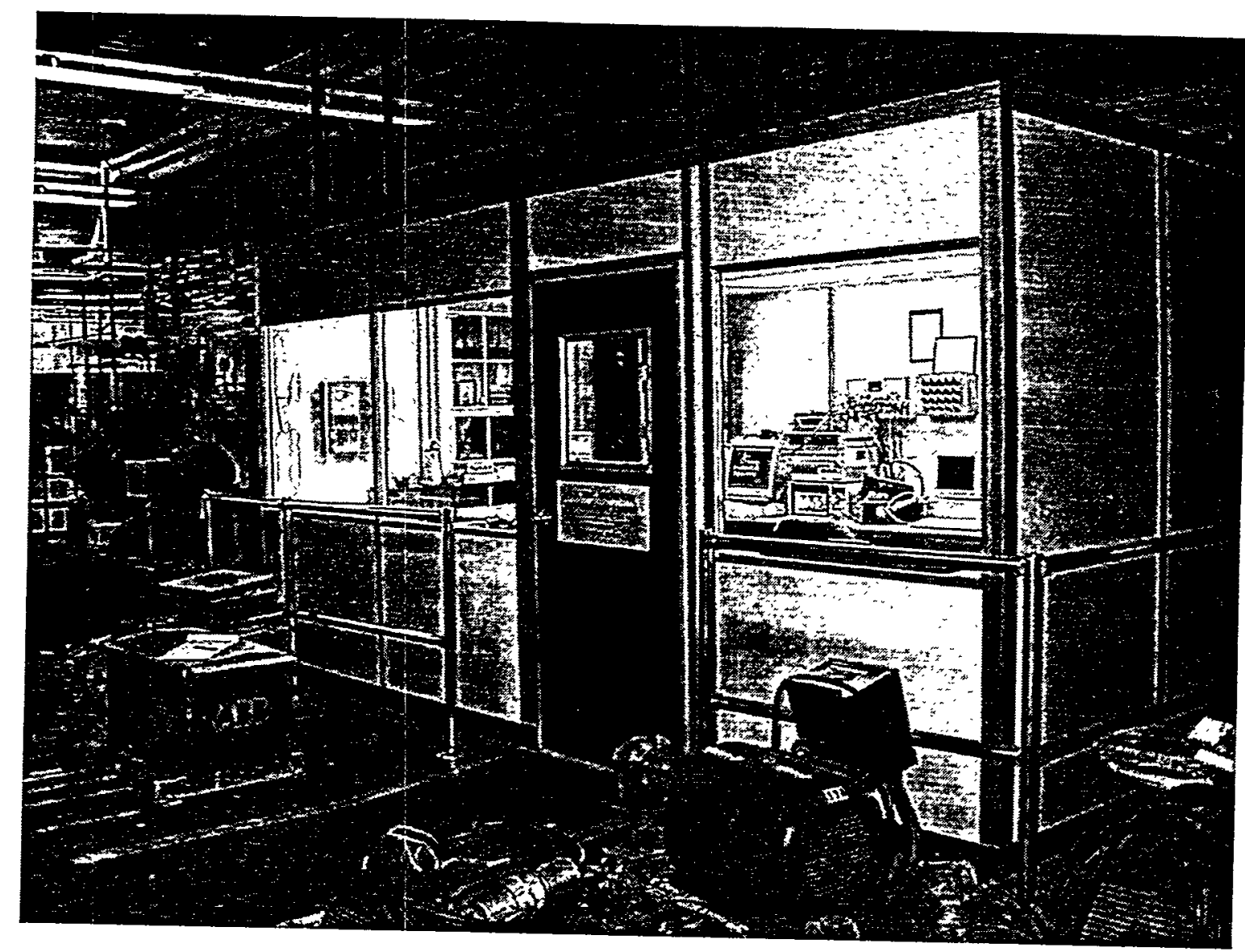

Figure J-8

Control Room for Electric Machinery Systems Test Center 


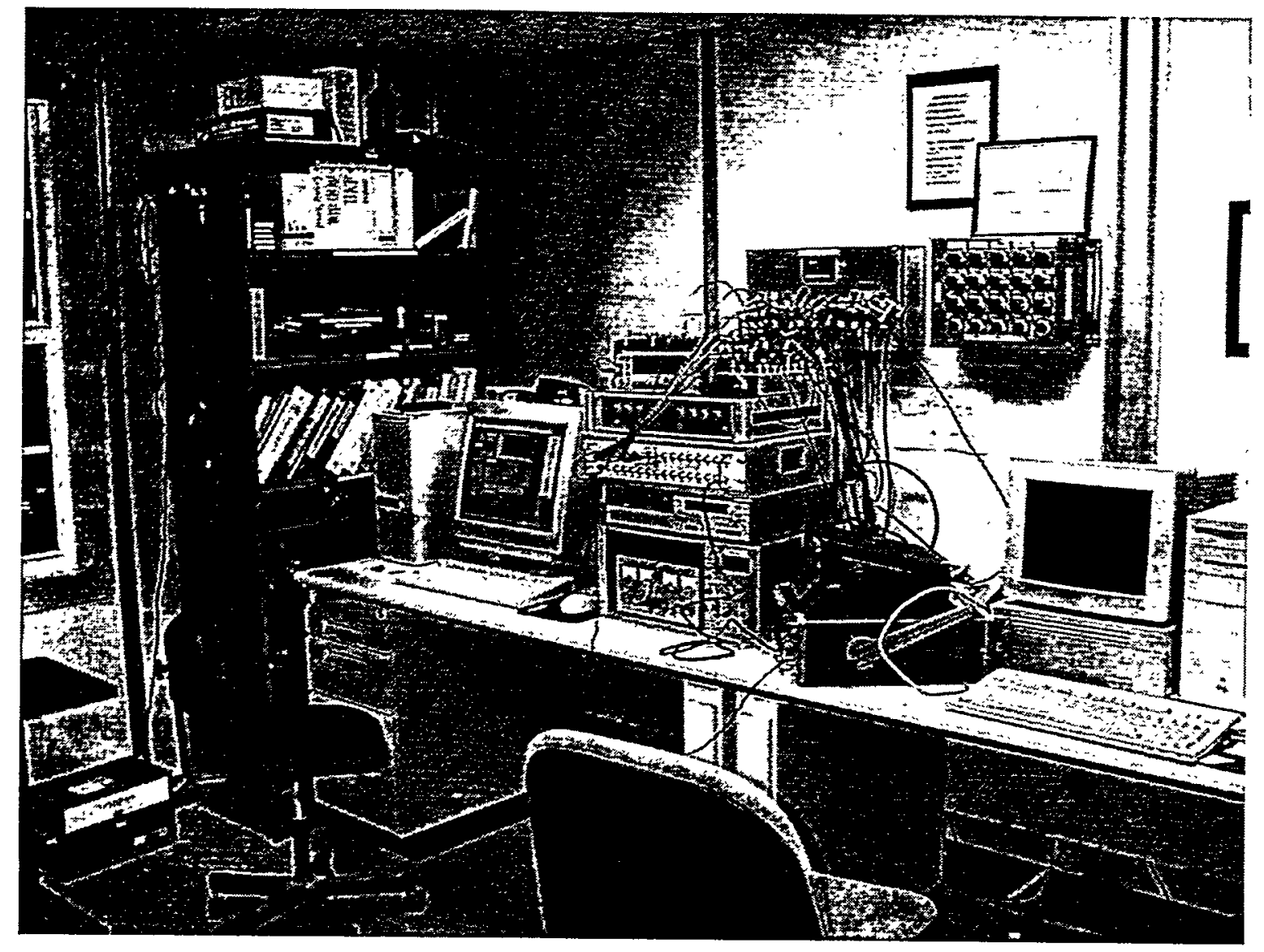

Figure J-9

Data Acquisition System for Test Center 


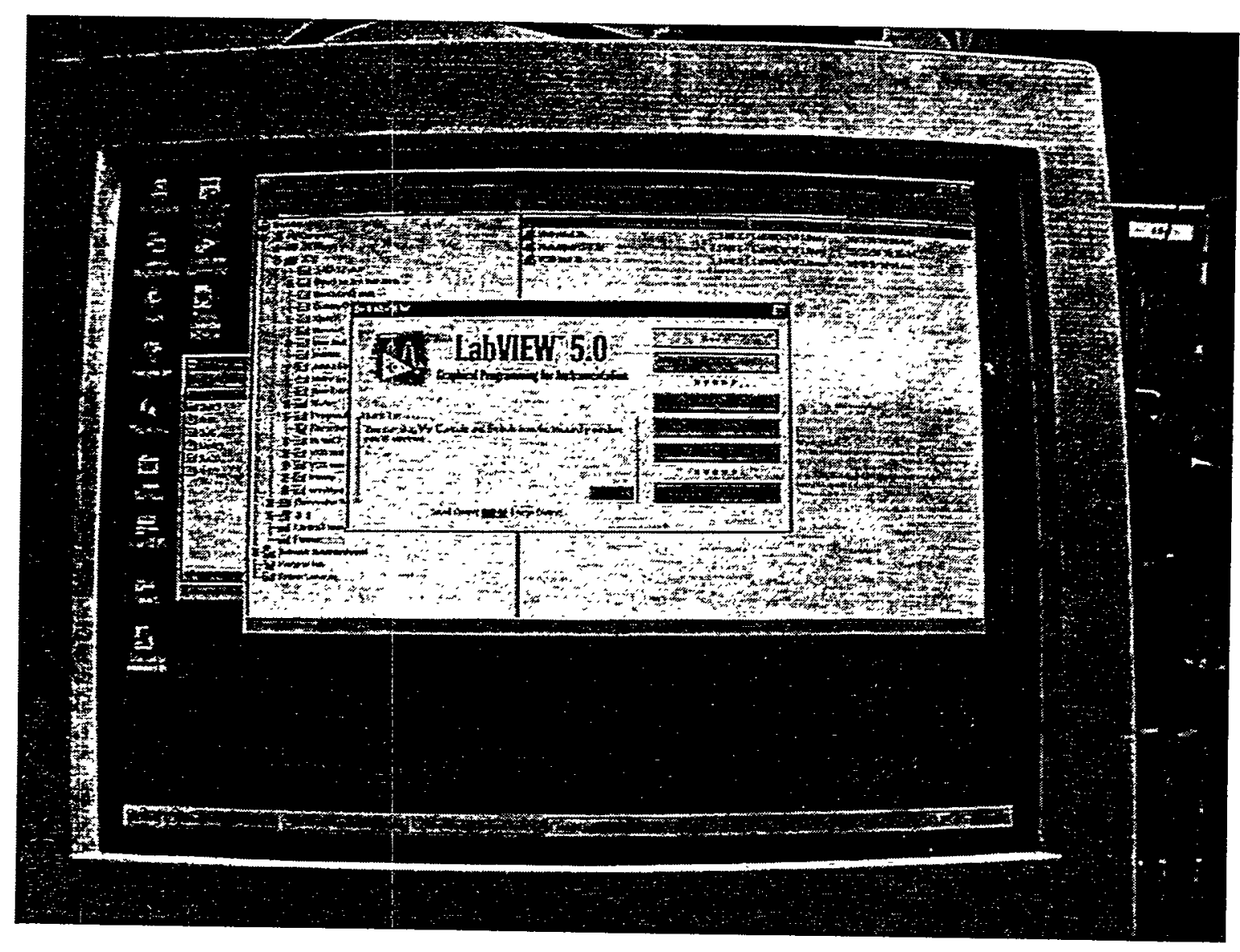

Figure J-10

Opening Screen for LabVIEW ${ }^{\mathrm{TM}}$ 


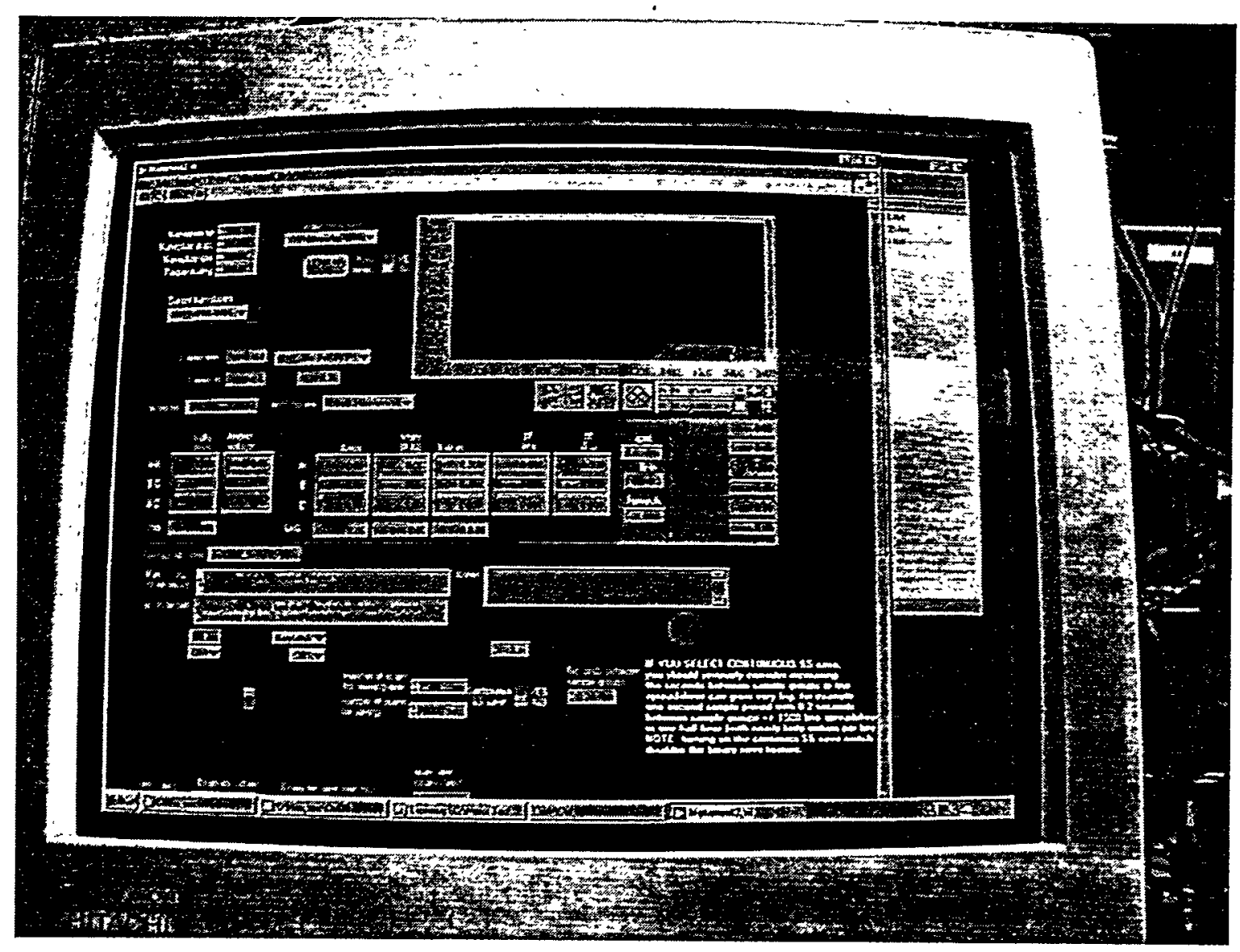

Figure J-11

Graphical and Numerical Display of Data on PC Screen 


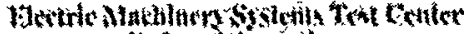

Bulor or Oinetiatlon Uil $20 x$

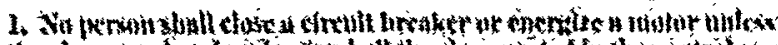

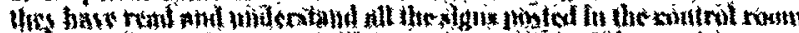

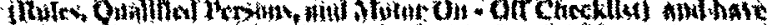

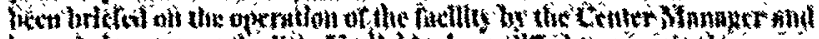

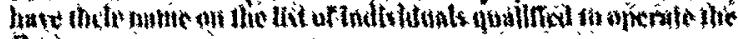
Canter.

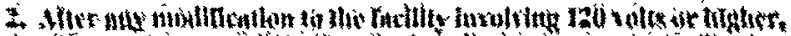

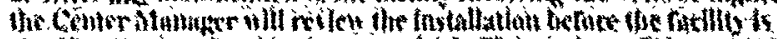

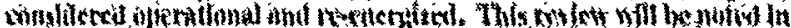

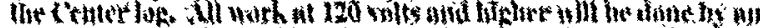

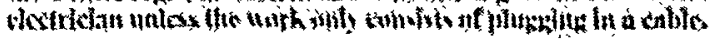

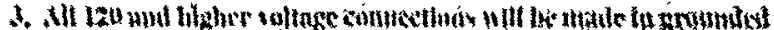

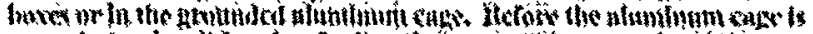

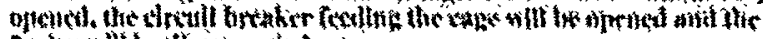

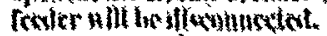

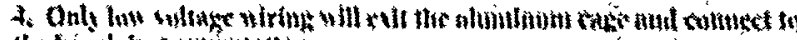

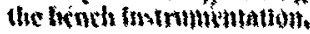

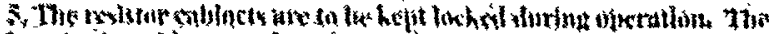

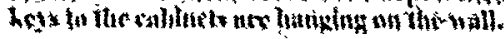

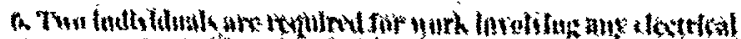

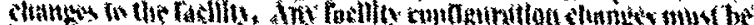

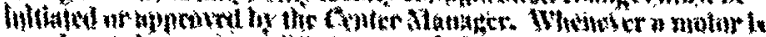

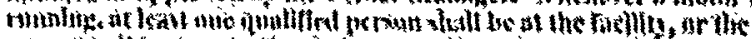

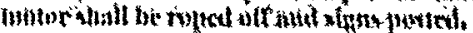

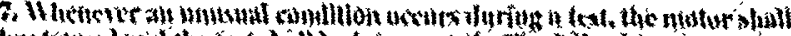

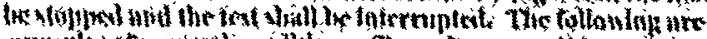

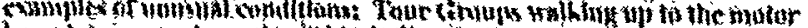

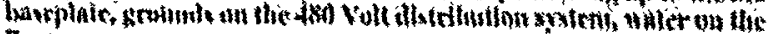
nowr.

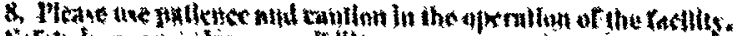

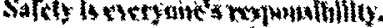

Figure J-12

Electric Machinery Systems Test Center Rules of Operation 


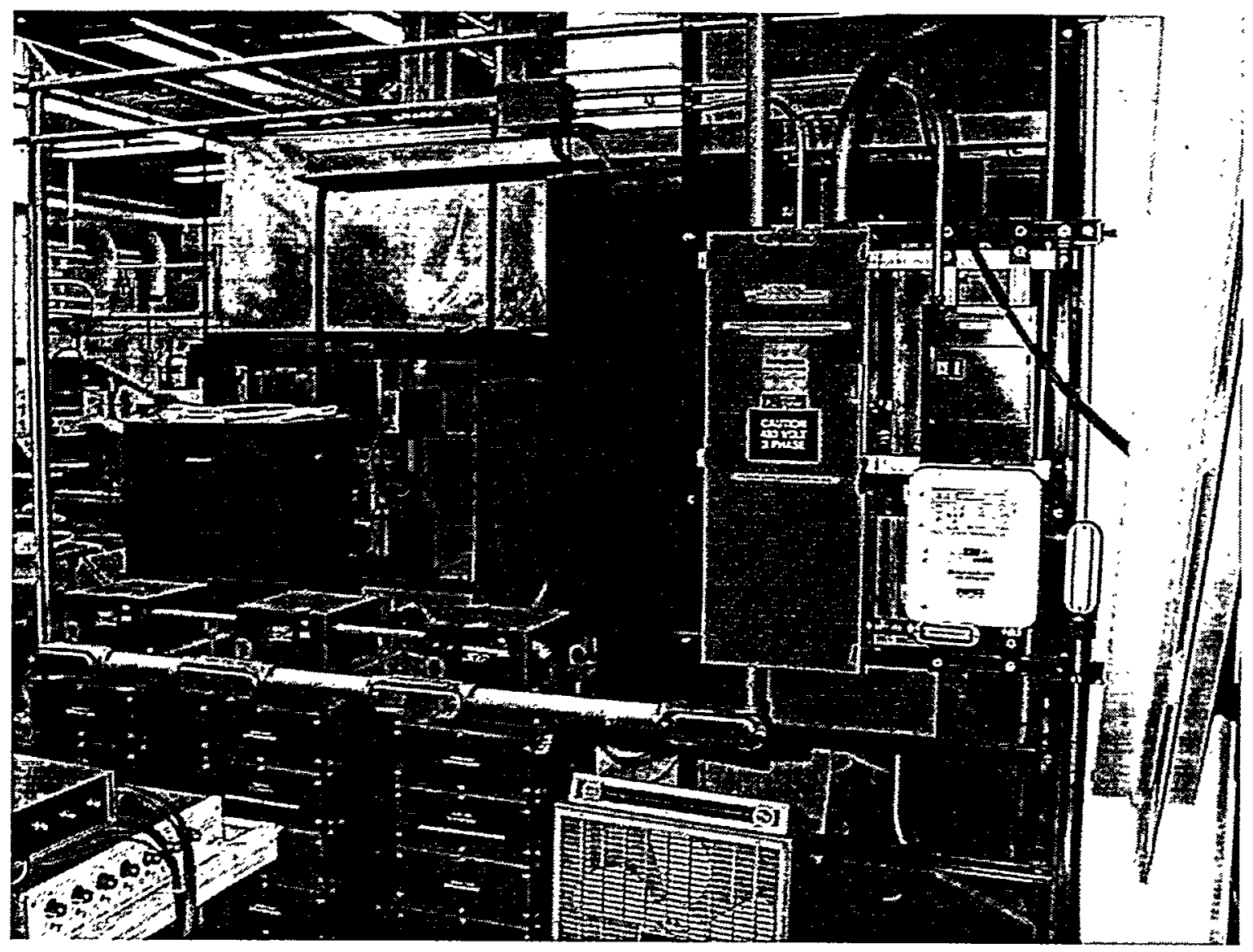

Figure J-13

Three-Phase Variac Voltage Control Center 


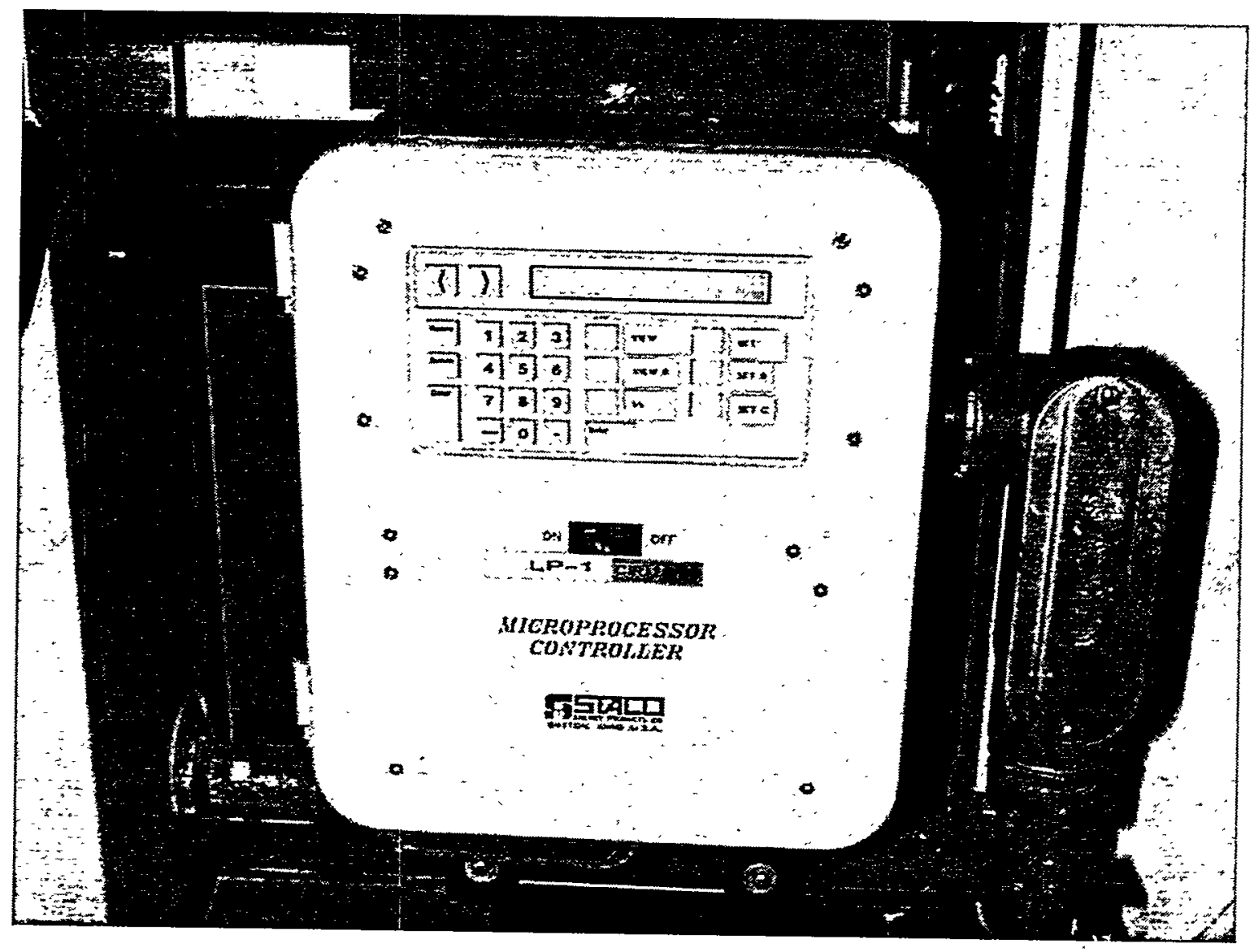

Figure J-14

Microprocessor. Controller For Voltage Control Center 


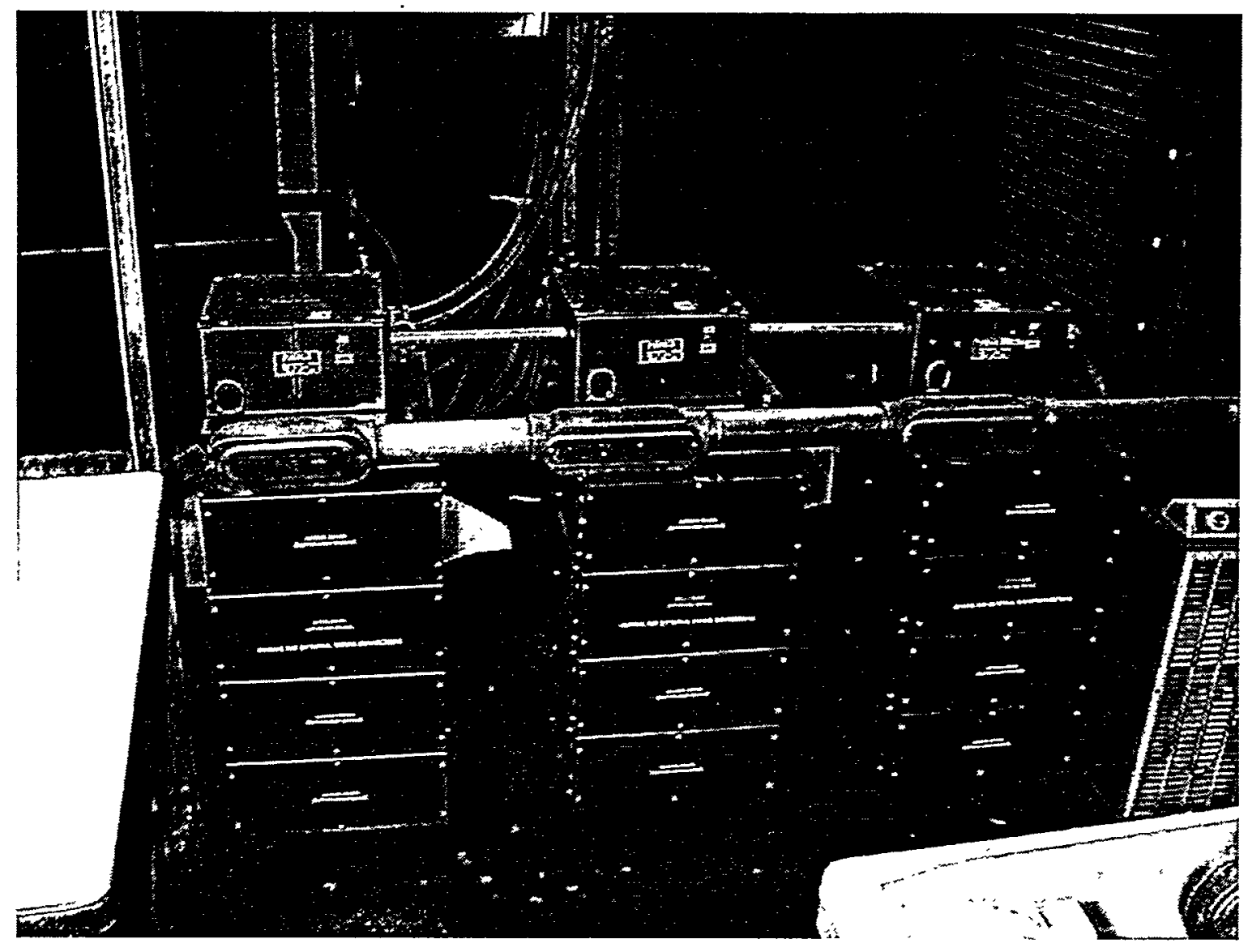

Figure J-15

Variacs Used in Voltage Control Center 


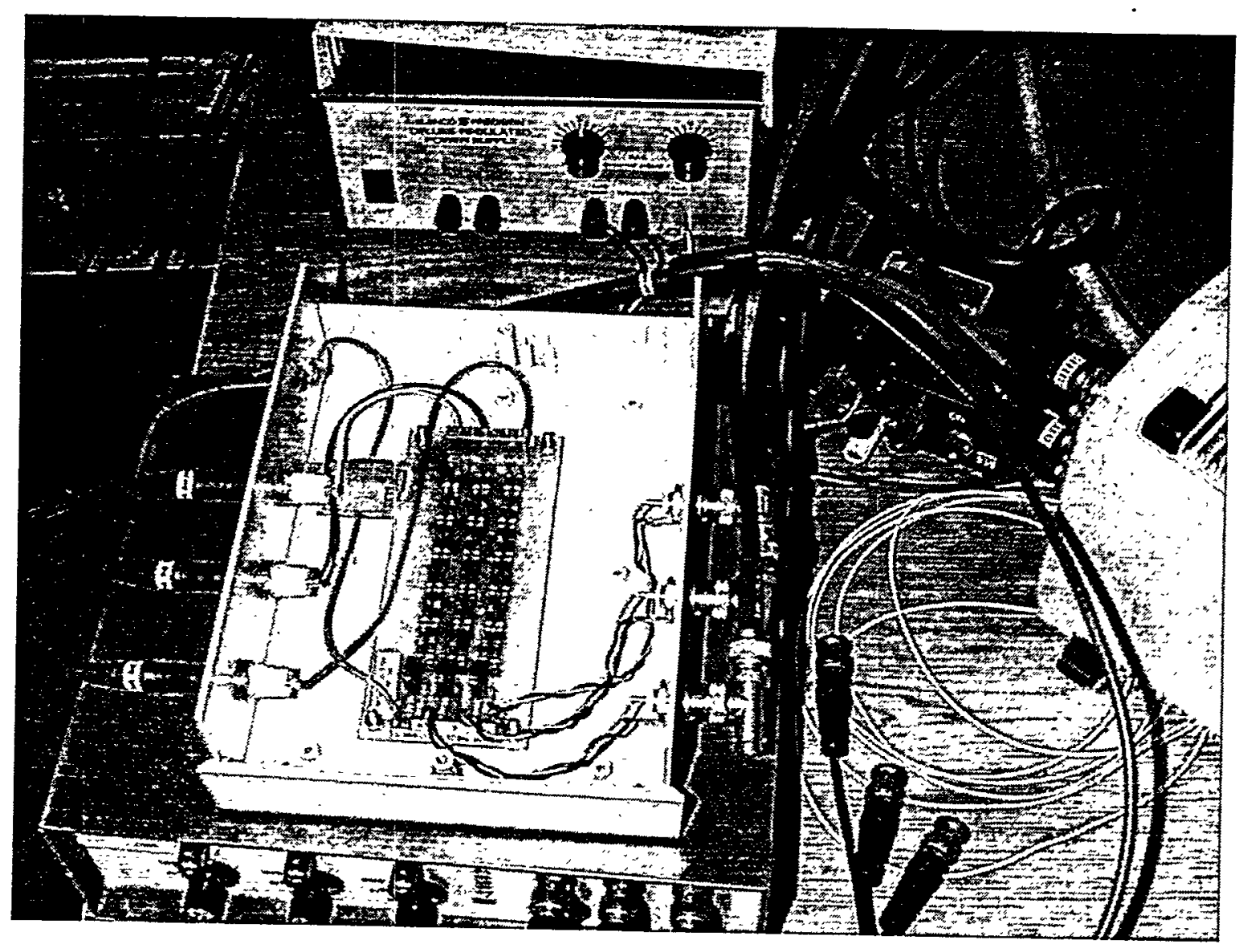

Figure J-16

Box Resistance Dividers for Measuring Voltages 


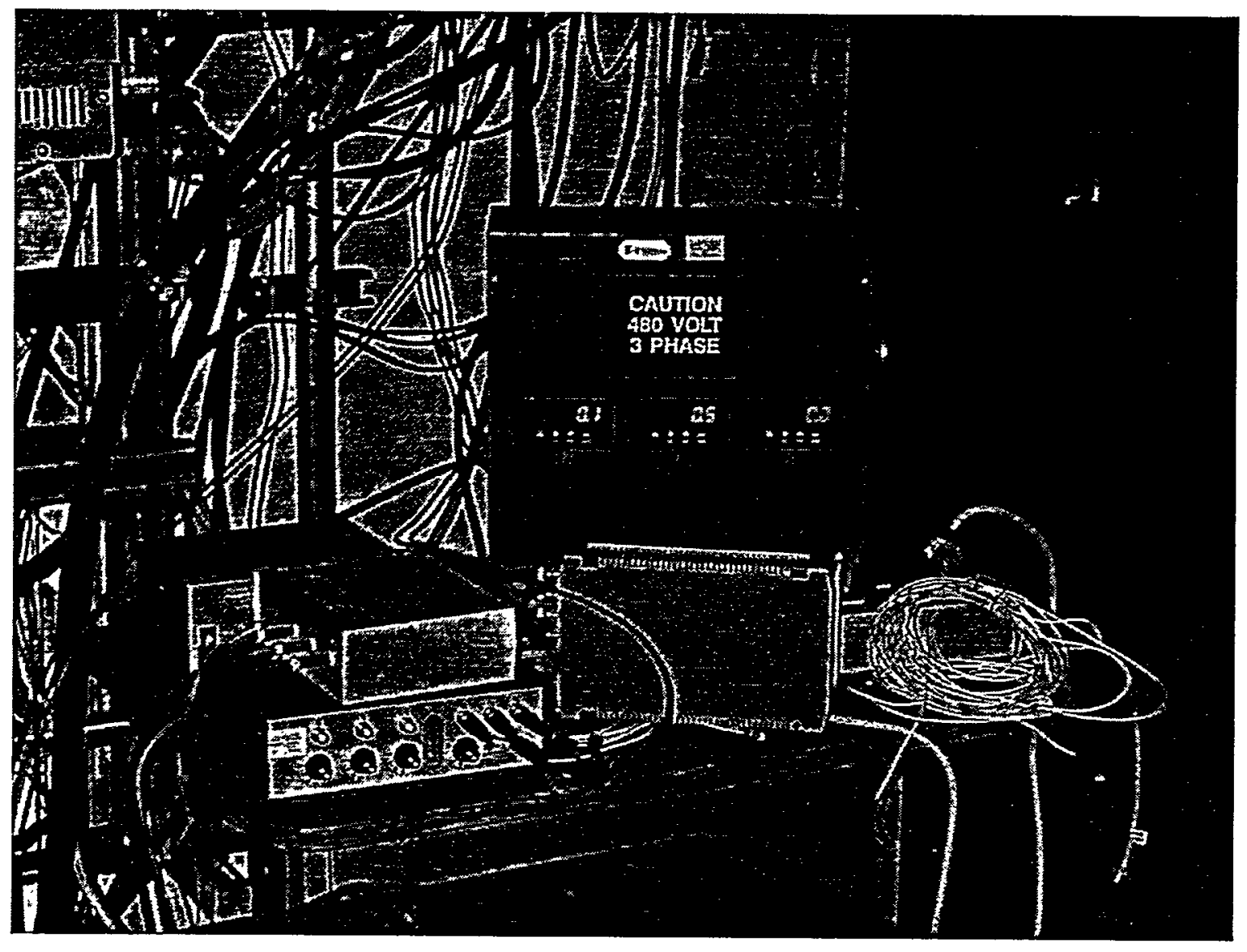

Figure J-17

Voltage Readout Device 


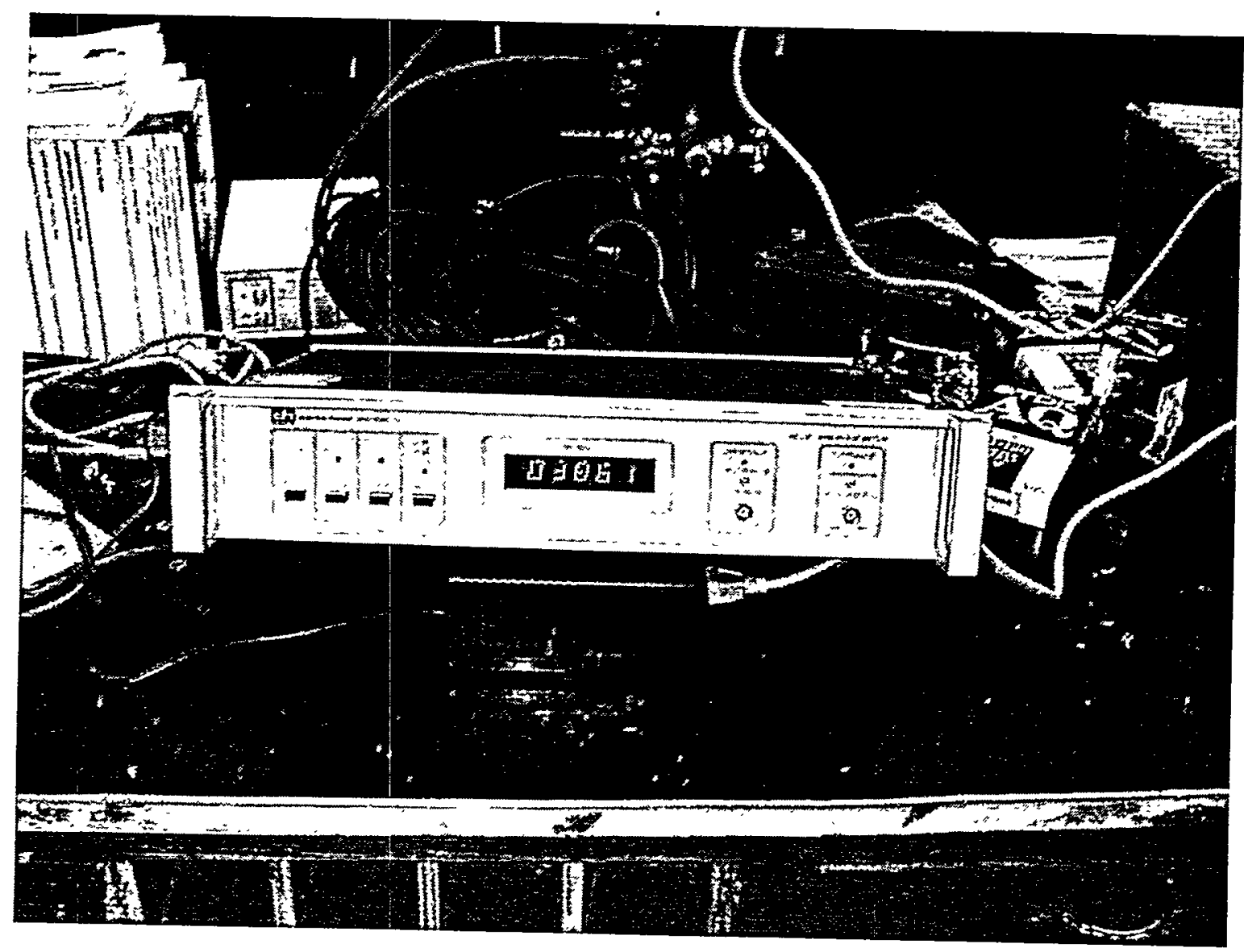

Figure J-18

Clark-Hess Phase Meter 


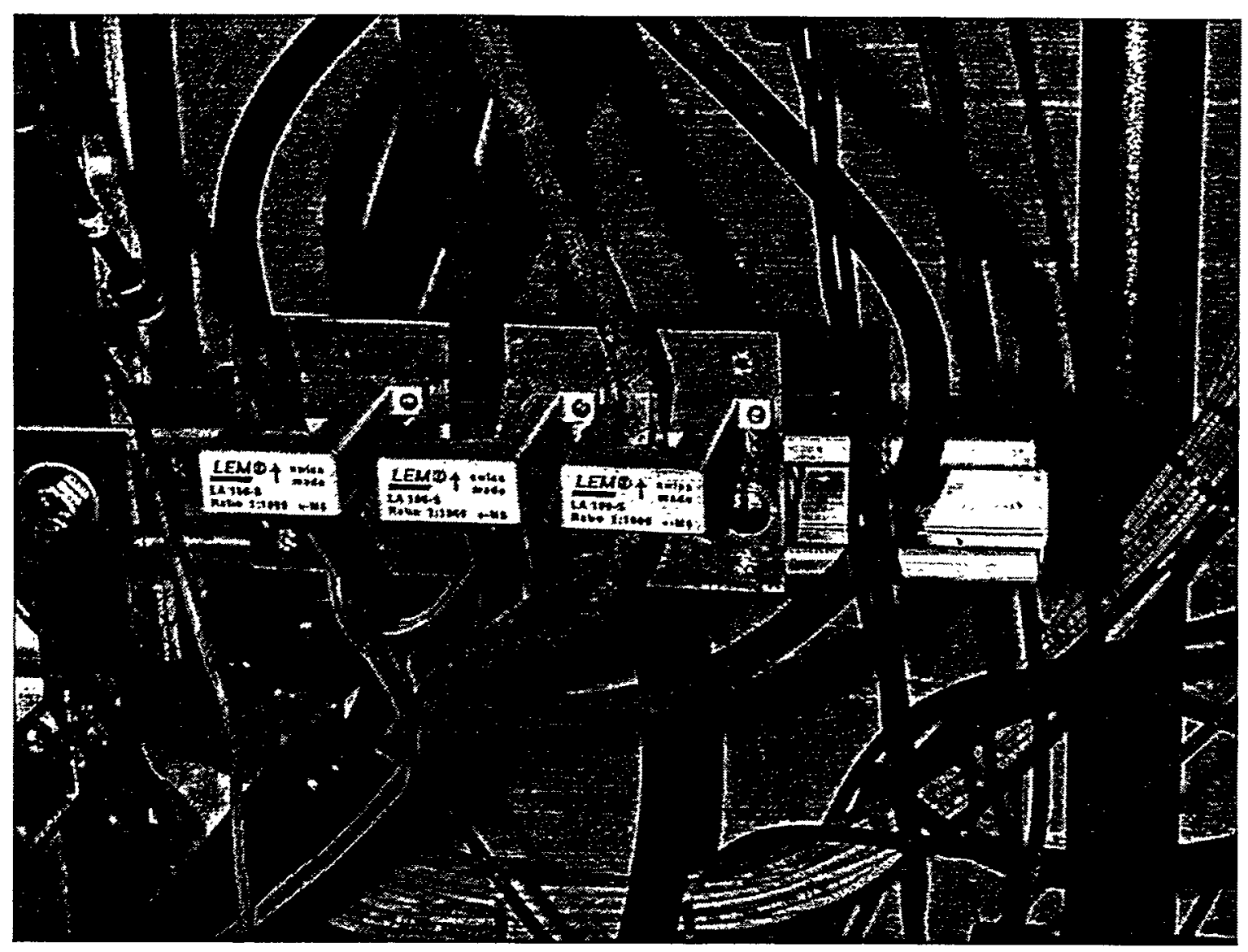

Figure J-19

Hall Sensors 


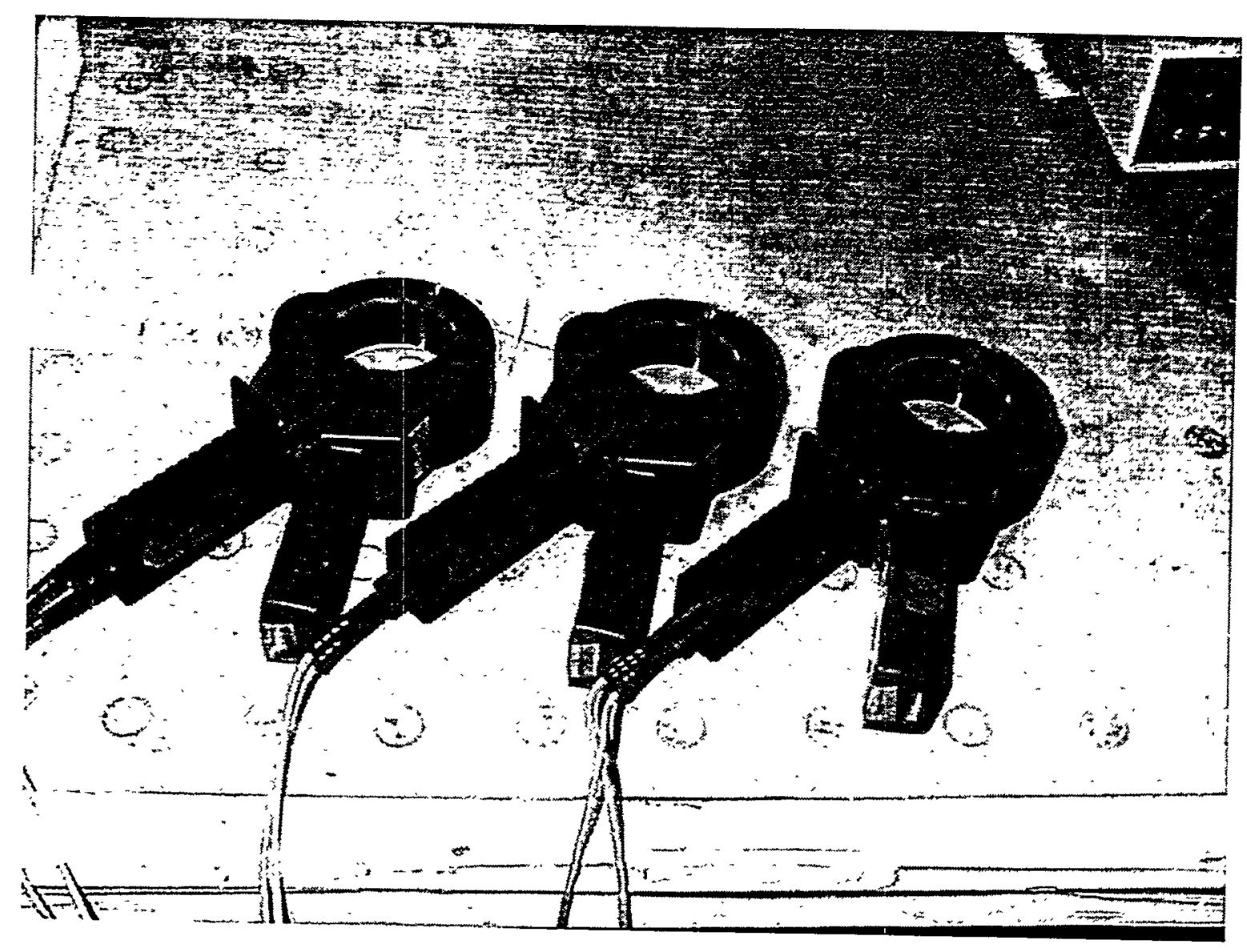

Figure J-20

Clamp-On Ammeters 


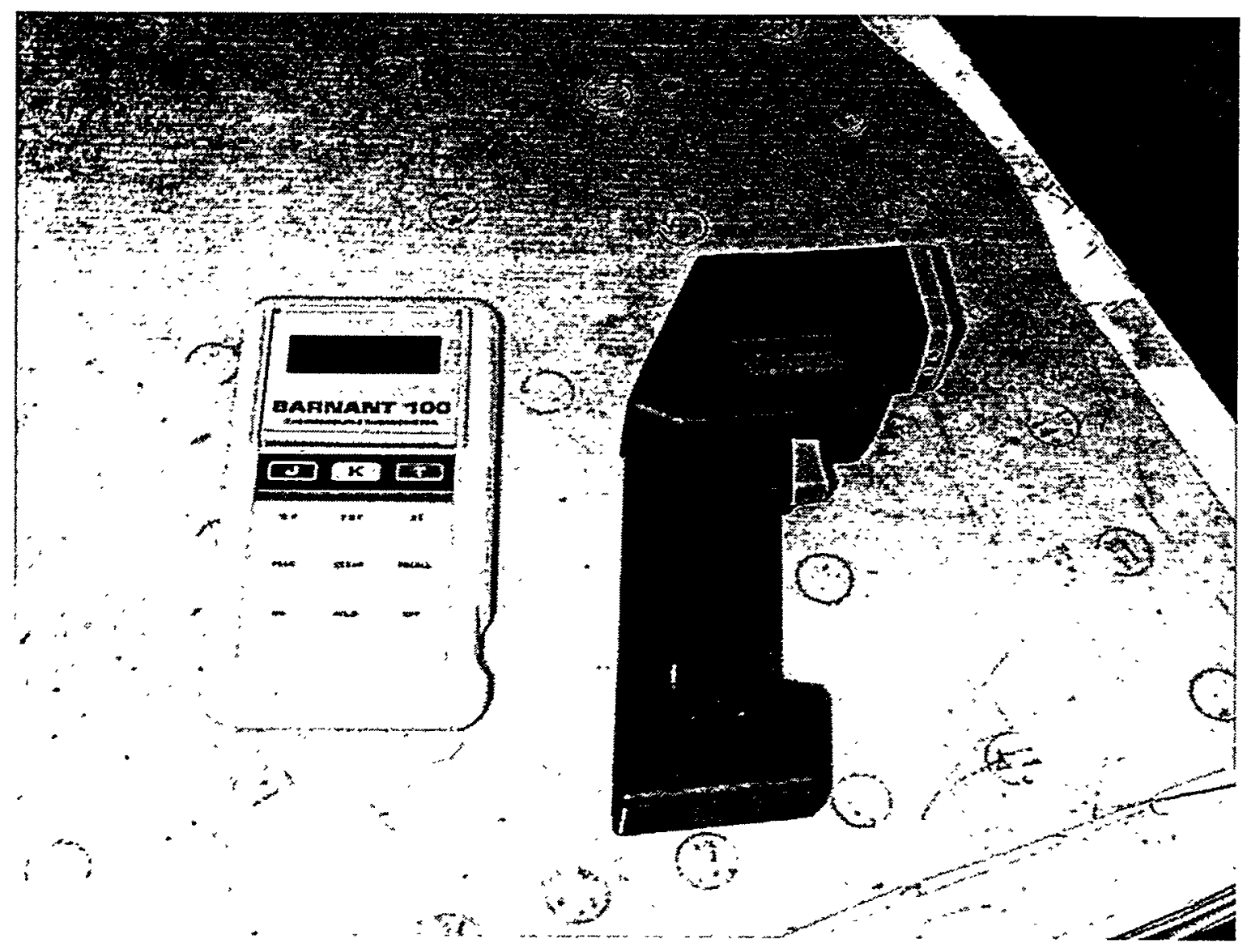

Figure J-21

Temperature Measuring Devices 


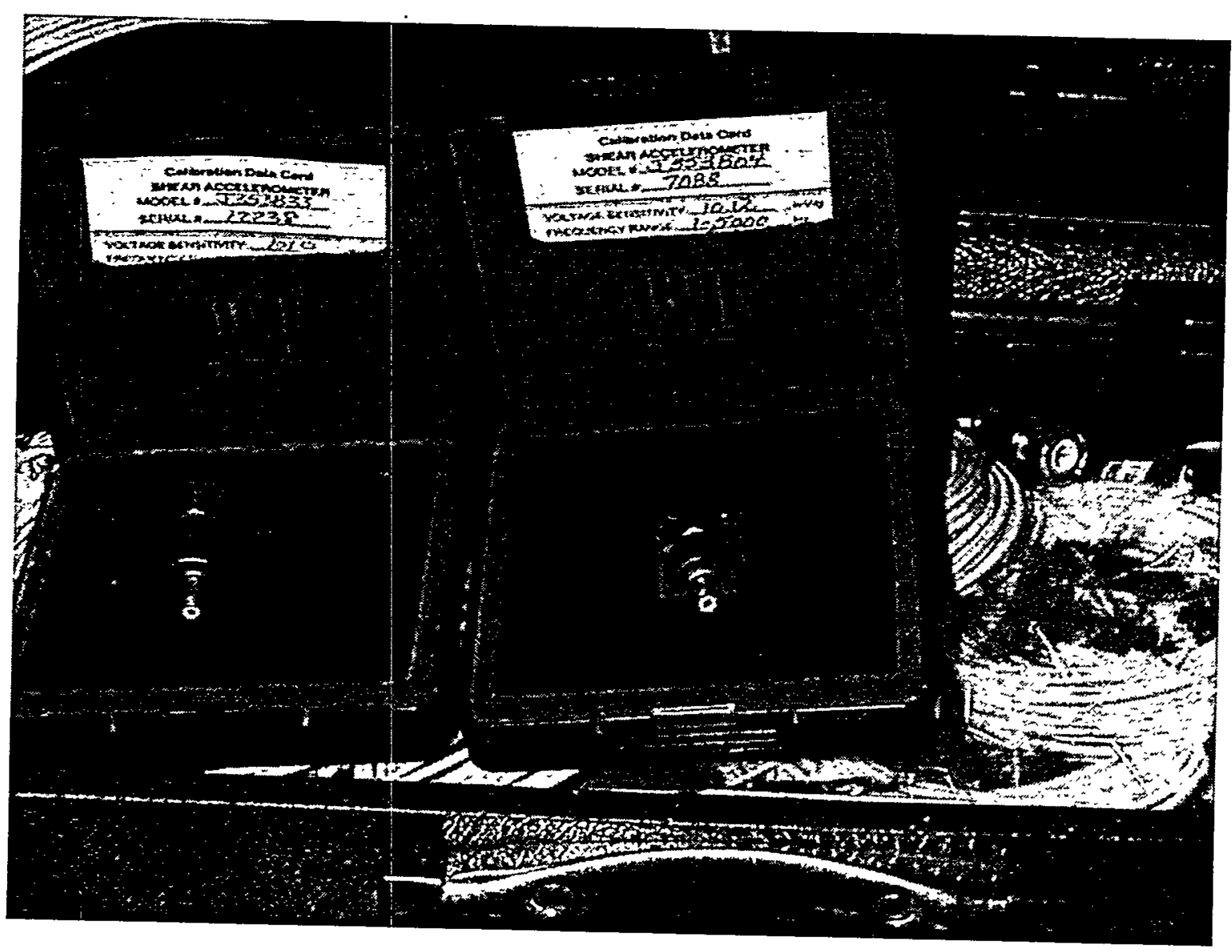

Figure J-22

Accelerometers 


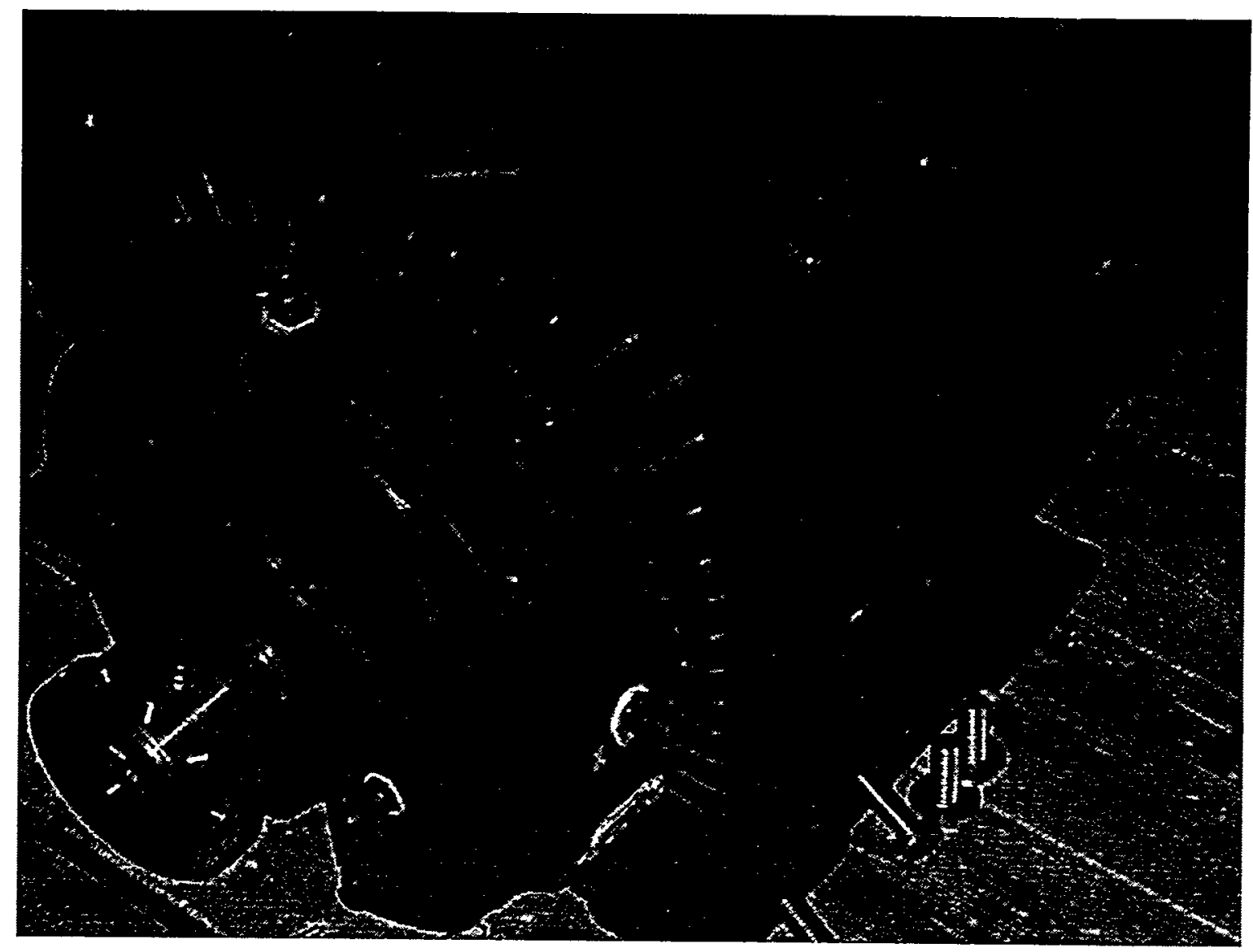

Figure J-23

Accelerometers Mounted on a Motor 


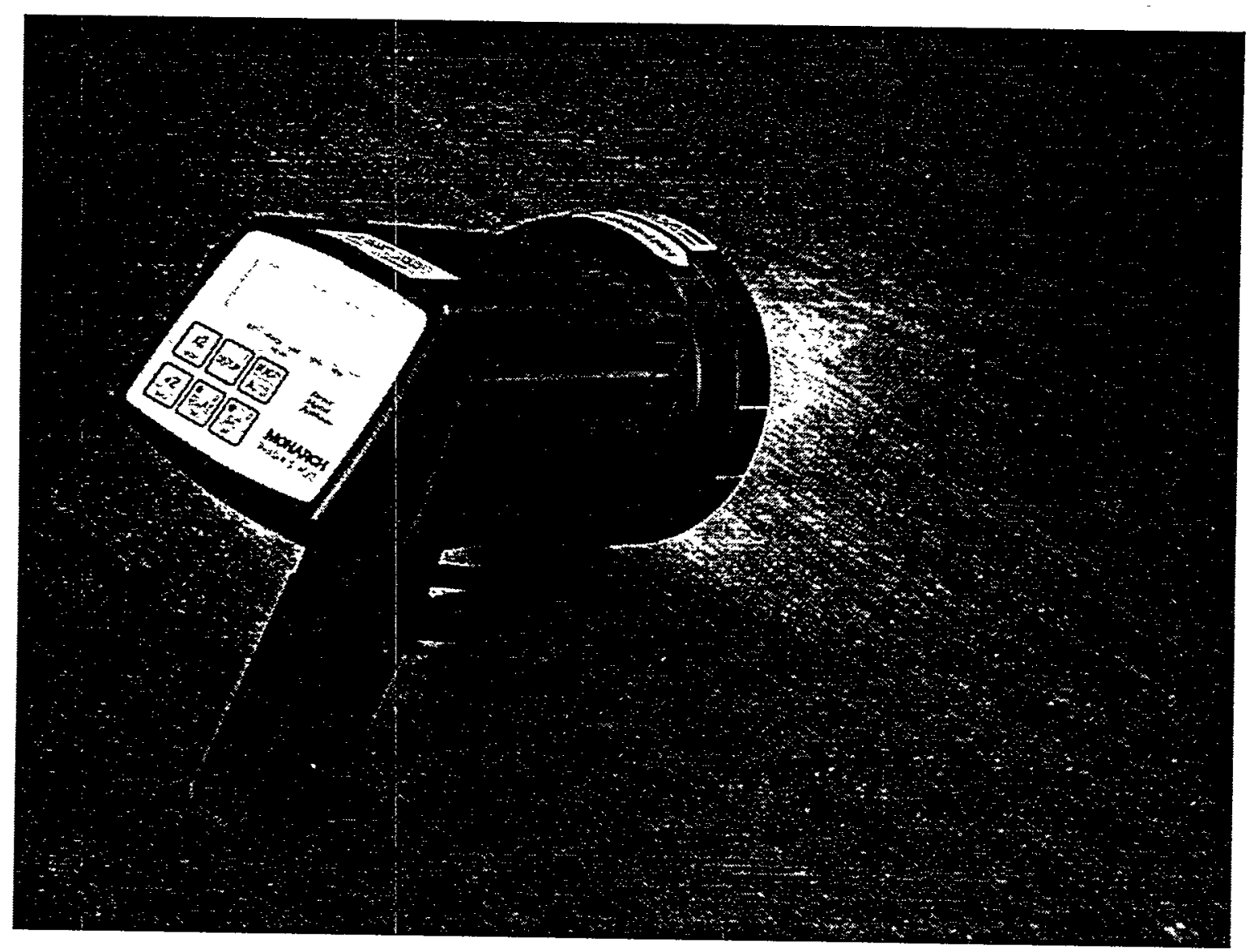

Figure J-24

Strobe Light 


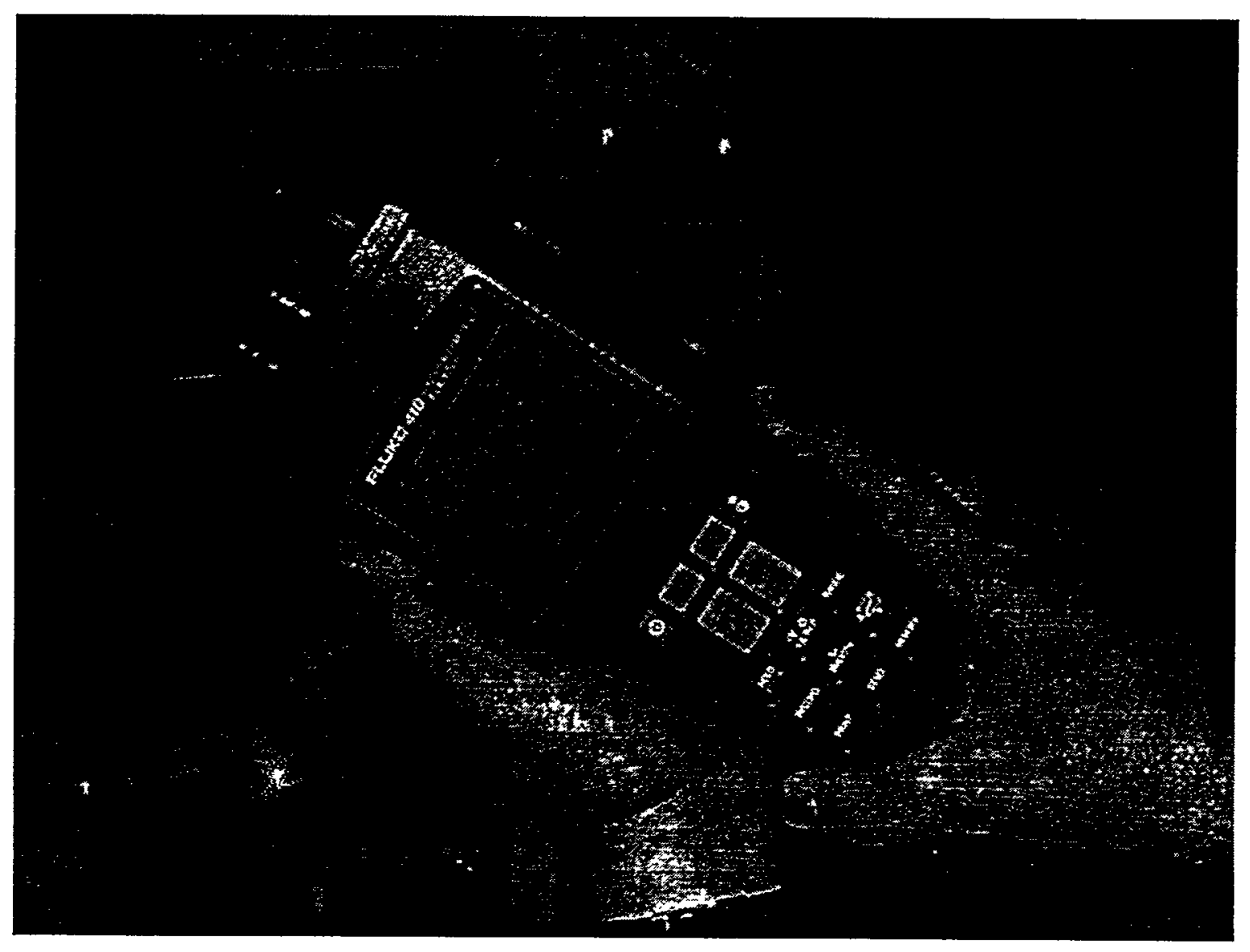

Figure J-25

Fluke Power Harmonics Analyzer 


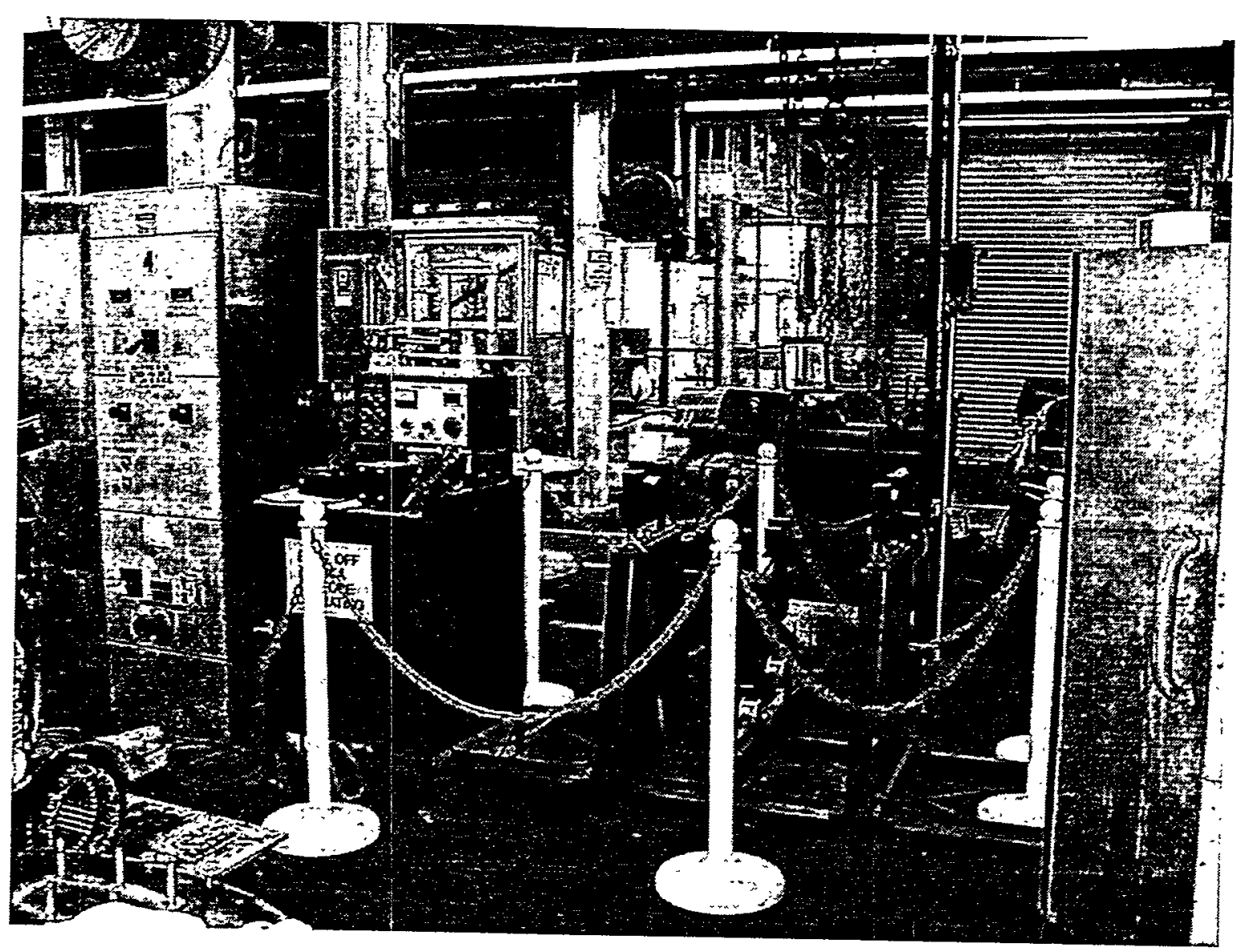

Figure J-26

Overall View of Balancing Facility 


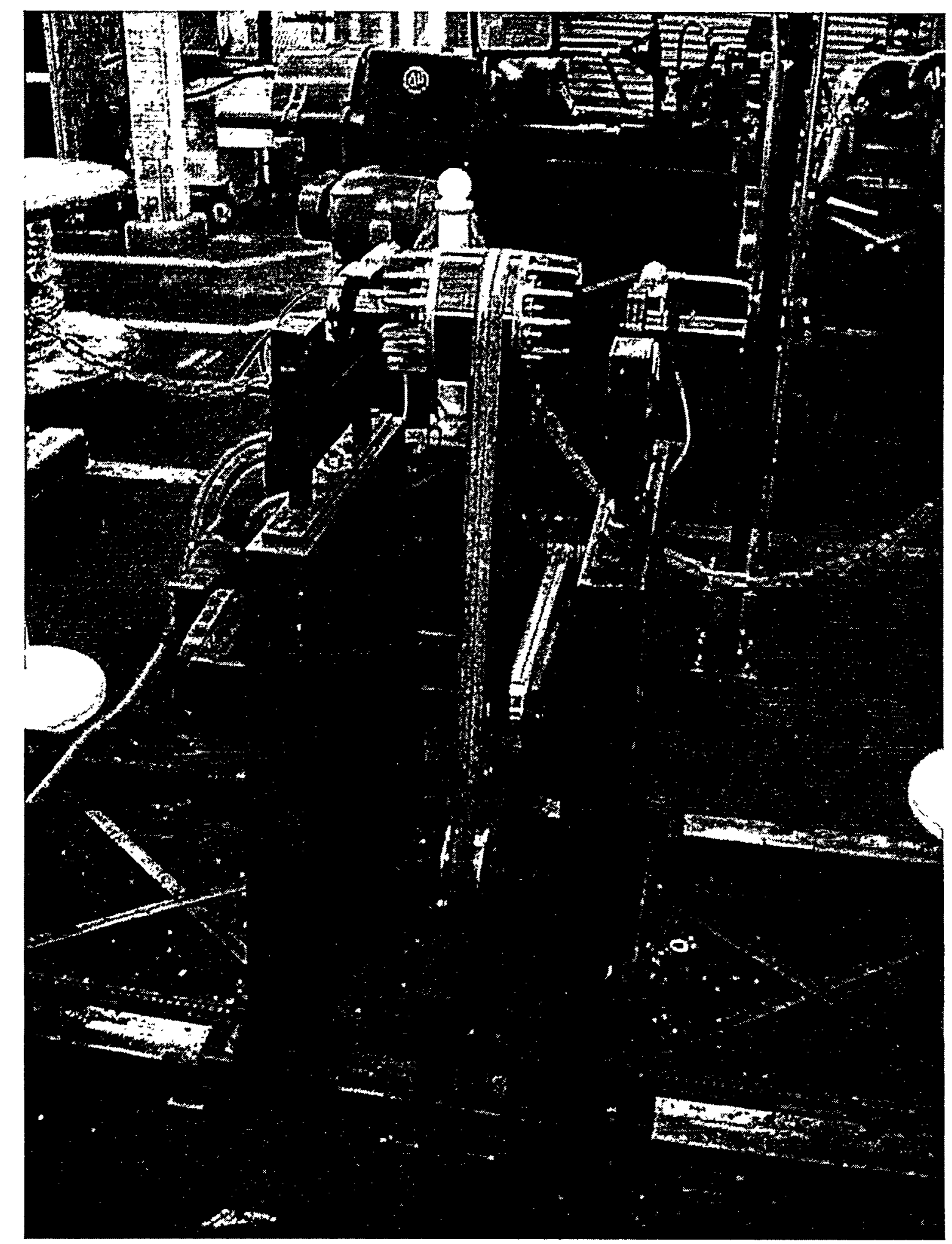

Figure J-27

Rotor Being Prepared For Balancing 


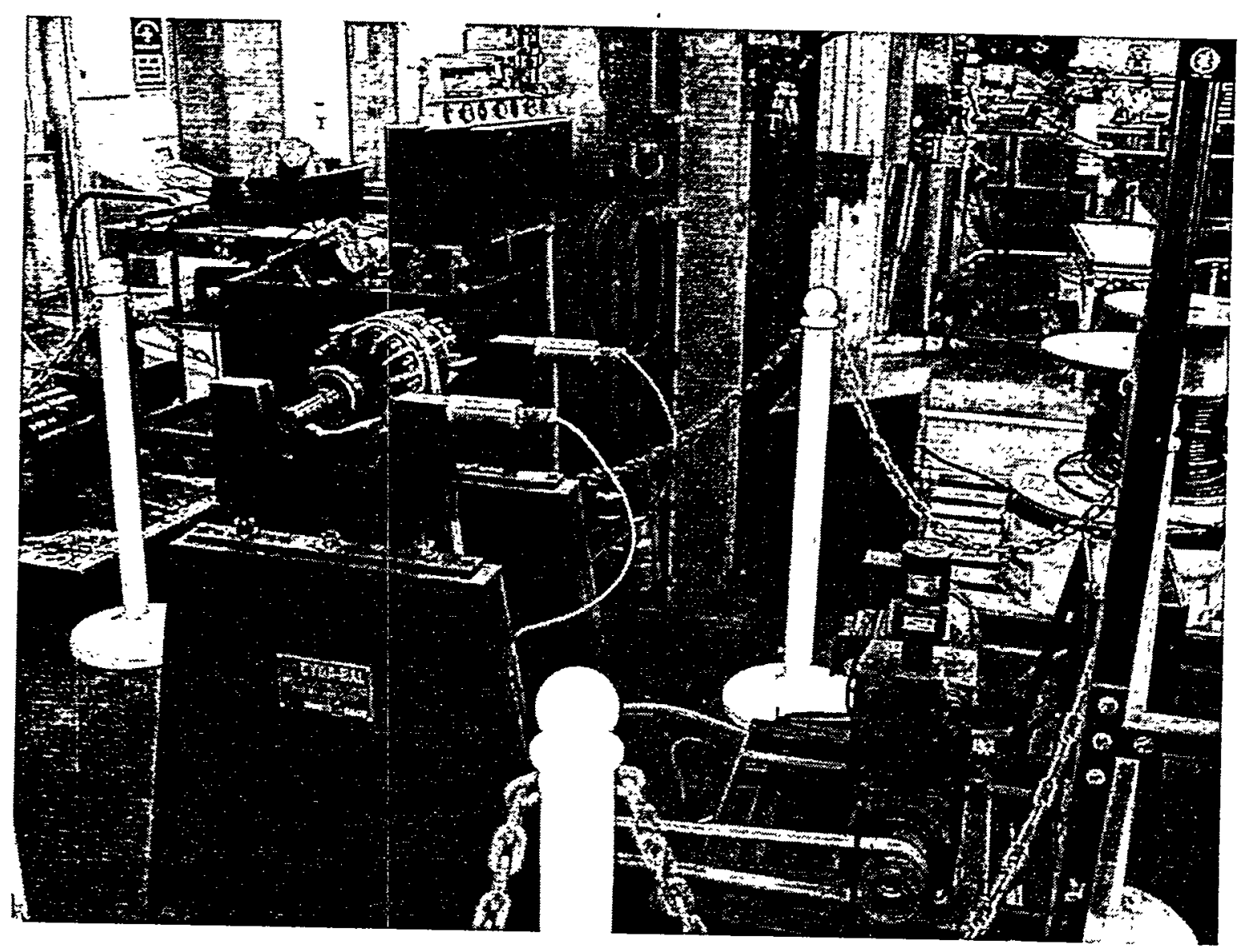

Figure J-28

Rotor Balancing Facility and Drive Motor 


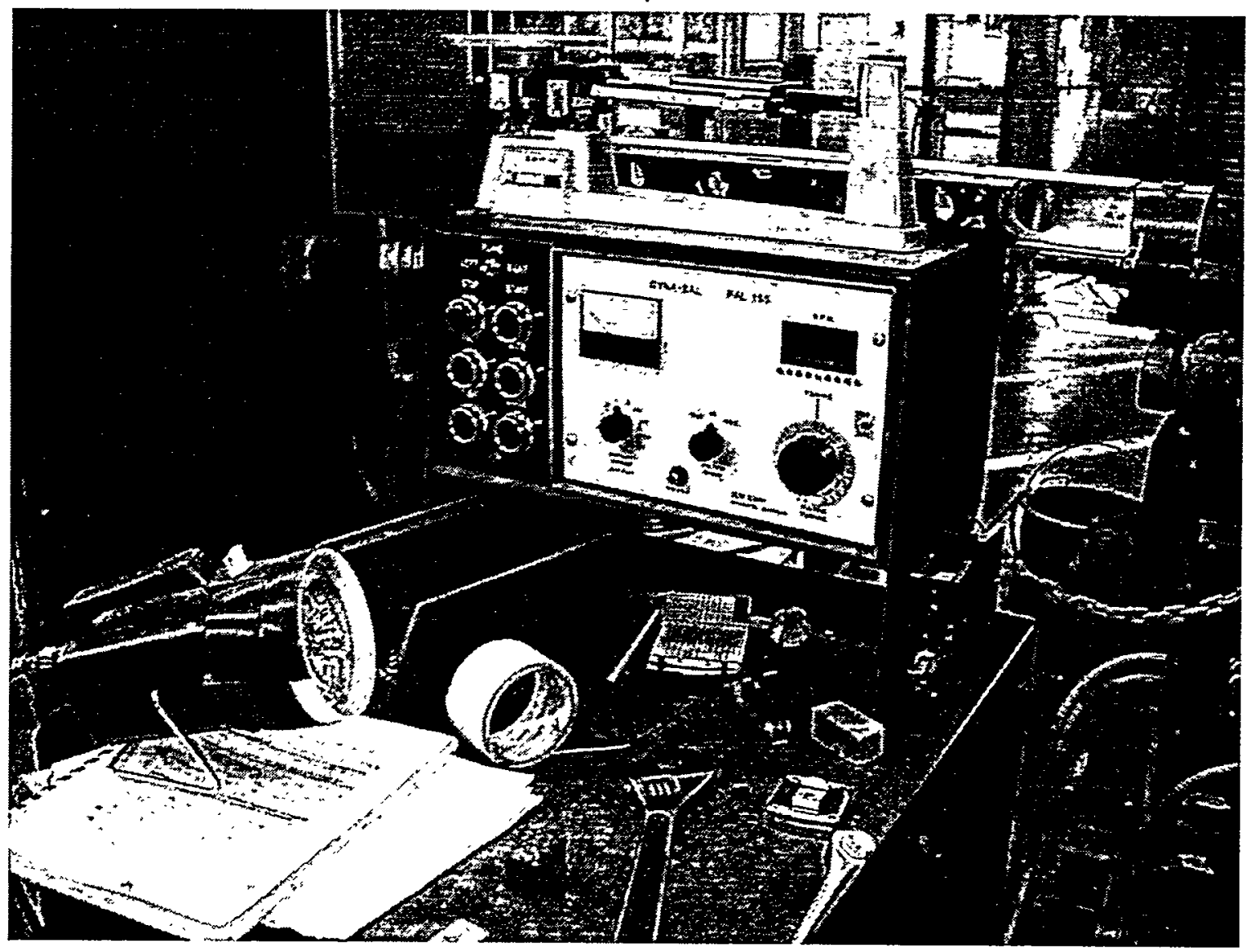

Figure J-29

Instrument Panel for Rotor Balancing Facility 


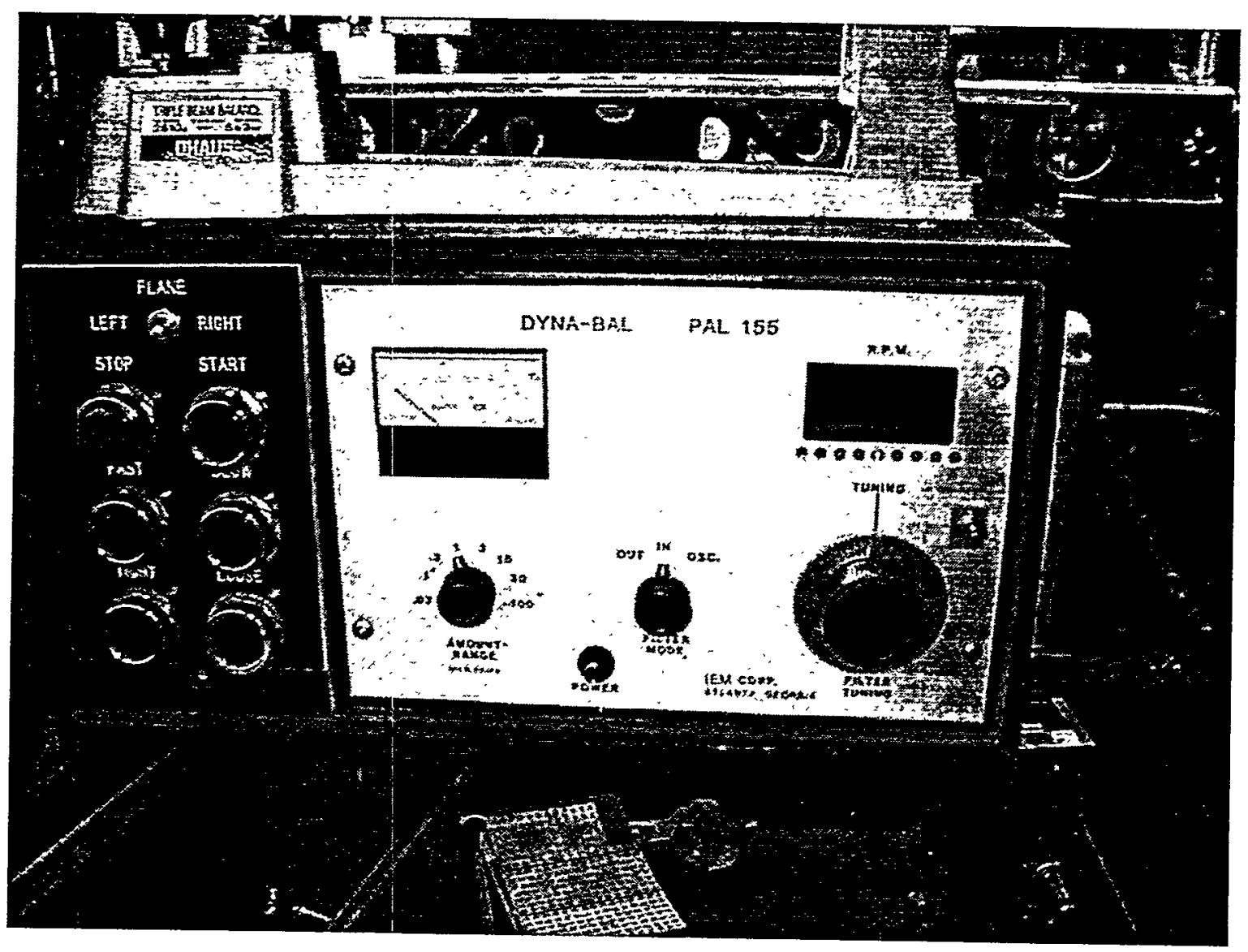

Figure J-30

Close-up of Display Panel for Rotor Balancing Facility 


\section{DISTRIBUTION}

1. D. J. Adams

2. E. C. Fox

3. R. G. Gilliland

4-5. J. S. Hsu

6. P. A. Jallouk

7. Mr. I. K. Mintah, Acting Executive Director, Technical Wing, Ministry of Mines and Energy, Post Office Box T40, Accra, Ghana

8-57. Dr. A. K. Ofosu-Ahenkorah, Executive Director, Energy Foundation, 20 Mankralo Street, P. O. Box CT 1671 Cantonments, Accra, Ghana

58. M. Olszewski

59. Dr. Peter Salmon-Cox, Office of Industrial Technologies, 1000 Independence Avenue, FORS, EE-20, Mail Stop 6B-025, Rm. 5F-065, Washington, D.C. 20585

60. R. M. Schilling

61. R. H. Staunton

62. Laboratory Records

63-64. Office of Scientific and Technical Information, P.O. Box 62, Oak Ridge, Tennessee 37831 